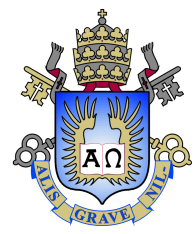

Pedro José Tobar Espinoza

\title{
Deslocamento de fluidos complexos em espaços anulares irregulares
}

Tese de Doutorado

Tese apresentada como requisito parcial para obtenção do título de Doutor pelo Programa de Pós-graduação em Engenharia Mecânica da PUC-Rio.

Orientador : Prof. Rafael Menezes de Oliveira Coorientador: Prof. Paulo Roberto de Souza Mendes 


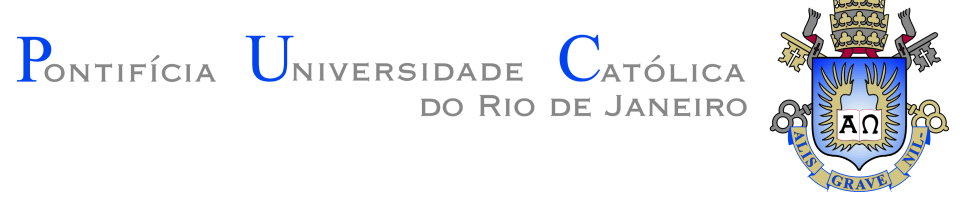

Pedro José Tobar Espinoza

\section{Deslocamento de fluidos complexos em espaços anulares irregulares}

Tese apresentada como requisito parcial para obtenção do título de Doutor pelo Programa de Pós-graduação em Engenharia Mecânica da PUC-Rio. Aprovada pela Comissão Examinadora abaixo.

Prof. Rafael Menezes de Oliveira

Orientador

Departamento de Engenharia Mecânica - PUC-Rio

Prof. Paulo Roberto de Souza Mendes

Coorientador

Departamento de Engenharia Mecânica - PUC-Rio

Profa. Mônica Feijó Naccache

Departamento de Engenharia Mecânica - PUC-Rio

Prof. Igor Braga de Paula

Departamento de Engenharia Mecânica - PUC-Rio

Prof. Flávio Henrique Marchesini de Oliveira Universiteit Gent - UGENT

Dr. Andre Leibsohn Martins

Petróleo Brasileiro - Petrobras

Rio de Janeiro, 23 de Setembro de 2020 
Todos os direitos reservados. É proibida a reprodução total ou parcial do trabalho sem autorização da universidade, do autor e do orientador.

\section{Pedro José Tobar Espinoza}

Bacharel em Mecânica pela Universidad Politecnica Salesiana; Mestre em Engenharia Mecânica pela PUC-RIO.

Ficha Catalográfica

Tobar Espinoza, Pedro

Deslocamento de fluidos complexos em espaços anulares irregulares / Pedro José Tobar Espinoza; orientador: Rafael Menezes de Oliveira; co-orientador: Paulo Roberto de Souza Mendes. - Rio de Janeiro : PUC-Rio, Departamento de Engenharia Mecânica, 2020.

119 f.: il. color.; $30 \mathrm{~cm}$

1. Tese (doutorado) - Pontifícia Universidade Católica do Rio de Janeiro, Departamento de Engenharia Mecânica.

Inclui bibliografia

1. Engenharia Mecânica - Teses 2. Deslocamento de fluidos 3. Fluidos não-Newtonianos 4. Geometrias complexas I. Menezes de Oliveira,Rafael. II. de Souza Mendes, Paulo Roberto. III. Pontifícia Universidade Católica do Rio de Janeiro. Departamento de Engenharia Mecânica. IV. Título. 


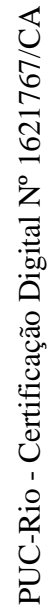

À memória do meu irmão José Luis, um anjo entre nós. 


\section{Agradecimentos}

Ao meu orientador Rafael Menezes de Oliveira e meu coorientador Paulo Roberto de Souza Mendes por me guiar e pelo valioso tempo que utilizaram em discussões. Sem vocês, não podia ter sido possível o desenvolvimento deste trabalho.

Aos membros do Grupo de Reologia (GReo), pela colaboração técnica.

O presente trabalho foi realizado com apoio da Coordenação de Aperfeiçoamento de Pessoal de Nível Superior - Brasil (CAPES) - Código de Financiamento 001.

À Petrobras e à PUC-Rio, pelos auxílios econômicos e técnicos concedidos.

Um agradecimento especial para Elias e Priscila, vocês foram um pilar fundamental durante o desenvolvimento da pesquisa.

Aos meus amigos Ricardo, Lorena, João, Isa, Eliana, Behbood e Daniel, por compartilhar alegrias e tristezas.

Minha mãe, Diana Lucia, que foi fundamental para sucesso na minha vida. Obrigado, o que sou e serei é graças a você.

A minha familia, obrigado pelo amor e amizade. Em especial, a minhas tias, por estarem sempre ao meu lado e me apoiar.

Às minhas incríveis amigas Camila e Tatiana, minhas irmãs brasileiras. 


\section{Resumo}

Tobar Espinoza, Pedro; Menezes de Oliveira,Rafael; de Souza Mendes, Paulo Roberto. Deslocamento de fluidos complexos em espaços anulares irregulares. Rio de Janeiro, 2020. 119p. Tese de Doutorado - Departamento de Engenharia Mecânica, Pontifícia Universidade Católica do Rio de Janeiro.

O deslocamento de um líquido por outro em espaços anulares é comumente encontrado na indústria do petróleo, e a maioria deles envolve materiais não newtonianos. O espaço anular muitas vezes apresenta irregularidades causadas pela erosão, onde quantidades consideráveis de fluido de perfuração podem ser deixadas para trás durante o processo de deslocamento, comprometendo a qualidade da operação de cimentação. Motivados por esse processo industrial, testes de deslocamento entre líquidos a vazão constante foram realizados em espaços anulares cuja parede externa possui, em uma determinada posição axial, um aumento repentino de diâmetro seguido de uma diminuição repentina de diâmetro mais a jusante. O objetivo dos experimentos era determinar a eficiência do deslocamento em função da vazão, reologia dos fluidos e geometria da cavidade. Os resultados revelaram forte influência desses parâmetros na eficiência de deslocamento. Ao mesmo tempo, um estudo numérico foi desenvolvido. Simulações numéricas das equações de Navier-Stokes em geometria axissimétrica para fluidos incompressíveis foram acopladas ao método Level-Set para captura da interface. Fluidos com viscosidade constante e o modelo newtoniano generalizado com função viscosidade de Carreau-Yasuda foram utilizados. Isso permitiu simular deslocamentos entre dois fluidos newtonianos e entre um fluido newtoniano e outro não-newtoniano. Este foi utilizado tanto como fluido deslocador quanto como deslocado. Foram realizadas simulações para várias razões de diâmetros, viscosidades, tempos de relaxação, e números de capilaridade e de Reynolds. Identificamos quando a aproximação do espaço anular por duas placas paralelas pode ser aplicada e calculamos como a forma da interface depende dos parâmetros investigados.

\section{Palavras-chave}

Deslocamento de fluidos complexas 


\section{Abstract}

Tobar Espinoza, Pedro; Menezes de Oliveira,Rafael (Advisor); de Souza Mendes, Paulo Roberto. Displacement of complex fluids in irregular annular spaces. Rio de Janeiro, 2020. 119p. Tese de Doutorado - Departamento de Engenharia Mecânica, Pontifícia Universidade Católica do Rio de Janeiro.

The displacement of a fluid caused by another one, inside annular spaces, is commonly found in the oil industry and most of these rearrangements involve non-Newtonian materials. The annular space often shows irregularities caused by erosion, in which considerable amounts of drilling fluid can be left behind during the displacement process, compromising the cementing operation efficiency. Motivated by that industrial process, fluid-fluid displacement tests at constant flow rate were performed in annular spaces in which their exterior walls displayed in a determined axial position - an abrupt expansion followed by an abrupt contraction. The purpose of the tests were to determine the displacement efficiency as a function of flow rate, rheological properties and geometric cavity. The results revealed a strong influence of these parameters on the displacement efficiency. At the same time, a numerical research was developed. Numerical simulations of the Navier-Stokes equations in axisymmetric geometry for incompressible fluids were coupled to the Level-Set method to capture the interface. Fluids with constant viscosity and the generalized Newtonian model with viscosity function of Carreau-Yasuda were used. That allowed to simulate displacements between two Newtonian fluids and a Newtonian and a non-Newtonian fluid. This was used both as a displacer and as a displaced fluid. Simulations were performed for several diameters and viscosities ratios, relaxatation time, capilar and Reynolds numbers. We identified when the approximation of the annular space by two parallel plates can be applied and calculated how the shape of the interface depends on the investigated parameters.

\section{Keywords}

Fluids displacement Non-Newtonians Fluids Complex geometries 


\section{Sumário}

$\begin{array}{ll}\text { Lista de figuras } & 10\end{array}$

1 Introdução $\quad 16$

1.1 Motivação 16

$\begin{array}{ll}1.2 \text { Objetivo da tese } & 16\end{array}$

$\begin{array}{lll}1.3 & \text { Revisão Bibliográfica } & 17\end{array}$

2 Materiais e métodos experimentais $\quad 21$

2.1 Bancada experimental 21

2.1.1 Seção de teste 21

$\begin{array}{ll}2.1 .2 & \text { Equipamentos } \\ 2.1 .2 & 22\end{array}$

2.1.2.1 Bomba peristáltica $\quad 22$

2.1.2.2 Densímetro 22

2.1.3 Procedimento experimental 23

2.2 Fluidos 24

2.2.1 Mistura glicerina-água 24

2.2.2 Carbopol 980 NF 25

2.2.2.1 Preparação das soluções aquosas de Carbopol 26

$\begin{array}{lll}2.3 & \text { Medição de propriedades dos fluidos } & 27\end{array}$

2.3.1 Reômetro rotacional $\quad 27$

2.3.1.1 Geometrias $\quad 27$

2.3.1.2 Sistema de controle de temperatura 29

2.3.1.3 Controle de evaporação 29

2.3.2 Testes reológicos 29

2.3.2.1 Teste de fluência ou creep test 30

2.3.2.2 Teste de varredura de tensão ou amplitude sweep test 30

2.3.2.3 Curva de escoamento 31

2.4 Parâmetros governantes e adimensionalização 31

2.5 Volume adimensional 34

3 Resultados dos testes experimentais $\quad 37$

3.1 Resultados da caracterização reológica 37

$\begin{array}{lll}3.1 .1 & \text { Testes de varredura de tensão } & 37\end{array}$

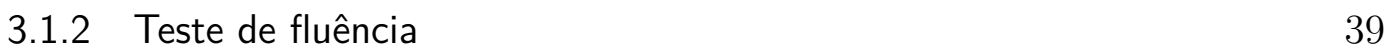

3.1.3 Teste curva de escoamento 40

3.2 Resultados dos testes experimentais 42

3.2.1 Influência dos parâmetros reológicos e geométricos 42

3.3 Considerações 49

4 Abordagem numérica $\quad 51$

4.1 Descrição do problema $\quad 51$

4.1.1 Metodologia númerica $\quad 53$

4.2 Level-set $\quad 56$

4.2.1 Método Level-Set $\quad 56$ 
4.3 Inicialização e Reinicialização da função level-set 57

4.3.1 Level-Set rápido $\quad 58$

$\begin{array}{lll}\text { 4.3.1.1 Tubo } & 58\end{array}$

4.3.1.2 Reinicialização $\quad 61$

4.3.1.3 Frequência da reinicialização 62

4.3.2 Modelagem da função viscosidade e tensão superficial 63

4.4 Limitações do método númerico: A abordagem Level-set rápido sem reinicialização 67

5 Resultados das simulações $\quad 69$

$\begin{array}{lll}5.1 & \text { Teste de malha } & 69\end{array}$

5.2 Validação 70

5.3 Fluido newtoniano deslocando outro newtoniano 70

$\begin{array}{lll}\text { 5.3.1 Forma da interface quase estacionaria } & 70\end{array}$

5.4 Fluido não newtoniano deslocando newtoniano e vice-versa 84

5.4.1 Características da interface quase estacionário 84

5.5 Efeitos da tensão interfacial na forma da interface 94

5.6 Fluido newtoniano deslocando outro newtoniano através de um espaço anular com expansão-contração abrupta. 97

$\begin{array}{lll}5.7 \text { Considerações finais } & 102\end{array}$

6 Referências bibliográficas $\quad 106$

$\begin{array}{lll}\text { A Difusão solução aquosa na mistura água/glicerina } & 116\end{array}$ 


\section{Lista de figuras}

Figura 2.1 - Representação esquemática da seção de teste. 22

Figura 2.2 - Densitômetro de efeito Coriolis 23

Figura 2.3 - Representação esquemática do arranjo experimental 24

Figura 2.4 - Reômetro rotacional AR-G2 27

Figura 2.5 - Geometria Couette 28

Figura 2.6 - Sistema de controle de temperatura para geometria de cilindros concêntricos e placa-placa ranhurada. $\quad 29$

Figura 2.7 - Sistema trampa-solvente 30

Figura 2.8 - Desenho esquemático e dimensões características da seção de teste 32

Figura 2.9 - Variação da densidade $\rho(t)$ em função do tempo $t$. 35

Figura 2.10 - Representação esquemática de Volume adimensional $V^{*} \quad 36$

Figura 3.1 - Teste de varredura de tensão para frequências $0.1,1 \mathrm{~Hz}$ para as soluções aquosas de Carbopol de concentrações a) $0.08 \%$, b) $0.10 \%$ e c) $0.12 \%$.

Figura 3.2 - Resposta da taxa de cisalhamento vs tempo dos testes de varredura de tensão constante para a solução aquosa de Carbopol em concentrações de a) $0.08 \%$, b) $0.10 \%$ e c) $0.12 \%$

Figura 3.3 - Curva de escoamento das soluções aquosas de Carbopol em concentrações de a) $0.08 \%$, b) $0.10 \%$, c) $0.12 \%$

Figura 3.5 - Curva de escoamento da mistura água-glicerina

Figura 3.4 - Comportamento da função viscosidade $\eta(\dot{\gamma})$ da solução aquosa de Carbopol com concentração de 0.08\% a diferentes temperaturas.

Figura 3.6 - Deslocamento dentro da expansão-contração para $\left(W i, D^{*}, L^{*}, \sigma^{*}\right)=(0.15,3.7,1.8,0.157)$.

Figura 3.7 - Volume $V^{*}$ em função de $W i$ para $D^{*}=$ a) 2.11 , b) 3.70 c) 4.25 e $\sigma^{*}=0.088$.

Figura 3.8 - Volume $V^{*}$ em função de $W i$ para $L^{*}=$ a) 0.9 , b) 1.8 c) 2.7 e $\sigma^{*}=0.094$.

Figura 3.9 - Volume $V^{*}$ em função de $W i$ para $D^{*}=3.7$ e $\sigma^{*}=$ a) 0.088 , b) 0.094 c) 0.157 .

Figura 3.10 - Volume $V^{*}$ em função de $L^{*}$ para para $\sigma^{*}=$ a) 0.088 , b) 0.094 c) 0.157.

Figura 3.11 - Volume $V^{*}$ em função da viscosidade $R_{\mu}$ para $\sigma^{*}=$ a) 0.088 , b) 0.094 c) 0.157 .

Figura 4.1 - Figura esquemática mostrando a geometria do problema, as condições de contorno para as componentes do campo de velocidades $\vec{u}=(u, v)$ e a condição de velocidade média de injeção constante. 
Figura 4.2 - Posicionamento das componentes das velocidades e dos termos associado à pressão na malha intercalada

Figura 4.3 - Largura dos tubos $\gamma$ e $\beta$ para a implementação do método Level-Set rápido.

Figura 4.4 - a) Localização da função distância em $t=t_{1}$. b) Depois de um passo de tempo $t_{2}=t_{1}+\Delta t$. c) Posição final da função distância depois da reinicialização.

Figura 4.5 - Representação esquemática do desvio de $\phi$ dentro do tubo $\beta$.

Figura 4.6 - Reinicialização da função auxiliar $\phi$.

Figura 4.7 - Viscosidade de um fluido Carreau Yasuda para $\left(\eta_{0}, \eta_{\infty}, n, a\right)=(20,0.25,0.9,0.88)$.

Figura 4.8 - Função auxiliar $\phi$ em função da posição $Z$ para $(w, R e, M)=(0.75,1,0.25)$ na posição radial 0.75 .

Figura 4.9 - Função auxiliar $\phi$ em função da coordenada axial $z$ para $(w, l, \delta, R e, M, t)=(0.75,3,0.1,1,0.25,1.1)$.

Figura 5.1 - Interface de deslocamento para diferentes resoluções de malha para $(w, R e, M, t)=(0.5,10,2,1.7)$.

Figura 5.2 - Comparação da forma da interface para $(w, R e, F)=(0.8,128,-0.4) \quad$ e $t=4.5, \quad 8.3$. A linha continua representa os resultados obtidos com as simulações do presente trabalho. Os marcadores vermelhos são os dados obtidos na pesquisa de Szabo et. al (1).

Figura 5.3 - Interfaces pseudo estáveis de deslocamento bidimensional entre dois fluidos newtonianos a velocidade constante para $(w, R e, t)=(0.5,10,4.0)$.

Figura 5.4 - Posição da ponta da interface $z_{t i p}$ em função do tempo adimensional $t$ para os parâmetros $(w, R e)=(0.5,1)$.

Figura 5.5 - Velocidade da ponta $u_{t i p}$ em função de $R e$.

Figura 5.6 - Deslocamento temporal entre fluidos newtonianos. Os parâmetros são $(w, R e)=(0.75,10)$ para $t=0,0.5, \ldots .5$ e $M=$ a) 0.25 , b) 0.5 , c) 20 , d) 30 .

Figura 5.7 - Interfaces geradas durante 0 deslocamento para a) $R e=1,10,100$ e b) $M=0.25,0.50,20,30$ para $(w, t)=(0.75,3.6)$.

Figura 5.8 - Largura $m$ em função do tempo $t$ para $(w, R e)=$ $(0.25,1.0)$ e $M=0.25,0.5,20,30$.

Figura 5.9 - Razão e larguras $m$ em função do número de Reynolds $R e$ para $w=0.25,0.5,0.75$ e $M=0.25,0.50,20,30$.

Figura 5.10-Largura $m$ em função da viscosidade $M$ para $w=$ $(0.25,0.5,0.75)$ e $R e=(1,10,100)$.

Figura 5.11 - Representação esquemática da definição de $r_{t i p}$.

Figura 5.12 - Desviação radial da ponta da interface $r_{t i p}$ em função de a) $R e$ b) $M$.

Figura 5.13 - Velocidade $u_{f}$ em funcão do tempo $t$. Os parâmetros são $(w, R e)=(0.25,1.0)$ e $M=0.25,0.5,20,30$. A velocidade da ponta da interface $u_{f}$ são mostradas no mesmo marcador para cada $M$. 
Figura 5.14 - Módulo do campo de velocidade $|u|$ para $(w, R e, t)=$ $(0.25,1.0,4.0)$ e $M=(a, b, c, d)=(0.25,0.5,20,30)$

Figura 5.15 - Campo de velocidade para um sistema de referência utilizado na figura 5.14 para $(w, R e, M, t)=$ $(0.25,1.0,0.25,4.4)$.

Figura 5.16 - Linhas de corrente para $(w, R e, C a, M, t)=$ $(0.25,1.0,0.1,20,4.4)$.

Figura 5.17 - Linhas de corrente para $(w, R e, C a, M, t)=$ $(0.25,1.0,0.1,0.25,4.4)$.

Figura 5.18 - Evolução temporal da interface durante o deslocamento de um fluido não newtoniano deslocando um newtoniano para $\lambda=$ a) 0.26 e b) 18 e $\left(w, R_{\eta}\right)=(0.5,2)$. Os tempos são $t=0.5,1.0 \ldots 3.5$.

Figura 5.19 - Posição da ponta da interface $z_{\text {tip }}$ em função do tempo adimensional $t$. Os parâmetros foram fixados em $\left(w, R_{\eta_{1}}\right)=(0.25,1)$ quando o fluido não newtoniano é a) injetado b) deslocado.

Figura 5.20 - Velocidade da ponta da interface de deslocamento $u_{t i p}$ em função do tempo de relaxação $\lambda$. Os parâmetros são $w=0.25,0.50,0.75$ e $R_{\eta}=1,2$ quando a viscosidade é não newtoniana do fluido a) deslocador b) deslocado.

Figura 5.21-Desvio radial $r_{\text {tip }}$ em função de $\lambda$, para todos os parâmetros investigados.

Figura 5.22 - Velocidade da ponta da interface $u_{t i p}$ em função da razão de viscosidade $R_{\eta}$ para $(w, t)=(0.5,3.8)$ e $\lambda=0.26,1.43,18$. A figura representa o deslocamento quando um fluido não newtoniano foi considerado como a) deslocador $b$ ) deslocado.

Figura 5.23 - Desenvolvimento temporal da interface de deslocamento para $\left(w, R_{\eta}\right)=(0.5,1)$ e $t=0,0.5 \ldots .5 .5$. Figuras $(a, b)$ são representações quando o fluido deslocador para $\lambda=0.26 \mathrm{e}$ 18 , respetivamente. Figuras $(c, d)$ mostram as interfaces quando o fluido não newtoniano foi deslocado. Os tempos de relaxação simulados foram $\lambda=0.26$ e 18 , respetivamente. 89

Figura 5.24-Largura $m$ em função do tempo adimensional $t$ para $\left(w, R_{\eta}\right)=(0.25,1)$ e $\lambda=0.26,1.43,18$.

Figura 5.25 - Largura $m$ em função do tempo de relaxação $\lambda$ para $w=0.25,0.5,0.75$ e $R_{\eta}=1,2$. A figura representa um deslocamento quando o fluido não newtoniano é $a$ ) deslocador $b$ ) deslocado.

Figura 5.26 - Módulo do campo de velocidades $|\vec{u}|$ e campo de velocidades $\vec{u}$ quando o fluido não newtoniano é deslocador, para tempos de relaxação $\lambda=$ a) 0.26 , b) 1.43, c) 18 para $\left(w, R_{\eta}, t\right)=(0.75,1,4.3)$.

Figura 5.27-Módulo do campo de velocidades $|\vec{u}|$ e campo de velocidades $\vec{u}$ quando um fluido newtoniano desloca um não newtoniano com tempo de relaxação $\lambda=$ a) 0.26 , b) 1.43 , e c) 18 para $\left(w, R_{\eta}, t\right)=(0.75,1,4.3)$. 
Figura 5.28 - Linhas de corrente para $\left(w, R_{\eta}, t\right)=(0.75,1,4.4)$. quando um fluido não newtoniano desloca um newtoniano para $\lambda=$ a) 0.26 b) 1.43 c) 18 .

Figura 5.29 - Linhas de corrente para $\left(w, R_{\eta}, t\right)=(0.75,1,4.4)$. quando um fluido não newtoniano é deslocado por um newtoniano para $\lambda=$ a) 0.26 b) 1.43 c) 18 .

Figura 5.30 - Posição da ponta da interface $z_{\text {tip }}$ em função do tempo adimensional $t$. Subfigura 5.30 a) mostra simulações entre fluidos newtonianos. Enquanto, subfigura 5.30 b) mostra deslocamentos que envolvem um fluido não newtoniano sendo deslocador ou deslocado.

Figura 5.31 - Velocidade da ponta da interface de deslocamento $u_{t i p}$ em função do número capilar $\mathrm{Ca}$. As linhas continuas representam deslocamentos entre fluidos newtonianos, tracejados quando o fluido deslocador é não newtoniano e linhas e pontos quando o fluido deslocado é não newtoniano. 96

Figura 5.32 - Interfaces geradas entre fluidos newtonianos de viscosidade $M=$ a) 0.25 , b) 20.0 , e $\left(R_{\eta}, \lambda\right)=(1.0,1.43)$ quando o fluido não newtoniano é c) deslocador $\mathrm{d}$ ) deslocado, para $C a=0.1$ e 1.0. O tempo adimensional, para todos os casos, é $t=3.8$.

Figura 5.33 - Razão de largura $m$ para diferentes posições $z$ e tempo adimensional $t=4.5$.

Figura 5.34 - Representação esquemática o espaço anular continuo com uma alargamento abrupto na parede externa.

Figura 5.35 - Posição da ponta da interface $z_{\text {tip }}$ em função do tempo adimensional $t$ para $(w, l, \delta, R e)=(0.75,3,0.1,1)$ e diferentes $M$.

Figura 5.36 - Velocidade da ponta da interface $u_{\text {tip }}$ em função do tempo adimensional $t$ para $(w, l, \delta, R e)=(0.75,3,0.1,10)$ e diferentes $M$.

Figura 5.37 - Comportamento da componente $v_{z}$ do campo de velocidade $\vec{u}$ para $M=$ a) 0.25 , b) 4 e $z=3$. Para cada subfigura, a componente $v_{z}$ do campo de velocidade desenvolvido dentro do espaço anular e na presença da expansão abrupta foram representadas em cor cinza e preto, respetivamente.

Figura 5.38-Comportamento da componente $v_{z}$ do campo de velocidade $\vec{u}$ para $M=$ a) 0.25 , b) 4 e $z=3$. Para cada subfigura, a componente $v_{z}$ do campo de velocidade desenvolvido dentro do espaço anular e na seção central da expansão-contração abrupta foram representadas em cor cinza e preto, respetivamente.

Figura 5.39 - Variação da componente $u$ do campo de velocidade $\vec{u}$. Para $M=$ a) 2 , b) 4 , c) 0.25 , d) 0.5 e $L=6$. Para cada sub-figura, a componente $u$ do campo de velocidade desenvolvido dentro do espaço anular 
Figura 5.40 - Interfaces geradas durante o deslocamento entre fluidos imiscíveis newtonianos, para varias viscosidades $M$.

Figura A.1 - Interface gerada entre os fluidos envolvidos no deslocamento 116

Figura A.2 - Representação esquemática da obtenção da largura da zona de difusão

Figura A.3 - Sequência do processamento digital de imagen. 117

Figura A.4 - Transformação de RGB para tons de cinza 118

Figura A.5 - Limiarização do histograma 119

Figura A.6 - Largura da interface $L$ em função do tempo da mistura água/glicerina e fluido não newtoniano com tensão limite de escoamento aparente $\tau_{y}=7.10 \mathrm{~Pa}$. 
Abandon hope all ye who enter here

Dante Alighieri, Divine Comedy. 


\section{Introdução}

\section{1}

\section{Motivação}

O deslocamento fluido-fluido é uma operação muito comum na indústria petrolífera. A injeção de pasta de cimento no espaço anular entre o revestimento e a formação rochosa para deslocar fluido de perfuração é uma das operações envolvidas na etapa de cimentação primária. Os principais objetivos da cimentação são obter estanqueidade, evitar a migração de fluidos do reservatório e prevenir falhas mecânicas da coluna de produção. Para isso ser alcançado de maneira eficaz, outros requisitos impostos durante a vida útil do poço devem ser atendidos. Tais requisitos incluem questões econômicas, de responsabilidade ambiental, de segurança, além de regulamentos governamentais, etc. A cimentação primária não está diretamente relacionada à produção. No entanto, é uma operação necessária que deve ser executada de maneira eficaz para permitir a realização de operações de produção ou estimulação. O sucesso de um poço depende dessa operação primária. Caso não seja bem executada, uma operação de cimentação corretiva torna-se necessária para ressarcir possíveis problemas. No entanto, isso acarreta em custos operacionais não planejados e perda de tempo, o que acarreta em mais custos. Uma operação bem-sucedida e econômica para a cimentação primária é o ideal. Isso depende de um bom projeto e execução minuciosa dos fluidos envolvidos e do processo de deslocamento do fluido de perfuração pela pasta de cimento. Para isso, é necessário conhecer e controlar os parâmetros que governam a operação de cimentação primária.

\section{2}

\section{Objetivo da tese}

Motivados pelo processo industrial de posicionamento da pasta de cimento através do deslocamento do fluido de perfuração, nossa intenção principal é identificar quais fatores físicos, parâmetros reológicos e adimensionais governam o deslocamento entre fluidos Newtonianos e complexos, em espaços anulares contínuos e irregulares. Para o caso de espaços 
irregulares, a parede externa possui em uma determinada posição axial, um aumento repentino de diâmetro seguido de uma diminuição repentina de diâmetro mais a jusante. A inclusão dessa irregularidade visa modelar processos de erosão observados pela indústria. Consideraremos a influência de parâmetros reológicos dos fluidos envolvidos, da tensão interfacial, configuração geométrica e velocidade de injeção entre os fluidos. Neste trabalho foram conduzidos investigações utilizando abordagens experimental e simulações numéricas.

\section{3 \\ Revisão Bibliográfica}

Pesquisas experimentais de escoamentos em geometrias, planares ou cilíndricas, formados por uma seção reta seguida por uma expansão-contração abrupta usando fluidos newtonianos revelaram o surgimento de regiões de circulação nos cantos que se formam nas mudanças abruptas de nível. Essas recirculações mostraram ser simétricas e dependentes com o número de Reynolds $R e(2-4)$ e aparecem ainda para escoamentos considerados lentos ou creep flow $(R e<<1)(5-7)$. Para os casos $R e>1$, as zonas de recirculação permanecem simétricas (4) com um aumento tanto na sua intensidade como tamanho. Resultados para $R e>>1$ revelaram a formação uma terceira região de recirculação a montante da expansão, i.e. na seção reta anterior à cavidade, além de assimetria nas recirculações formadas dentro da cavidade (8-11).

Boger (12) fez uma revisão ampla de várias trabalhos referentes ao escocamento de fluidos imiscíveis, newtonianos e não newtonianos inelásticos, através de geometrias complexas, com especial ênfase em geometrias cilíndricas com expansões-contrações abruptas localizadas. Os resultados mostraram a aparição das zonas de recirculação dentro da expansão-contração para $R e<1$ e uma aparente independência do tamanho dos vórtices com a configuração geométrica quando a razão de diâmetros é acima de 4 . A razão de diâmetros foi definido como a razão entre o diâmetro aumentado e o diâmetro da seção reta amontante da cavidade. Para $R e>1$ surgiram concavidades no perfil de velocidade no plano de entrada, mostrando que a inércia desempenha um papel importante na configuração do escoamento. Para escoamentos lentos $R e<<1$, o tamanho das zonas de recirculação mostra uma forte dependência com a razão de diâmetros, ainda para razões acima de 4. Os resultados anteriormente descritos foram obtidos com fluidos newtonianos. Para fluidos não newtonianos, resultados experimentais em geometrias formadas de uma expansão seguida de uma contração abrupta foram documentadas. A equação de Carreau para modelar a função de viscosidade foi uma das utilizada, sendo: 


$$
\frac{\eta(\dot{\gamma})}{\eta_{0}}=\left[1+\left(\lambda_{s} \dot{\gamma}^{2}\right)\right]^{(n-1) / 2}
$$

onde $\dot{\gamma}$ é a taxa de cisalhamento, $\lambda$ o tempo de relaxação, $n$ o índice power-law. De forma adimensional é:

$$
\eta^{\prime}=\left[1+\left(C r \dot{\gamma}^{\prime}\right)^{2}\right]^{(n-1) / 2}
$$

sendo $C r=\lambda_{s} V_{d} / R_{d}$ o número de Carreau. Os resultados mostraram que as mudanças no tamanho das zonas de recirculação dependem deste parâmetro adimensional Cr. Para $\mathrm{Cr}$ pequenos, o tamanho das zonas de recirculação são maiores. Caso contrário, à medida em que o número de Carreau aumenta, diminui-se o tamanho das zonas até $C r>100$ onde essencialmente desaparecem. No caso de escoamentos lentos, não foi possível associar o tamanho com $\mathrm{Cr}$.

As principais características geométricas da expansão-contração abrupta são seu comprimento e profundidade. Focados na influência destes parâmetros no escoamento, pesquisas usando fluidos newtonianos concluíram que as zonas de recirculação estão intimamente relacionadas com as características da geometria $(4,7,13)$. Cavidades compridas e pouco profundas geram menores zonas recirculação comparadas com cavidades profundas.

Diversos trabalhos acadêmicos concentrados em escoamentos de fluidos não newtonianos com tensão limite de escoamento consideraram a influência tanto das caraterísticas reológicas como as geométricas foram desenvolvidos. Dois parâmetros geométricos adimensionais foram estabelecidos, $h=\hat{H} / \hat{D}$ e $\delta=\hat{D} / \hat{L}$, sendo $\hat{H}, \hat{L}$ e $\hat{D}$ a profundidade da cavidade, o comprimento da cavidade e a largura da seção reta anterior à cavidade, respetivamente. Os escoamentos foram executados a vazão constante ignorando a influência da inércia. Segundo os resultados, as linhas de fluxo se espalham e são desviadas para dentro da expansão-contração. As áreas estagnadas aumentam com o tamanho de $h$ e são qualitativamente diferentes dependendo da profundidade. Com apêndices relativamente profundos e limite de escoamento grande, o fluxo reage de uma maneira que é qualitativamente independente da profundidade da cavidade (7,14-22). Roustaei et al. (23) abordaram o mesmo tema que com a influência da inércia. Resultados para Re altos, mostraram uma tendência a contornar a geometria da cavidade ainda para cavidades pouco profundas.

Interessados na dissipação viscosa, Hammad et al. (24) investigaram escoamentos lentos através de uma contração de fluido de Bingham. Um resultado relevante obtido foi a existência de um aquecimento viscoso significativo na vizinhança imediata da contração. Outras simulações, em geometrias com expansão abrupta (25), ilustraram um comportamento semelhante. 
Escoamentos de fluidos de Bingham através de expansões-contrações suavizadas foram as simulações feitas na pesquisa numérica de Roustaei et al. (26). Fluido estagnado foi observado quando se excede um valor crítico de profundidade para números de Bingham altos.

Estudos envolvendo a combinação de fluidos não newtonianos com tensão limite de escoamento e geometrias entre placas planas com pequenas oscilações foi desenvolvida por Frigaard et al. (27), os quais estudaram o escoamento de um fluido de Bingham ao longo de um canal paralelo bidimensional com variações pequenas na folga. Para números de Bingham pequenos, a velocidade da região tipo plug foi ligeiramente menor em comparação com a velocidade desenvolvida em um canal paralelo. Contrariamente, para $B i$ maiores, a velocidade foi maior que a velocidade de escoamento entre placas paralelas. Putz et al. (28) completaram a pesquisa iniciada por Frigaard (27), para variações maiores no canal. A diminuição significativa na zona sem escoamento foi atribuída à aparição de tensões maiores ao longo do escoamento.

Os trabalhos discutidos até aqui investigaram o escoamento de um único fluido, newtoniano ou complexo, em espaços confinados, cilíndricos ou entre placas, que incluem expansões ou contrações na geometria. $\mathrm{O}$ número de trabalhos encontrados na literatura que investigam processos de deslocamentos entre fluidos, foco desta tese, é menor. Descrevo abaixo alguns desses trabalhos em anulares concêntricos e excêntricos, com fluidos newtonianos e não-newtonianos, miscíveis e imiscíveis.

Deslocamentos de fluidos miscíveis newtonianos com diferentes densidades através de tubos retos foram investigados por diversos autores (1,29-35). Concordante com a instabilidade de Rayliegh-Taylor, a estabilidade do deslocamento aumenta se a densidade do fluido deslocador, for maior que a do fluido deslocado.

Consoante com a instabilidade de Saffman-Taylor, quando a viscosidade do fluido deslocado for maior que a do deslocador $(29,33,36,37)$, a interface é instável e gera-se dedos viscosos ou viscous fingers.

No caso de fluidos não newtonianos com tensão limite de escoamento aparente, o deslocamento ocorre estavelmente se a tensão limite do fluido deslocador é maior $(29,38,39)$ do que a do fluido deslocado. Um deslocamento viscosamente instável surgem quando o deslocado possui uma tensão limite de escoamento maior. Cabe enfatizar que estes deslocamentos são isodensos e em geometrias continuas.

Focados em deslocamentos de fluidos imiscíveis, característica similar à do presente trabalho, simulações numéricas (1) (31) (33) de escoamentos newtonianos mostraram que para fluidos mais densos deslocando menos densos 
produzem deslocamentos estáveis e as partículas na frente da interface são transportadas da região da parede para o centro, enquanto que as partículas por trás da interface tendem a se mover do centro para a parede do anular. Desta forma, há um campo de velocidade da interface envolvendo zonas de recirculação.

Estudos de deslocamento de fluidos não newtonianos de dois fluidos através de dutos anulares verticais com expansão-contração abrupta foram desenvolvidos, tanto para fluidos com a similar densidade como com densidades diferentes para fluidos não newtonianos com tensão limite de escoamento. O processo é muito complexo já que a eficiência de deslocamento é uma função da reologia dos fluidos, da razão de densidade, da taxa de fluxo e da geometria. Os resultados mostram que o deslocamento através da cavidade é melhor para regiões erodidas mais longas, menos profundas e com razão de densidade positiva (fluido mais denso deslocando um menos denso) (40). Também foi mostrado que a partir de uma razão de diâmetros característica, o deslocamento dentro da expansão-contração independe da profundidade da cavidade. Para os casos sendo a inercia influente, o comportamento do deslocamento mostrou que a interface tendeu a se deslocar em direção à parede de saída da cavidade, levando a menores eficiências durante o processo de deslocamento (41).

Para a industria alimentária, petrolífera, cosmética, por citar algumas, é de vital importância o estudo de deslocamento fluido-fluido em espaços anulares. Existem inúmeros trabalhos numéricos ou experimentais sobre escoamentos de fluidos tanto newtonianos como não-newtonianos, mas pesquisas sobre deslocamentos são reduzidos. Geometrias mais simples como folga constante entre placas são utilizadas, que podem-se assumir para poupar tempo, sem perder a essência da pesquisa. Alias, quanto mais próximo das condições reais forem os estudos laboratoriais, resultados mais acurados serão obtidos. Sendo assim, foram feitos testes experimentais e simulações numéricas de deslocamento fluido-fluido em espaços anulares, com ou sem descontinuidades, a fim de obter resultados que permitam compreender os mecanismos que governam o deslocamento fluido-fluido, tanto newtoniano como não-newtoniano. 


\section{2}

\section{Materiais e métodos experimentais}

Neste capítulo serão descritos equipamentos, materiais e técnicas utilizados na abordagem experimental, assim como os diferentes testes reológicos para a obtenção das propriedades reológicas tanto dos fluidos não-newtonianos como newtoniano. A metodologia usada é a medição da densidade da fração de volume saindo da seção de teste usando um densímetro que permite medir tanto a variação de densidade como a vazão contante baseado no efeito coriolis. Para nossa pesquisa experimental, o fluido injetado possui característica newtoniana e a densidade maior à da água. Mencionada densidade maior é obtida posterior à mistura de glicerina e água de porcentagens em peso preestabelecidos. Três soluções aquosas de Carbopol em concentrações diferentes de polímero, usado como fluido deslocado, possui a densidade similar à da água. Esta diferença permite calcular o volume de fluido não newtoniano deslocado a vazão constante par diferentes configurações geometrias da seção de teste. A seção de teste corresponde a um espaço anular concêntrico com um alargamento abrupto na sua parede externa.

\section{1}

\section{Bancada experimental}

\subsection{1}

\section{Seção de teste}

Foi construída uma seção de teste que simula um espaço anular concêntrico com uma expansão-contração abrupta centralizada. Esta seção é composta por dois tubos cilíndricos concêntricos, que contêm e uma expansão-contração posicionado entre eles. Toda a seção se encontra submersa em água, com o objetivo de manter a temperatura dos fluidos constante durante o teste e que a temperatura do meio circundante não afete as características reológicas. Figura 2.1 apresenta um desenho esquemático dessa seção de teste, onde a seção expandida está indicada em azul. Como é mostrado na representação esquemática, a expansão-contração foi posicionada a uma distância equidistante entre as seções retas. A cavidade foi prendida, por meio de um selo de borracha e parafusos de fixação, a discos fixados previamente ao 
espaço anular contínuo.

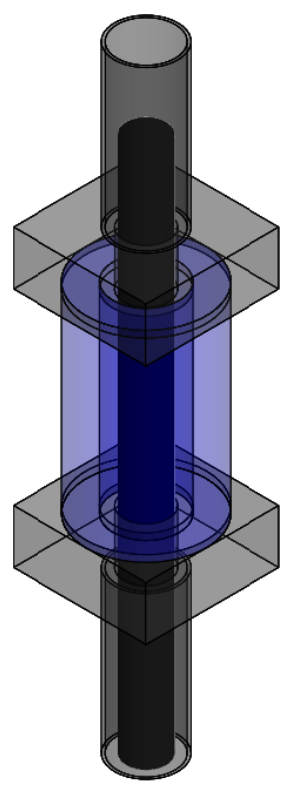

Figura 2.1: Representação esquemática da seção de teste.

\subsection{2}

\section{Equipamentos}

\subsubsection{1}

\section{Bomba peristáltica}

Duas bombas peristálticas da marca Cole-Palmer e modelos $\mathrm{KH}$ 07553-80/70 foram utilizadas para a injeção do fluido deslocador. Elas operam com faixas de trabalho de 1-100 e 6-600 rpm que produz vazões entre 0.007 $\mathrm{ml} / \mathrm{min}$ e $45 \mathrm{ml} / \mathrm{min}$. Cada uma das bombas foram utilizadas de acordo com a vazão constante que se pretende impor. Um controlador Masterflex, modelo 7553-71, foi acoplado à bomba a fim de controlar a velocidade de giro e portanto a vazão de injeção. Este tipo de bomba foi utilizada devido a que a uma superfície de contato entre a bomba e o fluido é a parede interna dos dutos, eliminando completamente a possibilidade de contaminação.

\subsubsection{2}

\section{Densímetro}

Um medidor de vazão e densidade, da marca MicroMotion, baseado no efeito coriolis, foi posicionado na saída da seção de teste (vide figura 2.2).

As medições são feitas através de sensores compostos por ímãs e bobinas posicionados na entrada e na saída do densitômetro. A vazão mássica do escoamento altera a posição da bobina, e, à medida que as bobinas se movem 
através do campo magnético criado pelo ímã, elas criam uma tensão na forma de uma onda senoidal. Essas ondas senoidais são a chave para medir o fluxo de massa. Sob condições de não fluxo, as ondas senoidais de entrada e saída estão em fase uma com a outra. Quando o fluido está se movendo através do dispositivo, ele se distorce na proporção da vazão mássica. A magnitude da torção é detectada pelos sensores de entrada e saída com base em uma mudança de fase (diferença de tempo) que ocorre nas ondas senoidais formadas pelos dois sensores. A vazão mássica é derivada da diferença na mudança de fase dessas ondas senoidais formadas pelos sensores de entrada e saída. Naturalmente, a dinâmica também se altera conforme a densidade do fluido muda. Os medidores por efeito coriolis são amplamente usados devido ao fato de fornecerem uma leitura direta da vazão mássica e da densidade com grande precisão. O equipamento possui a capacidade de de medir a densidade a vazão mássica na faixa entre 600-2000 $\frac{\mathrm{kg}}{\mathrm{m}^{3}}$ e $0.2-2 \frac{\mathrm{kg}}{\mathrm{hr}}$, respetivamente. A precisão da medição da densidade, para qualquer vazão mássica, é de $\pm 2 \frac{\mathrm{kg}}{\mathrm{m}^{3}}$.

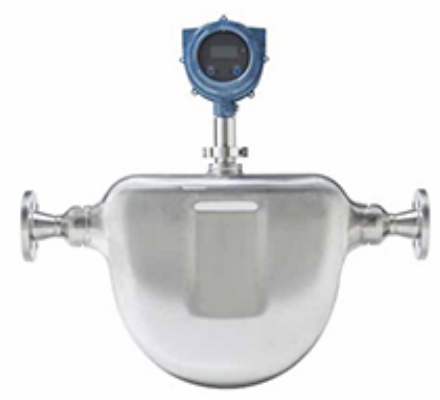

Figura 2.2: Densitômetro de efeito Coriolis

\subsection{3}

\section{Procedimento experimental}

Impomos um processo de deslocamento entre fluidos imiscíveis e incompressíveis a vazão contante.

A figura 2.3 mostra uma representação esquemática do arranjo experimental. Inicialmente dois reservatórios são preenchidos, um com o fluido deslocador, outro com o deslocado. Cada reservatório tem seu respectivo circuito de mangueiras bifurcadas. Na sequência, uma bomba peristáltica é ligada e o espaço anular é preenchido pelo fluido que será deslocado, uma solução aquosa de Carbopol. Posteriormente, conectamos o circuito do fluido deslocador, uma mistura entre glicerina e água, para então iniciar o processo de deslocamento. Cabe realçar que a bomba se encontra acoplada a um controlador que permite variar a velocidade de rotação, o que 


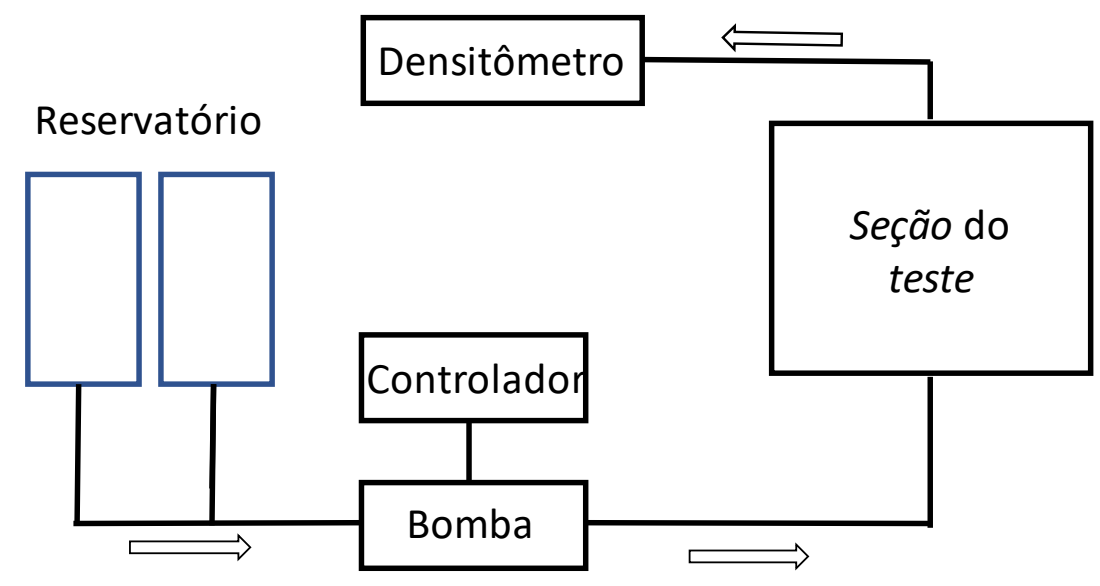

Figura 2.3: Representação esquemática do arranjo experimental

permite investigar uma vasta quantidade de vazões de injeção. Durante o deslocamento, o medidor de efeito coriolis transmite para um computador a vazão, a temperatura e a densidade da fraçao de fluido na saída em intervalos de um segundo. O volume de fluido saindo do densitômetro se descarta em um terceiro reservatório. Este procedimento é repetido várias vezes com diferentes vazões de injeção e diferentes concentrações da solução aquosa de Carbopol.

\section{2}

\section{Fluidos}

Como mencionado, soluções aquosas de Carbopol 980 NF serão deslocadas por uma mistura glicerina-água em nossos testes de deslocamento em espaço anular com uma expansão-contração abrupta centralizada.

\subsection{1}

\section{Mistura glicerina-água}

O glicerol é um dos álcoois poli-hídricos mais usados em pesquisas laboratoriais e no âmbito industrial. Glicerol se refere ao álcool tri-hidrico $\mathrm{C}_{3} \mathrm{H}_{5}(\mathrm{OH})_{3}$. Ele é higroscópico, claro, tem viscosidade newtoniana, é inodoro e reconhecido como seguro. É usado para prevenir o congelamento, dispõe de uma longa vida útil e possui uma densidade maior que a da água. A glicerina usada durante a pesquisa foi fornecida por SP Labor. A tabela 2.1 mostra suas características técnicas.

Uma mistura glicerina/água foi preparada usando glicerina bi-destilada e água deionizada, obtida mediante o processo de osmose reversa. Sendo a glicerina higroscópica, ela absorve água do ambiente. Portanto, é inexorável misturar uma quantidade de água/glicerina preestabelecida, a modo de evitar 
Tabela 2.1: Boletim técnico da glicerina bidestilada

\begin{tabular}{cc}
\hline Cloretos & $<0.001 \%$ \\
\hline Compostos clorados & $<0.003 \%$ \\
\hline Densidade @ $25{ }^{\circ} \mathrm{C}\left(\mathrm{g} / \mathrm{cm}^{3}\right)$ & 1.2609 \\
\hline Teor & $99.98 \%$
\end{tabular}

a mudança arbitrária de suas propriedades influenciadas pelo seu meio circundante. A proporção usada foi $80 \%$ glicerina e $20 \%$ água em massa.

A densidade da mistura água-glicerina foi medida através do uso de um picnômetro. Os dados recompilados pela Glycerine Producers Association (42) mostram a densidade da mistura água-glicerina a diferentes temperaturas. Interpolando os dados de (42) e comparando com os obtidos no laboratório de caracterização de fluidos da PUC-RIO, foram obtidos valores próximos, como são vistos na tabela 2.2 .

Tabela 2.2: Densidade da mistura água-glicerina.

\begin{tabular}{cc}
\hline Densidade obtida pelo LCF @ $23.5^{\circ} \mathrm{C}$ & $1206.3 \mathrm{~kg} / \mathrm{m}^{3}$ \\
\hline Densidade interpolada de (43) @23.5 ${ }^{\circ} \mathrm{C}$ & $1200 \mathrm{~kg} / \mathrm{m}^{3}$ \\
\hline
\end{tabular}

\subsection{2}

\section{Carbopol 980 NF}

Carbopol 980 NF é um copolímero de alto peso molecular que apresenta uma densidade de $176 \mathrm{Kg} / \mathrm{m}^{3}$ na forma reticulada. É de fácil e rápida dispersão em água. Em solução aquosa, possui excelente efetividade de espessamento e uma boa claridade. Suas moléculas possuem um arranjo em formato helicoidal, que uma vez que escoar, elas começam a se desenrolar, podendo ficar totalmente esticada. Consequentemente, o Carbopol é considerado um eficiente modificador da reologia, proporcionando à solução uma tensão limite de escoamento aparente $\tau_{y}$ e uma função viscosidade que cai rapidamente associada ao aumento da taxa de cisalhamento $(44,45)$.

A neutralização, processo necessário durante o preparo da solução, converte os grupos ácidos da cadeia polimérica em sua forma de sal. Esse processo acrescenta as propriedades não newtonianas à solução. Para a neutralização, emprega-se uma base comum, como o hidróxido de sódio (NAOH). Três diferentes concentrações de Carbopol 980 NF em água foram considerados para esta abordagem experimental. Elas são discutidas a seguir.

\subsubsection{1}




\section{Preparação das soluções aquosas de Carbopol}

Abaixo, descrevemos as etapas laboratoriais, juntamente com os equipamentos usados na preparação da base para neutralizar a solução de $\mathrm{NaOH}$ são:

- Pesar o NaOH.

Materiais: Bequer e scoopula.

Equipamento: Balança de precisão.

- Acrescentar o $\mathrm{NaOH}$ em um balão volumétrico previamente preenchido com água deionizada. O balão não deve ser preenchido em sua totalidade devido ao processo exotérmico que ocorre durante a dissolução.

Materiais: Balão volumétrico.

Equipamento: Agitador e barra magnética

- Completar o volume do balão volumétrico uma vez que a solução atinja uma temperatura de $23{ }^{\circ} \mathrm{C}$.

- Guardar a base em um recipiente plástico lacrado.

Utilizamos três concentrações distintas da solução aquosa de Carbopol. A Tabela 2.3 apresenta as massas usadas na preparação das soluções:

Tabela 2.3: Preparação da solução aquosa de Carbopol

\begin{tabular}{cccc}
\hline \multicolumn{2}{c}{ Carbopol } & Solução aquosa de $\mathrm{NaOH}(18 \%)$ & Água \\
\hline $\mathrm{C}[\%]$ & $\mathrm{m}[\mathrm{g}]$ & $\mathrm{m}[\mathrm{g}]$ & $\mathrm{m}[\mathrm{g}]$ \\
\hline 0.08 & 4.0 & 9,2 & 4986.8 \\
0.10 & 5.0 & 11.5 & 4983.6 \\
0.12 & 6.0 & 13.8 & 4980.2 \\
\hline
\end{tabular}

Para o preparo dessas soluções aquosas, seguimos o procedimento sugerido por Sikorski et al. (46), descrito abaixo:

- Peneirar e pesar o Carbopol, afim de eliminar partículas aglutinadas que absorvem água do ambiente;

Materiais: Bequer e espátula.

Equipamento: Balança de precisão.

- Colocar no agitador mecânico um recipiente com água. Uma vez posicionado, o agitador com uma haste helicoidal é ligado com o propósito de dispersar o polímero, que é acrescentado cuidadosamente;

Misturador com haste helicoidal 
- Agitar vigorosamente (1200 rpm) durante 15 minutos;

- Substituir a haste helicoidal por uma haste naval e adicionar o Hidróxido de sódio;

- Misturar durante 5 dias a uma rotação de 200 rpm.

\section{3}

\section{Medição de propriedades dos fluidos}

\subsection{1}

\section{Reômetro rotacional}

A caracterização reológica dos fluidos utilizados é determinada através de um reômetro rotacional AR-G2, da TA Instruments (vide figura 2.4). O equipamento atua com tensão controlada, e a deformação é mensurada pelo transdutor posicionado no eixo do motor.

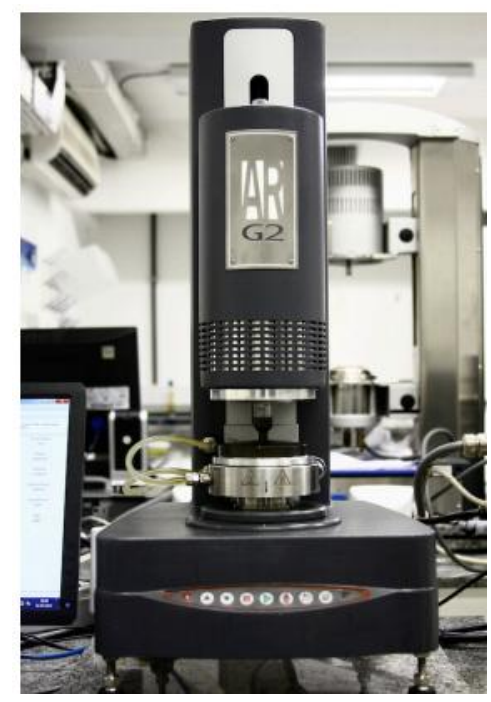

Figura 2.4: Reômetro rotacional AR-G2

\subsubsection{1}

\section{Geometrias}

Três diferentes testes reológicos foram realizadas nas soluções aquosas de Carbopol. Em medições de suspensões poliméricas, as geometrias de superfície lisa podem facilitar o deslizamento na interface entre a amostra e a geometria. Sendo o Carbopol um polímero estruturado com tensão limite de escoamento aparente, o efeito de deslizamento da amostra em taxas baixas de cisalhamento é comum (47). Na tabela 2.4, apresentam-se geometrias usadas por vários pesquisadores na caracterização reológica. Os pesquisadores, e baseados na experiência adquirida no Laboratório de Reología da PUC-RIO, utilizamos 
geometrias que possuem paredes rugosas a fim de evitar o deslizamento. Placa-placa ranhurada ou (crosshatched plate) para os testes oscilatórios e de fluência, e Couette ranhurado para a curva de escoamento foram utilizados. Estas geometrias são apresentadas na figura 2.5.
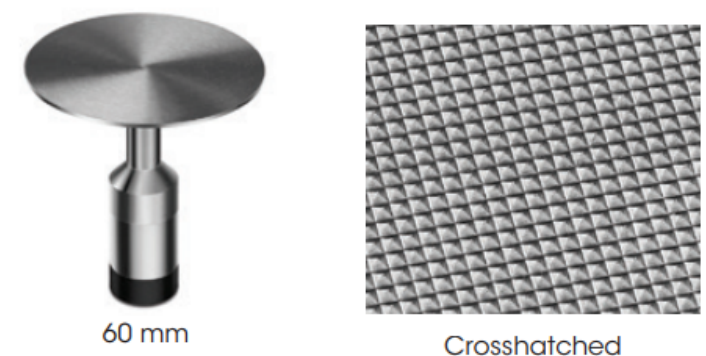

Crosshatched

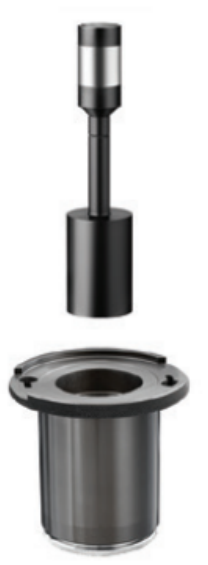

Figura 2.5: Geometria placa-placa plana ranhurada e Couette ranhurado usados nos ensaios reológicos.

Tabela 2.4: Pesquisas e geometrias usadas para caracterizar as propriedades reológicas das soluções e suspensões

\begin{tabular}{ccc}
\hline Pesquisa & Solução/suspensão & Geometria \\
\hline Roberts et al. (48) & Carbopol 980 & Vane-cup \\
Coussot et al. (49) & Carbopol & Cil. conc. recoberto de lixa \\
Huang et al. (50) & Suspensão densa & Vane-cup \\
Ovarlez et al. (51) & Suspensão densa & Cil. conc. recoberto de lixa \\
Barnes et al. (52) & Varias & Vane-cup \\
Poumaere et al. (53) & Carbopol & Placas paralelas ranhuradas \\
\hline
\end{tabular}

Para os testes reológicos, feitos com a geometria Couette ranhurada, utilizamos uma geometria com as características $D=15 \mathrm{~mm} ; D c=14$ $\mathrm{mm} ; L=42 \mathrm{~mm}$ para taxas de cisalhamento de até $250 \mathrm{~s}^{-1}$. Para o caso de testes realizados com geometria placa-placa ranhurado, cujo diâmetro é $60 \mathrm{~mm}$, devido à não homogeneidade do escoamento, é necessária uma correção da tensão de cisalhamento. Para materiais cuja função viscosidade é não-newtoniano, a equação de Weissenberg-Rabinowitsch é a mais usada:

$$
\sigma_{R}=\frac{2 M}{\pi R^{3}}\left[\frac{3}{4}+\frac{1}{4} \frac{\mathrm{d} \ln (M)}{\mathrm{d} \ln \left(\dot{\gamma_{R}}\right)}\right]
$$

onde $M$ é o torque, $R$ o raio da placa e $\dot{\gamma}_{R}$ a taxa de cisalhamento. 


\subsubsection{2}

\section{Sistema de controle de temperatura}

Tanto para as geometrias de placa-placa ranhurada como para cilindros concêntricos ranhurados, o reômetro possui um sistema de controle de temperatura tipo Peltier, (vide figura 2.6). Um arranjo de quatro elementos de aquecimento em contato com o copo inferior, que é mantida no lugar por uma jaqueta isolada, fornece uma transferência de calor rápida e eficiente às paredes internas. Um termômetro de resistência de platina garante a medição e controle preciso da temperatura. Todos os testes foram realizados a uma temperatura constante de $23.5^{\circ} \mathrm{C}$
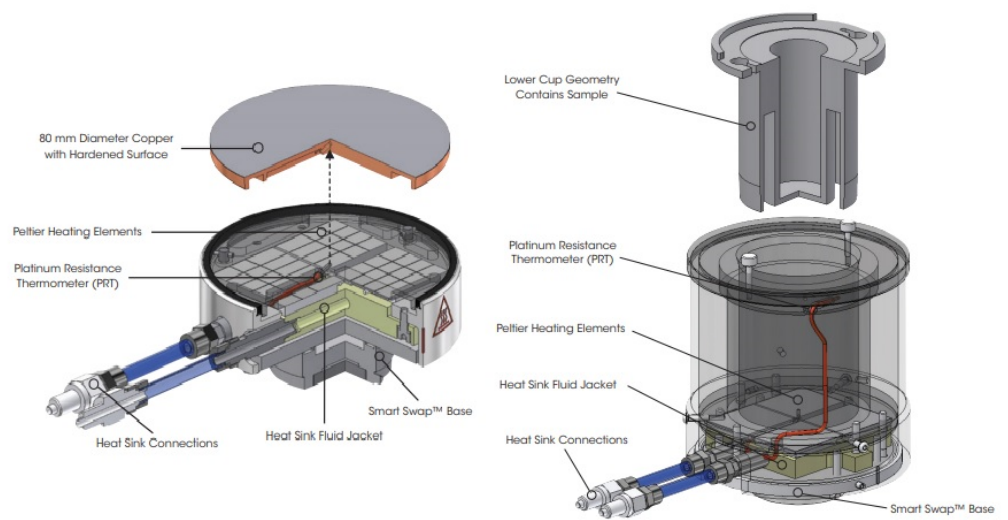

Figura 2.6: Sistema de controle de temperatura para geometria de cilindros concêntricos e placa-placa ranhurada.

\subsubsection{3}

\section{Controle de evaporação}

O equipamento possui geometrias com controle de evaporação que criam uma barreira líquida como a mostrada na figura 2.7. O arranjo praticamente elimina a perda de amostra devido à evaporação durante o teste. A geometria placa-placa ranhurada possui um reservatório preenchível com solvente. As capas protetoras da geometria assentam-se diretamente sobre a placa de Peltier para a geometria placa-placa ranhurada. Para o caso Couette ranhurado, as capas protetoras assentam-se sobre o copo externo. Sendo os fluidos empregados base água, a volatilidade é uma variável importante que deve ser controlada (48).

\subsection{2}

\section{Testes reológicos}




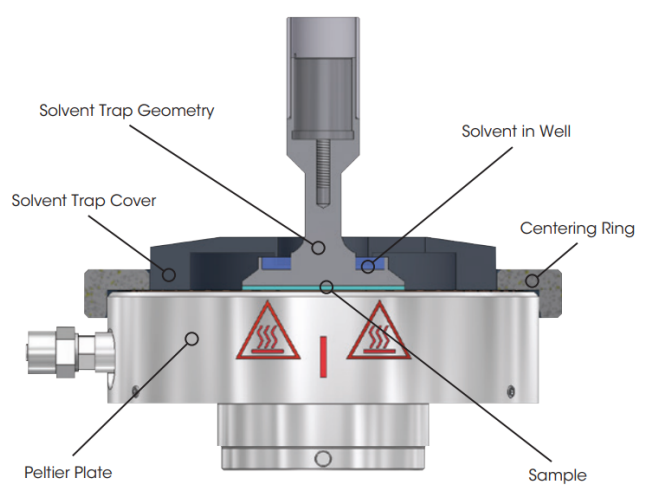

Figura 2.7: Sistema trampa-solvente

\subsubsection{1}

\section{Teste de fluência ou creep test}

O teste de fluência pode usado para obter a tensão limite de escoamento estática de materiais viscoplásticos (54-57). Nesses testes, uma tensão de cisalhamento constante é aplicada e a taxa de deformação é monitorada ao longo do tempo. A tensão limite de escoamento obtida é chamada de tensão de escoamento estática. Essa é a tensão necessária para provocar uma mudança microestrutural em uma amostra inicialmente totalmente estruturada (57). Para tensões impostas acima da tensão limite de escoamento estática $\tau_{o}$, o fluido escoa e a taxa de cisalhamento aumenta até se estabilizar e entrar em regime permanente. Enquanto para tensões menores a $\tau_{o}$, o material se comporta como um sólido, e a taxa de cisalhamento $\dot{\gamma}$ tende a zero ao longo do tempo. O afastamento entre esses dois comportamentos mostra a região do valor estimativo da tensão limite de escoamento estática. Note que não é possível determinar o valor exato da tensão limite de escoamento estática com este teste. O tempo escolhido para o teste foi de 7200 segundos, muito maior que o tempo do deslocamento nos testes experimentais, que é de aproximadamente 6 minutos nas taxas de injeção menores.

\subsubsection{2}

\section{Teste de varredura de tensão ou amplitude sweep test}

O teste de varredura é um teste que caracteriza o comportamento da deformação da amostra em uma faixa não destrutiva (58). Sendo um teste oscilatório com frequência fixa e tensão variável, sua resposta mostra o comportamento do módulo elástico ou storage modulus $G^{\prime}$ e do módulo viscoso ou loss modulus $G^{\prime \prime}$. Para uma deformação elástica, os módulos se mantêm constantes e a estrutura da amostra não é transformada irreversivelmente. Esta região é chamada de viscoelástica linear. Assim que os módulos abandonam 
esta região, a estrutura é transformada. Quando que o comportamento dos módulos não é mais constante, a tensão se encontra fora da região viscoelástica linear e o teste perde seu significado físico. A relação dos dois módulos fornece informações sobre a característica da amostra. Se o módulo de armazenamento é maior que o módulo viscoso, a amostra se comporta mais como um sólido elástico. No caso oposto, i.e., $G^{\prime \prime}>G^{\prime}$, existe predominância de efeitos viscosos. Outro parâmetro reológico que é possível obter com o teste de varredura de tensão é a ordem de grandeza da tensão limite de escoamento $\tau_{0}$, sendo o ponto de partida para facilitar a realização do teste de fluência.

\subsubsection{3}

\section{Curva de escoamento}

A curva de escoamento ou flow curve revela o comportamento da função viscosidade em relação a taxa de cisalhamento (59). Para obter cada valor da função viscosidade, a amostra tem que estar imperativamente em regime permanente e laminar. Cabe enfatizar que a tensão limite de escoamento aparente obtida pela flow curve é menor que aquela obtida pelo teste de fluência. Isto é devido a que $\tau_{y}$ obtido pela curva de escoamento é a chamada tensão dinâmica, caso contrario à obtida pelo teste de fluência (60).

\section{4}

\section{Parâmetros governantes e adimensionalização}

A figura 2.8 mostra um desenho esquemático da seção de teste e suas dimensões características. As medidas principais são o diâmetro e comprimento do tubo a montante e a jusante da expansão-contração, $D e=24 \mathrm{~mm}$ e $L e=120$ mm, comprimento e diâmetro da expansão-contração, $L$ e $D$, e diâmetro do eixo central $d=15 \mathrm{~mm}$. A tabela 2.4 mostra as dimensões de cada uma das expansões-contrações testadas no estudo experimental. Para avaliar as grandezas cinemáticas, é necessário estabelecer uma seção característica. Para nosso caso foi escolhida a seção transversal de saída. Formada por um anular concêntrico, o diâmetro hidráulico é $D_{h}=4 A / P$ sendo $A$ a área molhada e $P$ o perímetro molhado, ou $D_{h}=D_{e}-d$. A velocidade característica $\bar{u}$ e a taxa de cisalhamento característica são definidas como:

$$
\begin{gathered}
\bar{u}_{c}=\frac{4 Q}{\pi\left(D_{e}^{2}-d^{2}\right)} \\
\dot{\gamma}_{c}=\frac{8 Q}{\pi\left(D_{e}+d\right)\left(D_{e}^{2}-d^{2}\right)}
\end{gathered}
$$

As expressões adimensionais que envolvem as características geométricas 
Tabela 2.5: Características geométricas das expansões-contrações testadas

\begin{tabular}{cc}
\hline \hline$D(m m)$ & $L(m m)$ \\
\hline 31.65 & 13.5 \\
31.65 & 27 \\
31.65 & 40.5 \\
55.5 & 13.5 \\
55.5 & 27 \\
55.5 & 40.5 \\
63.75 & 13.5 \\
63.75 & 27 \\
63.75 & 40.5 \\
\hline
\end{tabular}

da expansão-contração abrupta são o comprimento adimensional $L^{*}$ e o diâmetro adimensional $D^{*}$.

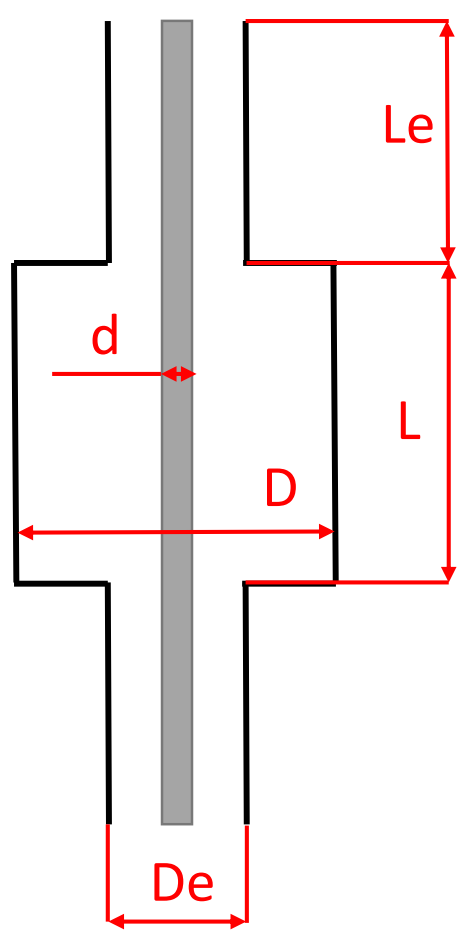

Figura 2.8: Desenho esquemático e dimensões características da seção de teste

$$
\begin{aligned}
D^{*} & =\frac{D}{d} \\
L^{*} & =\frac{L}{d}
\end{aligned}
$$


A tabela 2.4 mostra os modelos utilizados para caracterizar $\eta\left(\dot{\gamma}_{c}\right)$ do fluido de perfuração por diversos pesquisadores:

Tabela 2.6: Modelos reológicos utilizados na literatura para caracterizar o comportamento reológico do fluido de perfuração

\begin{tabular}{cc}
\hline Pesquisa & Modelo \\
\hline Hemphill et al. (61) & H-B \\
Merlo et al. (62) & H-B \\
Maglione et al. (63) & H-B \\
Escudier et al. (64) & H-B \\
Kelessidis et al. (65) & H-B \\
Ozbayoglu et al. (66) & H-B \\
Founargiotakis et al. (67) & H-B \\
Hamed et al. (68) & H-B \\
Majidi et al. (69) & H-B \\
Sorgun et al. (70) & P-L \\
Reed et al. (71) & P-L \\
\hline H-B Herschel-Bulkley & \\
P-L Power Law &
\end{tabular}

De acordo com a maioria dos autores da tabela 2.4, em nossa pesquisa, a viscosidade da solução aquosa de Carbopol foi modelada utilizando a função viscosidade tipo Herschel-Bulkley:

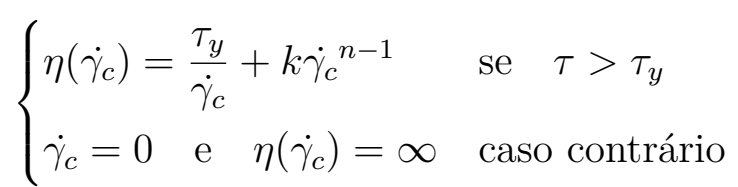

Para nosso estudo experimental, o número de Weissenberg foi definido através da razão entre efeitos viscosos e efeitos elásticos:

$$
W i=\frac{\tau}{G^{\prime}}=\frac{\eta_{\left(\dot{\gamma}_{c}\right)} \dot{\gamma}_{c}}{G^{\prime}}
$$

Cabe enfatizar que o módulo elástico $G^{\prime}$ é obtido da fase $L V E$ do teste de varredura de tensão. A viscosidade adimensional e tensão adimensional são expressadas como:

$$
\begin{aligned}
R_{\mu} & =\frac{\eta_{\left(\dot{\gamma}_{c}\right)}}{\mu} \\
\sigma^{*} & =\frac{\tau_{y}}{G^{\prime}}
\end{aligned}
$$




\section{5}

\section{Volume adimensional}

Ao longo do deslocamento, a densidade mensurada pelo densitômetro varia da densidade do fluido deslocado para a densidade do fluido deslocador. Este processo se desenvolve a vazão constante. Mencionada transição ocorre de forma não abrupta (vide fig 2.9). Convenientemente, a mudança da densidade é normalizada $[1,0]$ e dada por:

$$
\frac{\rho_{1}-\rho(t)}{\rho_{1}-\rho_{2}}
$$

sendo $\rho_{1}$ e $\rho_{2}$ as densidades do fluidos deslocador e deslocado, respetivamente. O cálculo da fração de volume deslocado ou Yielded volume fraction $Y v f$ é dado por:

$$
Y v f=Q \int_{0}^{\infty} \frac{\rho_{1}-\rho(t)}{\rho_{1}-\rho_{2}} d t
$$

onde $Q$ a vazão de injeção constante. O calculo da fração de volume deslocado permite quantificar o volume de fluido não newtoniano retirado dentro da seção de teste ao longo do processo de deslocamento. Note que quando a densidade normalizada é igual à unidade (1), o volume que encontra-se saindo da seção de teste é somente constituído pelo fluido não newtoniano. Se a densidade normalizada encontra-se em valores intermediários, representa que o volume deslocado é constituído por frações de fluido deslocador e deslocado. Finalmente quando a densidade normalizada atinge zero (0), o fluido utilizado como deslocador é o único em sair da seção de teste e a o volume de fluido não newtoniano deslocado, a partir de esse instante de tempo, é nulo. 


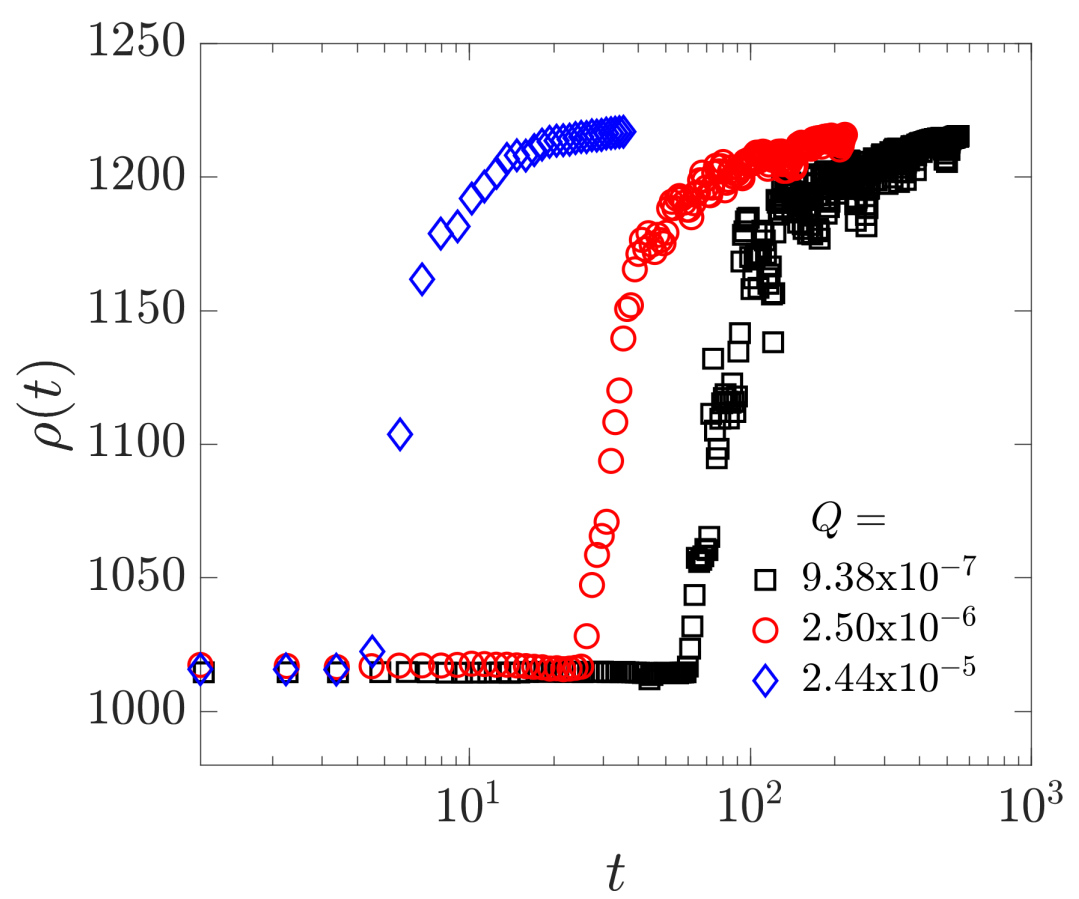

Figura 2.9: Variação da densidade $\rho(t)$ em função do tempo $t$.

O volume adimensional $V^{*}$, é definido como a normalização da fração de volume deslocado $Y v f$ e um volume característico definido como $V$ (vide fig. 2.10). O objetivo do volume adimensional é mostrar a influência dos parâmetros geométricos, reológicos e cinemáticos no experimento de deslocamento. De um modo geral, a escolha do volume característico mostra a dificuldade de definir uma relação que permita mostrar de forma independente a influência de cada parâmetro geométrico. Se o volume característico fosse o volume total, ou seja, o volume envolve a seção anular e a expansão-contração, é impossível mostrar a influência dos parâmetros geométricos separadamente, uma vez que muda com cada configuração de cavidade. A mesma desvantagem foi observada se o volume característico fosse escolhido como o volume da expansão-contração. Por outro lado, se o volume característico for o volume do anular, $V^{*}$ estará condicionado ao comprimento da seção de teste. A melhor escolha encontrada foi o volume formado pela fenda anular e o comprimento de expansão-contração, que é $V=\pi L / 4\left(D_{e}^{2}-d^{2}\right)$. 


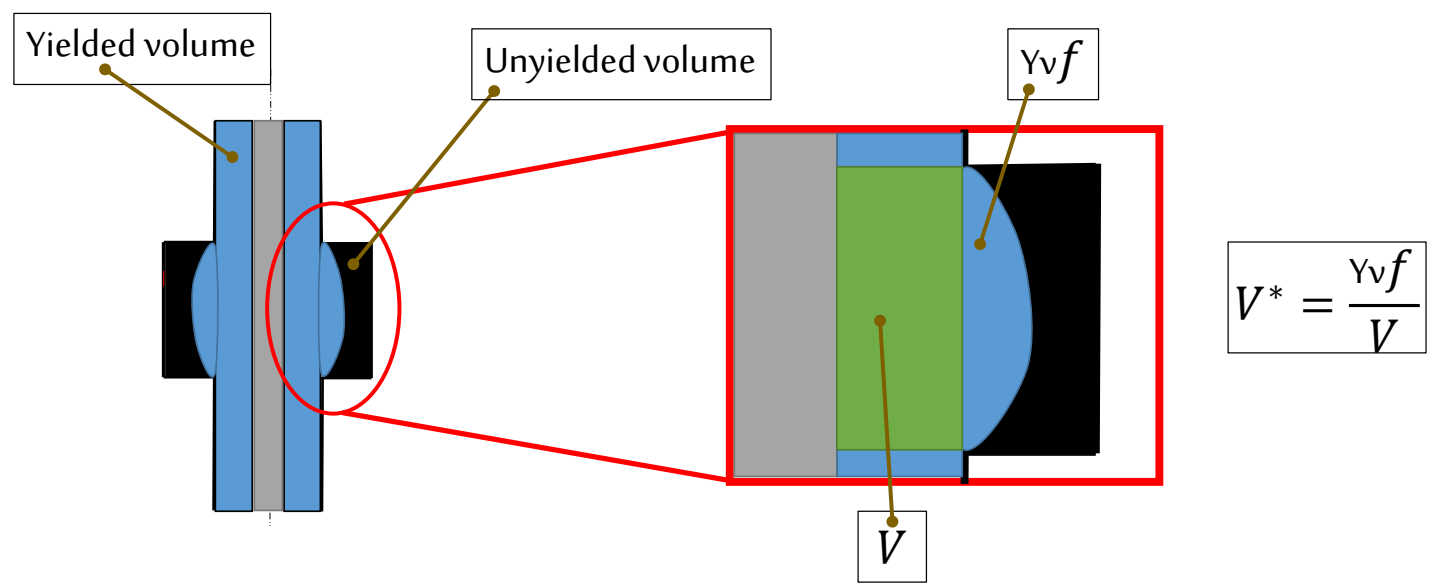

Figura 2.10: Representação esquemática de Volume adimensional $V^{*}$ 


\section{3 \\ Resultados dos testes experimentais}

Nesta seção os resultados de cada um dos testes reológicos e experimentais previamente descritos serão apresentados. Foram executados uma ampla quantidade de testes para obter as propriedades reológicas dos fluidos. Em seguida, esses mesmos fluidos foram utilizados nos processos de deslocamento em espaços anulares com expansão-contração. As soluções de carbopol foram utilizadas como fluido deslocado, e a mistura água/glicerina como fluido deslocador.

\section{1}

\section{Resultados da caracterização reológica}

\subsection{1}

\section{Testes de varredura de tensão}

Resultados dos testes de varredura de tensão para frequências de 0.1 e 1 $\mathrm{Hz}$ são mostrados na figura 3.1 para as três soluções aquosas de carbopol utilizadas. O comportamento da solução aquosa mostrou três regiões bem definidas: a região viscoelástica linear (LVE), a região próxima ao escoamento e a região não linear.

De modo geral, para maiores concentrações de polímero na solução aquosa, maiores são os módulos elástico e viscoso. LVE foi observada na faixa de baixas tensões impostas, onde os módulos elástico e viscoso se mostraram quase constantes. As soluções se comportam essencialmente como corpos elásticos ao longo dessa região viscoelástica linear. Para a faixa de baixas tensões, observa-se um incremento no módulo elástico e viscoso quando aumentamos a frequência. Este fenômeno pode ser explicado usando o modelo generalizado de Maxwell para fluidos viscoelásticos, que é representado por um amortecedor e uma mola conectados em série. Para altas frequências, a mola consegue se esticar e se contrair sob a tensão imposta, ao igual que o amortecedor. Isso leva a um maior armazenamento de energia.

Uma informação importante que pode ser obtida do teste de varredura de tensão é uma estimativa da tensão limite de escoamento aparente $\tau_{0}$. Cabe notar que vários autores sugerem que $\tau_{0}$ é o valor resultante quando os valores 

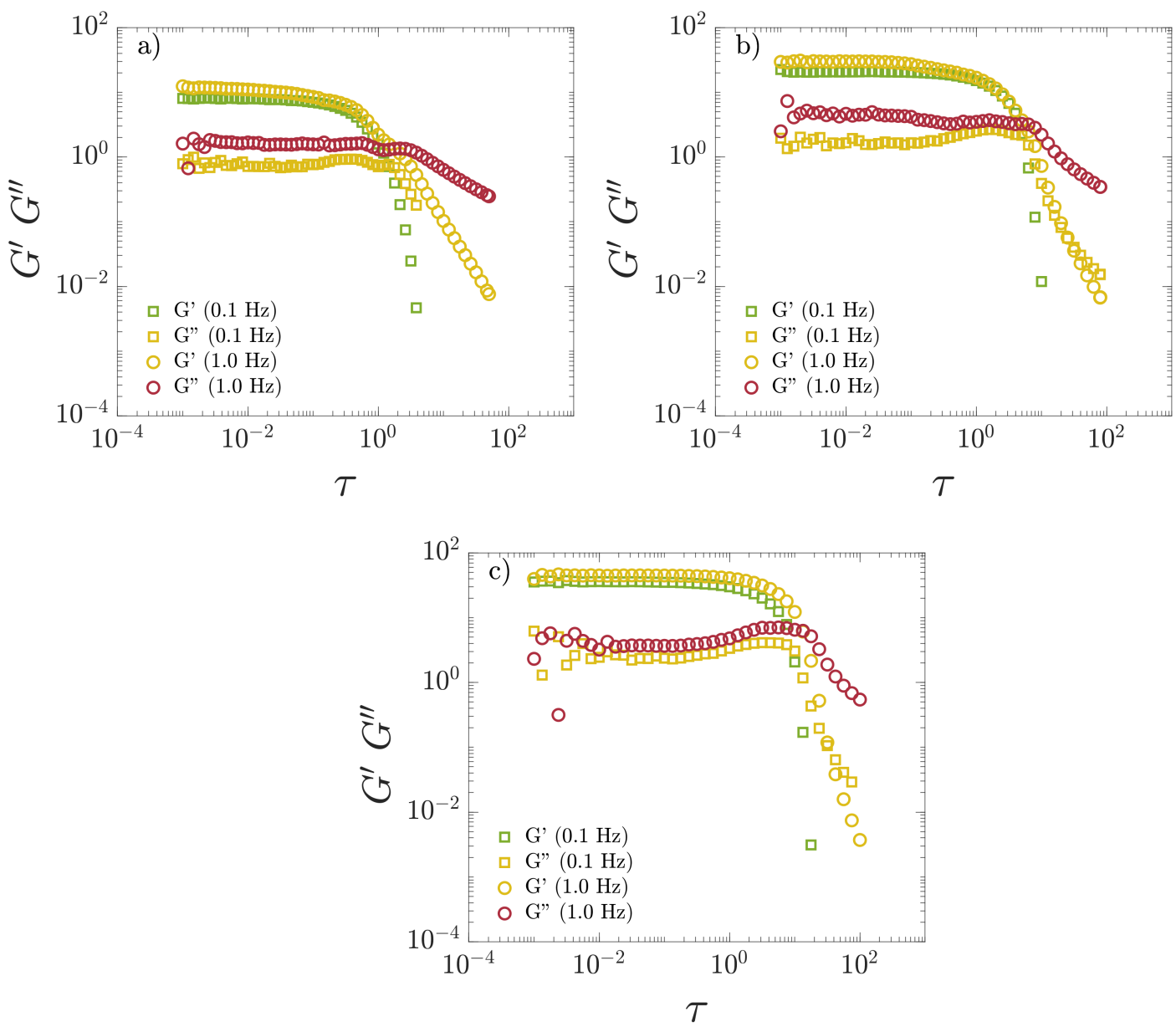

Figura 3.1: Teste de varredura de tensão para frequências $0.1,1 \mathrm{~Hz}$ para as soluções aquosas de Carbopol de concentrações a) $0.08 \%$, b) $0.10 \%$ e c) $0.12 \%$.

dos módulos elástico e viscoso são iguais, mas ainda não existe um consenso. Este valor, apesar de ser aproximado, estima a mesma ordem de grandeza para a tensão limite dos valores encontrados pelos testes de fluência. Este comportamento se deve a que o teste inicia de um estado estacionário onde as forças elásticas são predominantes. A tabela 3.1.1 mostra os valores médios dos módulos elásticos e viscosos de cada solução aquosa de Carbopol na região viscoelástica linear.

Tabela 3.1: Valores dos módulos elástico e viscoso para cada solução aquosa de Carbopol

\begin{tabular}{ccc}
\hline $\begin{array}{c}\text { Concentração } \\
\text { wt\% }\end{array}$ & $\begin{array}{c}G^{\prime} \\
(P a)\end{array}$ & $\begin{array}{c}G^{\prime \prime} \\
(P a)\end{array}$ \\
\hline \hline 0.08 & 9.31 & 0.81 \\
0.10 & 31.38 & 4.87 \\
0.12 & 45.22 & 7.86 \\
\hline
\end{tabular}




\subsection{2}

\section{Teste de fluência}
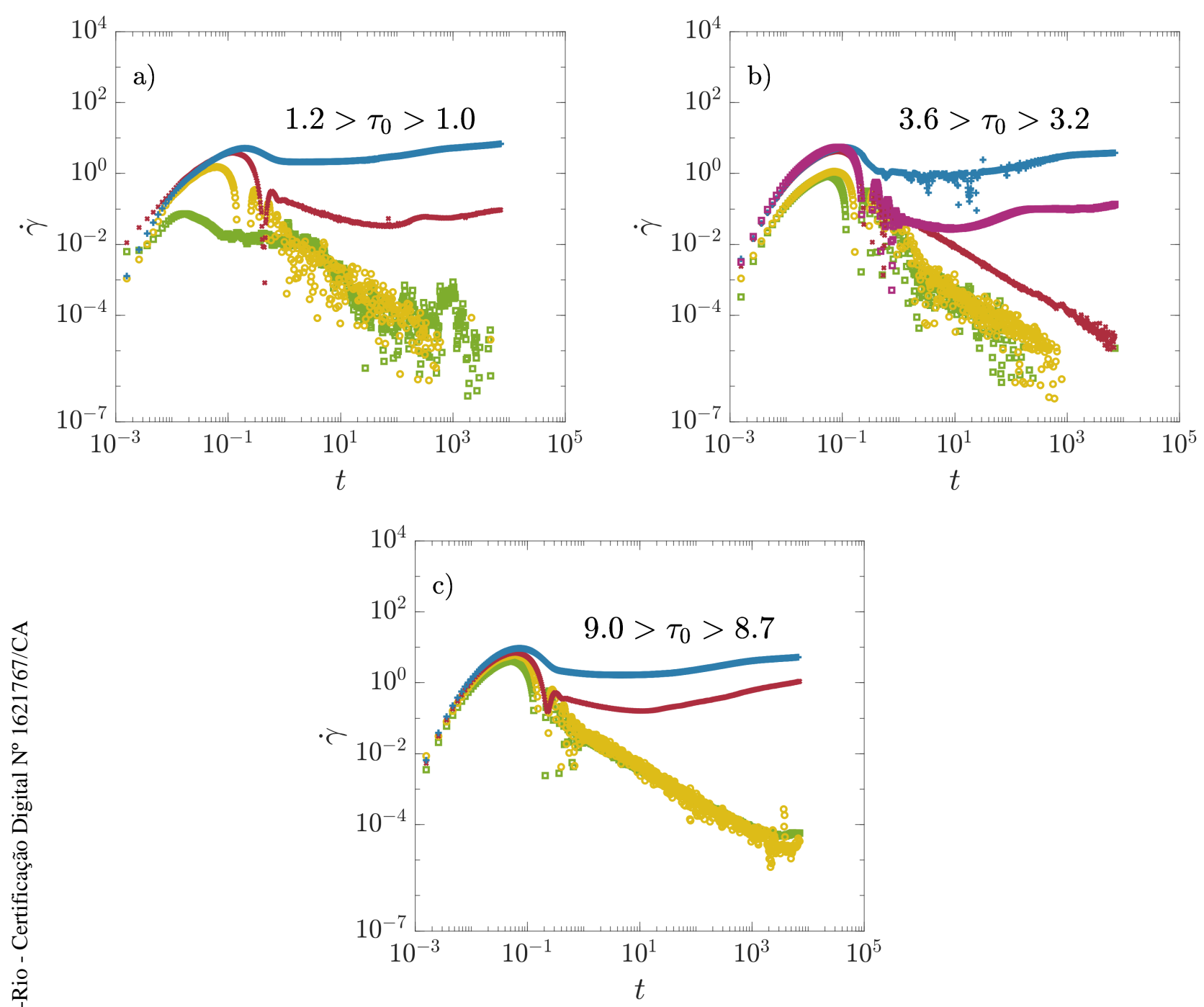

Figura 3.2: Resposta da taxa de cisalhamento vs tempo dos testes de varredura de tensão constante para a solução aquosa de Carbopol em concentrações de a) $0.08 \%$, b) $0.10 \%$ e c) $0.12 \%$

A figura 3.2 mostra os testes de fluência que foram obtidas para as três concentrações das soluções aquosas de Carbopol utilizadas. Determinar a região da tensão limite de escoamento estática é o principal objetivo desses testes. Cada sub-figura mostra a taxa de cisalhamento em função do tempo para uma extra-tensão fixa. Vários testes de fluência são necessários para identificar a região da tensão limite de escoamento estática, $\tau_{0}$ : Se a extra-tensão imposta for menor que a tensão limite de escoamento estática, a taxa de cisalhamento mostra uma queda paulatina que se aproxima de zero. Se a extra-tensão for maior que $\tau_{0}$, a taxa de cisalhamento mostra um comportamento quase constante ao longo do tempo para $t>1$. Essa mudança 
de comportamento está relacionada à viscosidade que passa por uma transição entre uma viscosidade finita, característica do escoamento, e uma viscosidade aparente infinita.

Para as três soluções aquosas de Carbopol, a taxa de cisalhamento $\dot{\gamma}$ exibe um crescimento abrupto seguido por uma queda em um tempo não maior de 1 segundo. Este comportamento é atribuído à ação tanto da inércia do equipamento como dos efeitos elásticos do fluido, $(72,73)$. Cabe notar que quanto maior é a tensão imposta, mais notórios são tais efeitos. Também foi observado que ao aumentar a concentração de polímero na solução aquosa, maior é a faixa onde se encontra a tensão limite estática $\tau_{0}$. Este fenômeno deve-se ao aumento das cadeias poliméricas dentro da solução, as quais requerem uma maior extra-tensão para serem forçadas a se alinhar e abandonar a região de comportamento elástico. O efeito avalanche de escoamento não foi observado, o qual foi identificado nas pesquisas realizadas por Ewoldt et al. (73) e Coussot et al. (54) para tempos maiores de teste.

\subsection{3}

\section{Teste curva de escoamento}

A figura 3.3 mostra as curvas de escoamento das soluções aquosas de Carbopol para taxas de cisalhamentos $0.01<\dot{\gamma}<250 \mathrm{~s}^{-1}$. As curvas foram obtidas diminuindo a taxa de cisalhamento do valor máximo ao mínimo. Isso reduz significativamente o tempo de duração dos testes porque o estado permanente é atingido rapidamente para taxas maiores. Viscosidade dependente de $\dot{\gamma}$ e a presença de uma tensão limite de escoamento aparente foram observados para todas as concentrações. À medida que a taxa de cisalhamento diminui, a tensão tende a reduzir sua variação, permitindo extrapolar essa tendência para obter a tensão limite de escoamento dinâmica ou tensão limite de escoamento aparente (60).

Diferentes pesquisadores observaram que a solução aquosa de Carbopol mostra baixa dependência com respeito à temperatura (74-76), apesar de ser uma solução polimérica base-água. A função viscosidade $\eta(\dot{\gamma})$ da solução aquosa de Carbopol usada nesta pesquisa não mostra uma dependência significativa com respeito à variação da temperatura, como pode ser visto na figura 3.4 . 

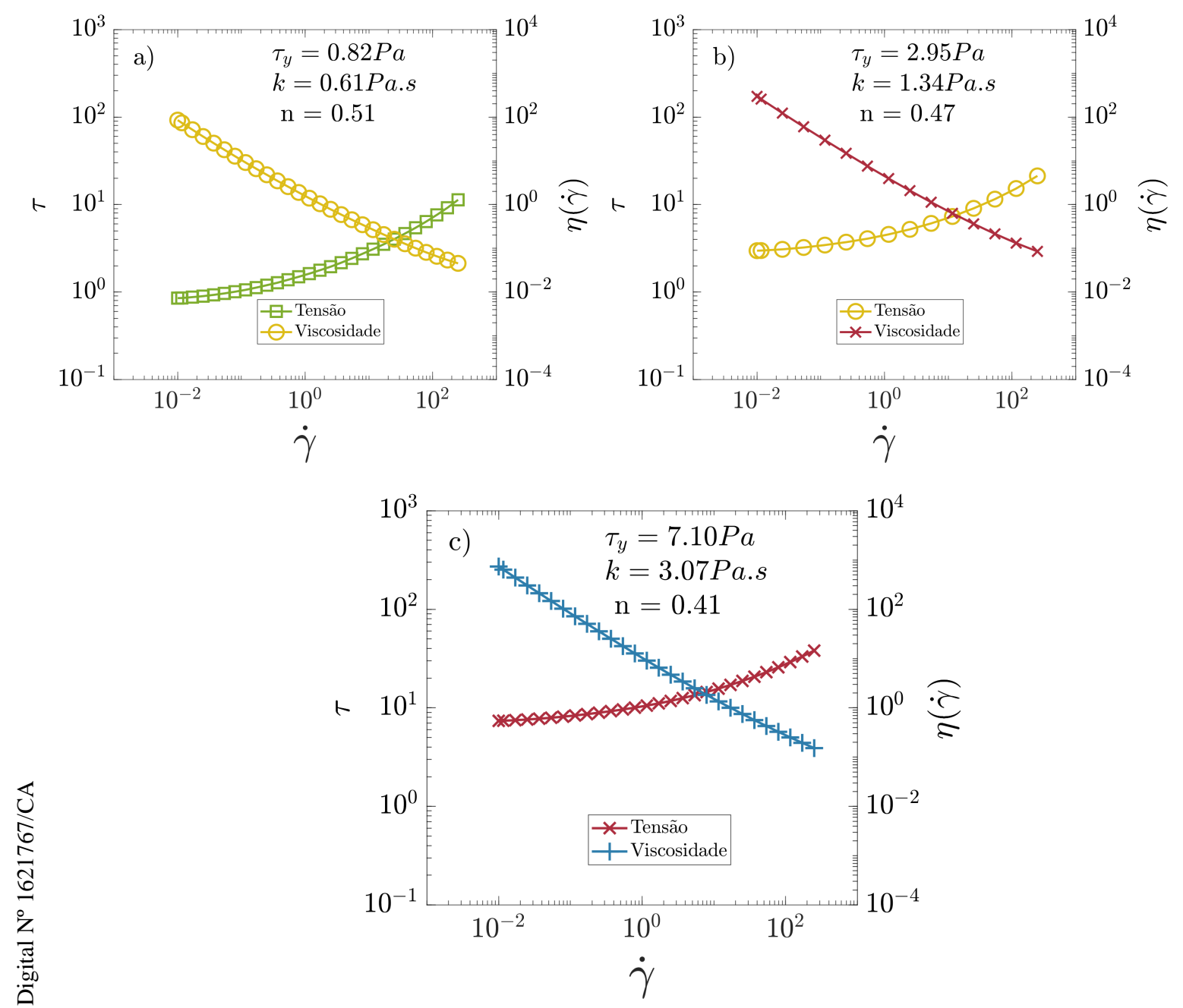

Figura 3.3: Curva de escoamento das soluções aquosas de Carbopol em concentrações de a) $0.08 \%$, b) $0.10 \%$, c) $0.12 \%$

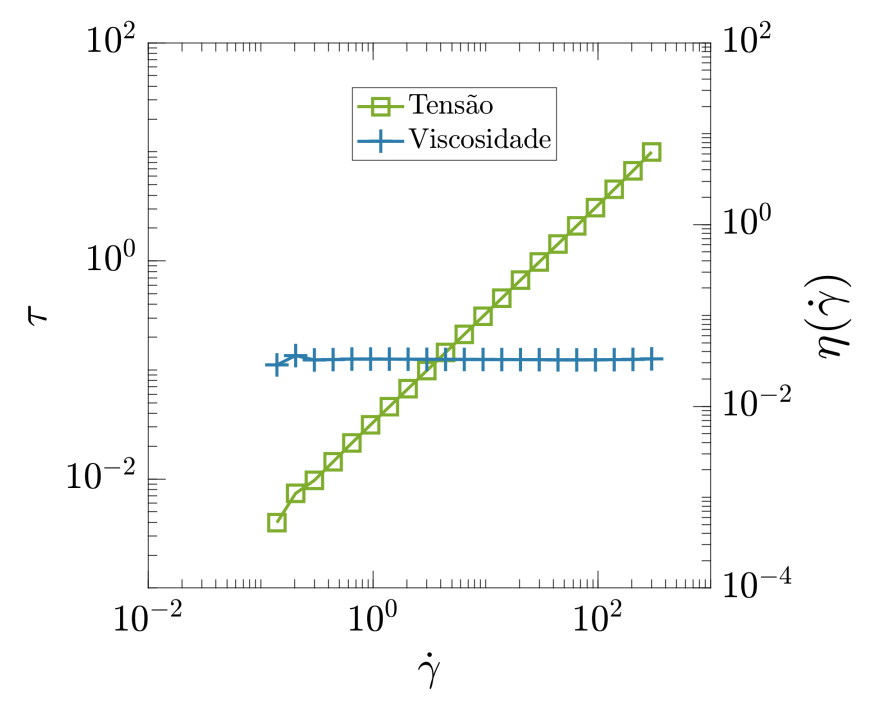

Figura 3.5: Curva de escoamento da mistura água-glicerina 


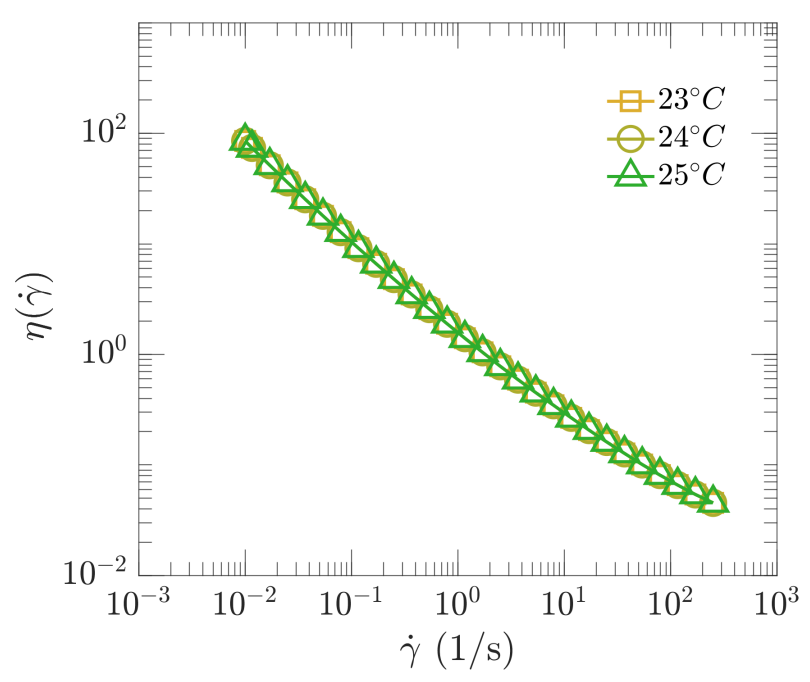

Figura 3.4: Comportamento da função viscosidade $\eta(\dot{\gamma})$ da solução aquosa de Carbopol com concentração de $0.08 \%$ a diferentes temperaturas.

A curva de escoamento da mistura água/glicerina (vide figura 3.5) mostra a viscosidade independente da taxa de cisalhamento $\dot{\gamma}$.

\section{2}

\section{Resultados dos testes experimentais}

Nesta seção serão apresentados os resultados experimentais obtidos nos testes de deslocamento. Foram feitos aproximadamente 300 testes experimentais para diversas vazões constantes de injecção e várias configurações geométricas. Os parâmetros geométricos, que caracterizam a expansão-contração são $\quad D^{*}=(2.11,3.7,4.25) \quad$ e $\quad L^{*}=(0.9,1.8,2.7)$. Os parâmetros reológicos investigados foram: $\sigma^{*}=(0.088,0.094,0.157)$ para $0.1<W i<0.3$ e $10^{1}<R_{\mu}<10^{3}$.

\subsection{1}

\section{Influência dos parâmetros reológicos e geométricos}

Usando uma geometria similar à utilizada na presente pesquisa, Chevalier et al. (77) mostraram experimentalmente que existem três tipos de escoamento axissimétricos quando um único fluido com tensão limite de escoamento aparente escoa a vazão constante. O escoamento no espaço anular revelou que (i) existe uma velocidade quase uniforme que independe da posição axial, (ii) que existe um escoamento cuja velocidade diminui radialmente na presença da expansão-contração abrupta, (iii) e que existe uma região externa, dentro da expansão-contração, onde o fluido se encontra aparentemente estagnado.

A figura 3.6 mostra um resultado de nosso deslocamento dentro da 


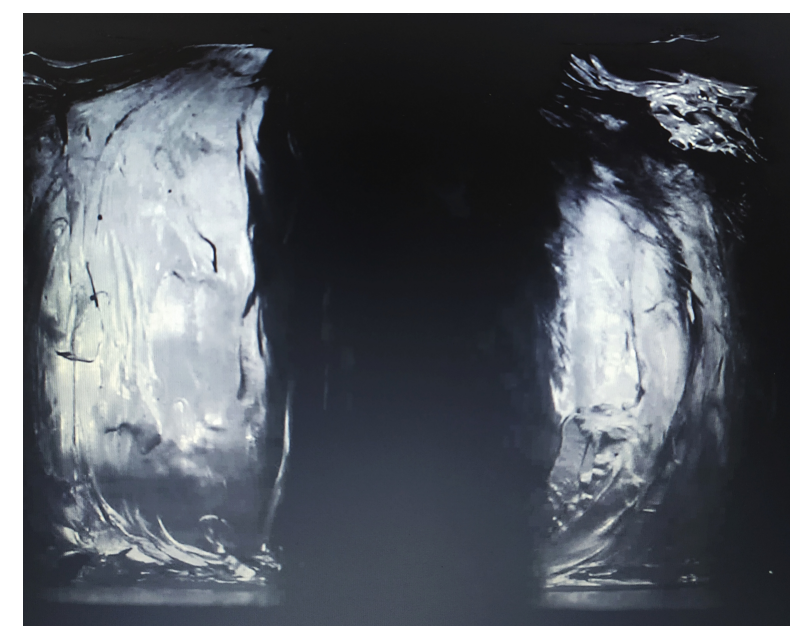

Figura 3.6: Deslocamento dentro da expansão-contração para $\left(W i, D^{*}, L^{*}, \sigma^{*}\right)=(0.15,3.7,1.8,0.157)$.

expansão-contração para os parâmetros $\left(W i, D^{*}, L^{*}, \sigma^{*}\right)=(0.15,3.7,1.8,0.157)$. Foram observados deslocamentos tridimensionais dentro da expansão-contração abrupta. Também observamos volume de fluido não newtoniano estagnado próximos dos cantos. Este comportamento difere do observado por Chevalier et al. (77), Roustaei et al. $(19,26)$, Naccache et al. (7) e de Souza Mendes et al. (78). Estas divergências são atribuídas ao fato de nossa pesquisa envolver um processo de deslocamento viscosamente instável de um fluido não newtoniano com tensão limite de escoamento aparente sendo deslocado por um fluido newtoniano, enquanto os autores citados consideram o escoamento de um único fluido com tensão limite de escoamento aparente pelo espaço anular. Portanto, apesar de se tratar de fluidos não newtonianos com as mesmas características reológicas e a mesma configuração geométrica, existem efeitos tridimensionais durante o deslocamento que não são capturadas com simplificações de escoamentos de um único fluido, as quais dependente dos casos, podem ser relevantes.

A figura 3.7 mostra o volume $V^{*}$ em função do número de Weissenberg $W i$ para $D^{*}=(a, b, c)=(2.11,3.70,4.25)$ e $\sigma^{*}=0.088$. As retas horizontais contínua, tracejada e ponto-tracejada definem o valor o máximo de $V^{*}$ para cada uma das configurações geométricas. De modo geral, maiores valores de $V^{*}$ correspondem a melhores eficiências de deslocamento, e ao aumentar $W i$ leva a menores valores de $V^{*}$. Este comportamento é qualitativamente similar ao encontrado nas simulações numéricas de Naccache et al. (41) e Roustaei et al. (19). Os pesquisadores afirmaram que esse comportamento se deve ao fato que quando as forças inerciais se tornam influenciáveis para deslocamentos instáveis em expansões-contrações abruptas, uma menor quantidade de fluido deslocado é removido de dentro da geometria complexa. Para profundidades 

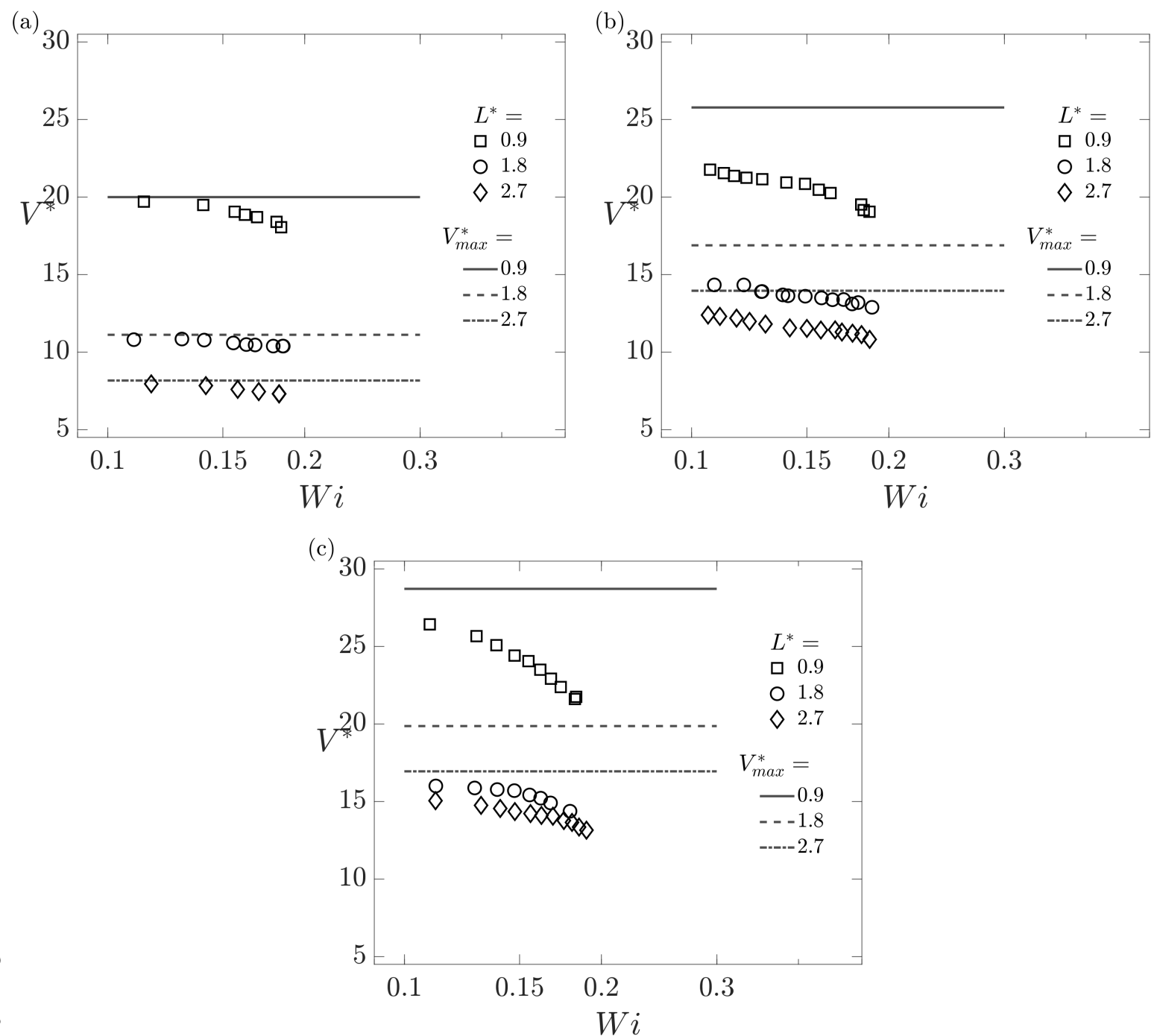

Figura 3.7: Volume $V^{*}$ em função de $W i$ para $D^{*}=$ a) 2.11, b) 3.70 c) 4.25 e $\sigma^{*}=0.088$.

relativamente pequenas, isto é $D^{*}=2.11$, (vide fig. 3.7(a) valores próximos de $V_{\text {max }}^{*}$ para os três comprimentos adimensionais $L^{*}$, foram atingidos para os menores $W i$ testados. Os resultados sugerem um deslocamento quase total do fluido não newtoniano com a menor tensão adimensional $\sigma^{*}$ testada. A figura 3.7(b) mostra que, ao aumentar $D^{*}$, valores menores de $V^{*}$, para números similares de $W i$, foram obtidos comparados com seus respetivos $V_{\text {max }}^{*}$. Isto mostra que, ao aumentar a profundidade da expansão-contração, uma maior quantidade de volume de fluido não newtoniano permaneceu estagnado dentro da geometria durante o processo de deslocamento. Para o caso de $D^{*}=4.25$, mostrado na 3.7 (c), valores semelhantes de $V^{*}$ para $L^{*}=1.8$ e 2.7 mostram uma menor influência da profundidade da expansão no volume $V^{*}$ para maiores comprimentos adimensionais $L^{*}$. Sendo assim, uma possível independência do volume $V^{*}$ com relação à profundidade da expansão-contração é plausível. 

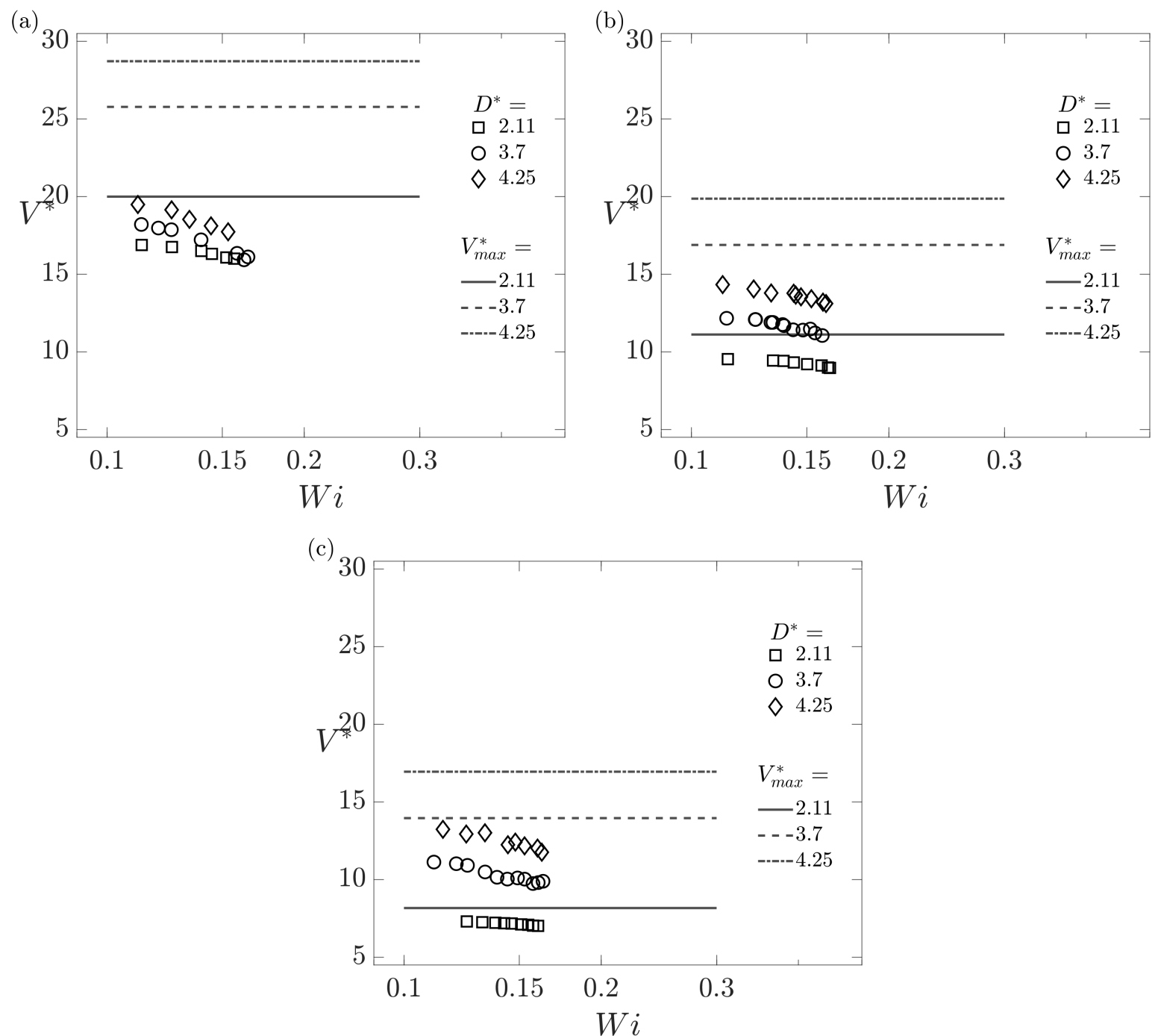

Figura 3.8: Volume $V^{*}$ em função de $W i$ para $L^{*}=$ a) 0.9 , b) 1.8 c) 2.7 e $\sigma^{*}=0.094$.

A figura 3.8 mostra o volume $V^{*}$ em função do número de Weissenberg $W i$ quando aumentamos a tensão limite de escoamento aparente e o modulo elástico do fluido deslocado. Os parâmetros geométricos investigados são os mesmos da figura 3.7, no entanto, (a) $L^{*}=0.9$, (b) $L^{*}=1.8$ e (c) $L^{*}=2.7$ e cada quadro compara a influência dos diâmetros adimensionais $D^{*}=(2.11,3.7,4.25)$. Para $L^{*}=(1.8,2.7)$, o volume $V^{*}$ é menor para menores valores de $D^{*}$. Mesmo para $L^{*}$ relativamente pequeno, encontramos dependência com respeito a $D^{*}$ para baixos número de Weissenberg. À medida que $W i$ aumenta, o volume deslocado parece convergir para um valor único independente de $D^{*}$ para $L^{*}=0.9$. Ao aumentar $L^{*}$ (vide figuras $3.8 \mathrm{~b}, \mathrm{c}$ ), observa-se influência, ao longo de toda a faixa de $W i$, da profundidade da expansão-contração $D^{*}$. Por outro lado, para maiores $L^{*}$, é possível apreciar maiores valores de $V^{*}$ para os casos $D^{*}=(3.7,4.25)$, comparados com sua símiles de $L^{*}$ menores. 
Consequentemente, o aumento do comprimento da expansão-contração beneficia o processo de deslocamento do fluido não newtoniano, para uma mesma profundidade.
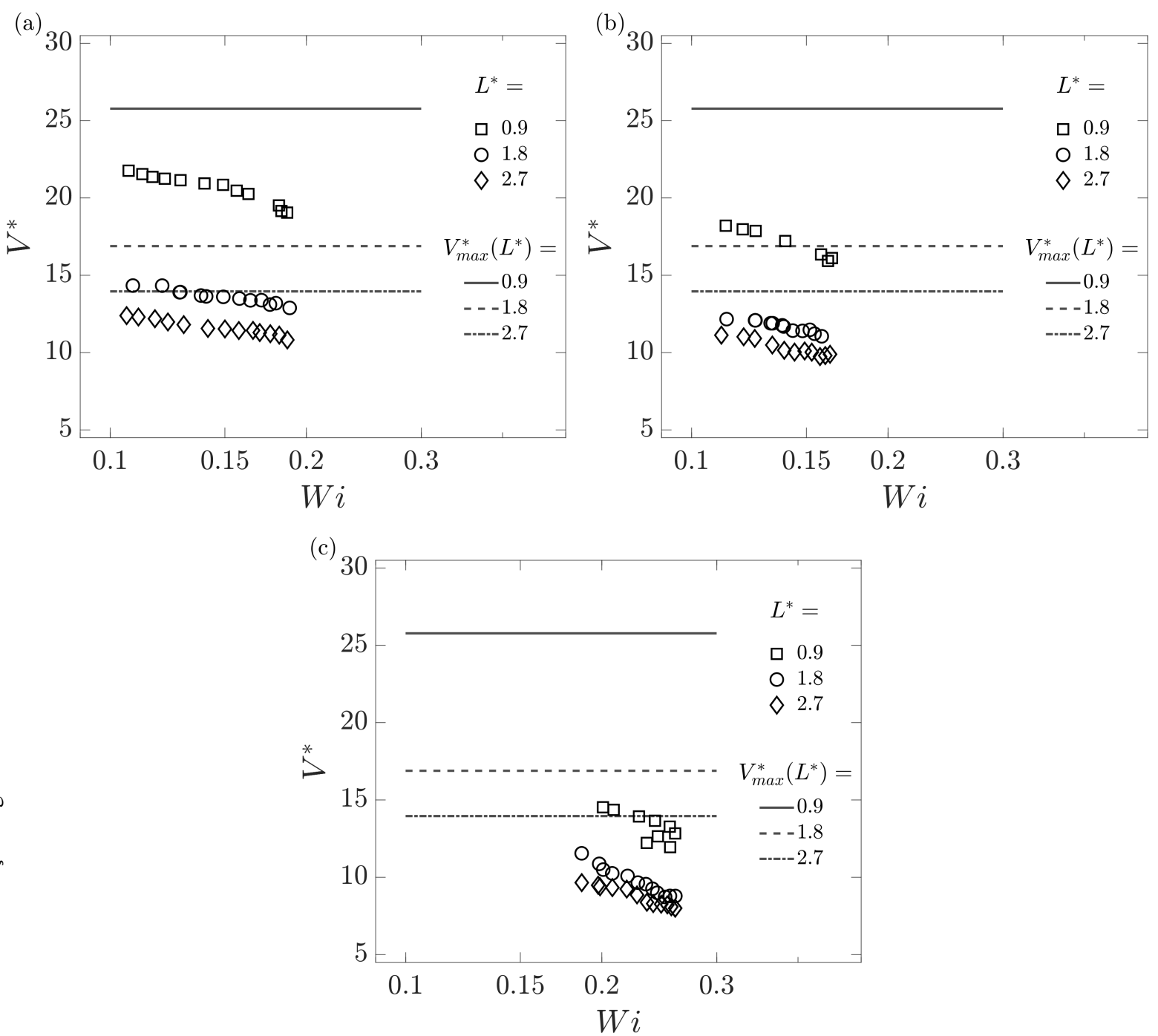

Figura 3.9: Volume $V^{*}$ em função de $W i$ para $D^{*}=3.7$ e $\sigma^{*}=$ a) 0.088 , b) 0.094 c) 0.157 .

A figura 3.9 mostra o comportamento de $V^{*}$ em função de $W i$ para $D^{*}=3.7$ e as três tensões adimensionais $\sigma^{*}$ investigadas. Para uma mesma profundidade da expansão-contração $D^{*}$, o volume $V^{*}$ apresenta uma maior dependência no comprimento adimensional, quando a tensão adimensional é a menor. Ao aumentar $\sigma^{*}, V^{*}$ mostra valores menores e mais próximos para os diferentes comprimentos adimensionais. À vista disso, para maiores tensões adimensionais, menor é a influência do comprimento da expansão, isto é, o sucesso do deslocamento depende das características reológicas do fluido não newtoniano. Resultados qualitativamente similares foram obtidos das pesquisas numéricas desenvolvidas por Roustaei et al. (19) e Naccache et al. (41). 

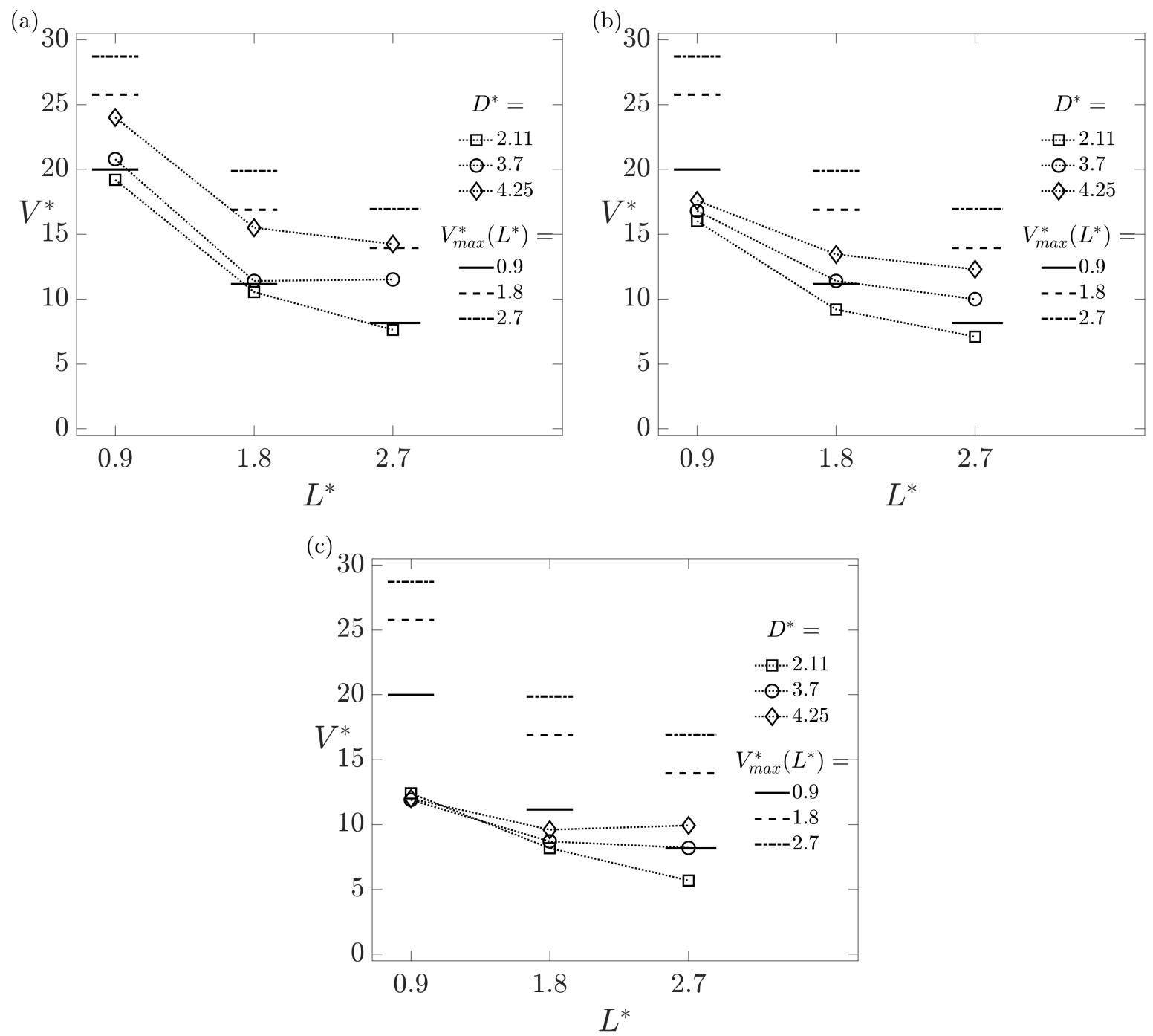

Figura 3.10: Volume $V^{*}$ em função de $L^{*}$ para para $\sigma^{*}=$ a) 0.088 , b) $0.094 \mathrm{c}$ ) 0.157 .

A figura 3.10 mostra o volume $V^{*}$ em função de $L^{*}$ para os três diâmetros adimensionais $D^{*}$ e $\sigma^{*}=(a, b, c)=(0.088,0.094,0.157)$, respetivamente. A fim de avaliar a influência das características geométricas no comportamento de $V^{*}$ para as diferentes tensões $\sigma^{*}$, foi fixado $W i=0.15$ para os casos $\sigma^{*}=0.088 \mathrm{e}$ 0.094 e $W i=0.20$ para $\sigma^{*}=0.157$. Os resultados ilustram que, para qualquer $\sigma^{*}$, quanto menor é $L^{*}$ maior é o volume $V^{*}$. Também podemos observar que para $L^{*}=(1.8,2.7)$, o diâmetro $D^{*}$ se mostra influente em $V^{*}$, para todo $\sigma^{*}$ estudado. Para Maiores $D^{*}$ gera menores $V^{*}$. Finalmente para $L^{*}=0.9$, $V^{*}$. Finalmente para o menor comprimento da expansão-contração estudado $\left(L^{*}=0.9\right)$, o volumes $V^{*}$ mostra aparente independência com respeito a $D^{*}$ para o maior $\sigma^{*}$. Isto pode ser explicado da seguinte forma: para o menor comprimento e a maior tensão, a profundidade da expansão tende a não afetar o deslocamento, na faixa de número de Weissenberg escolhida. 

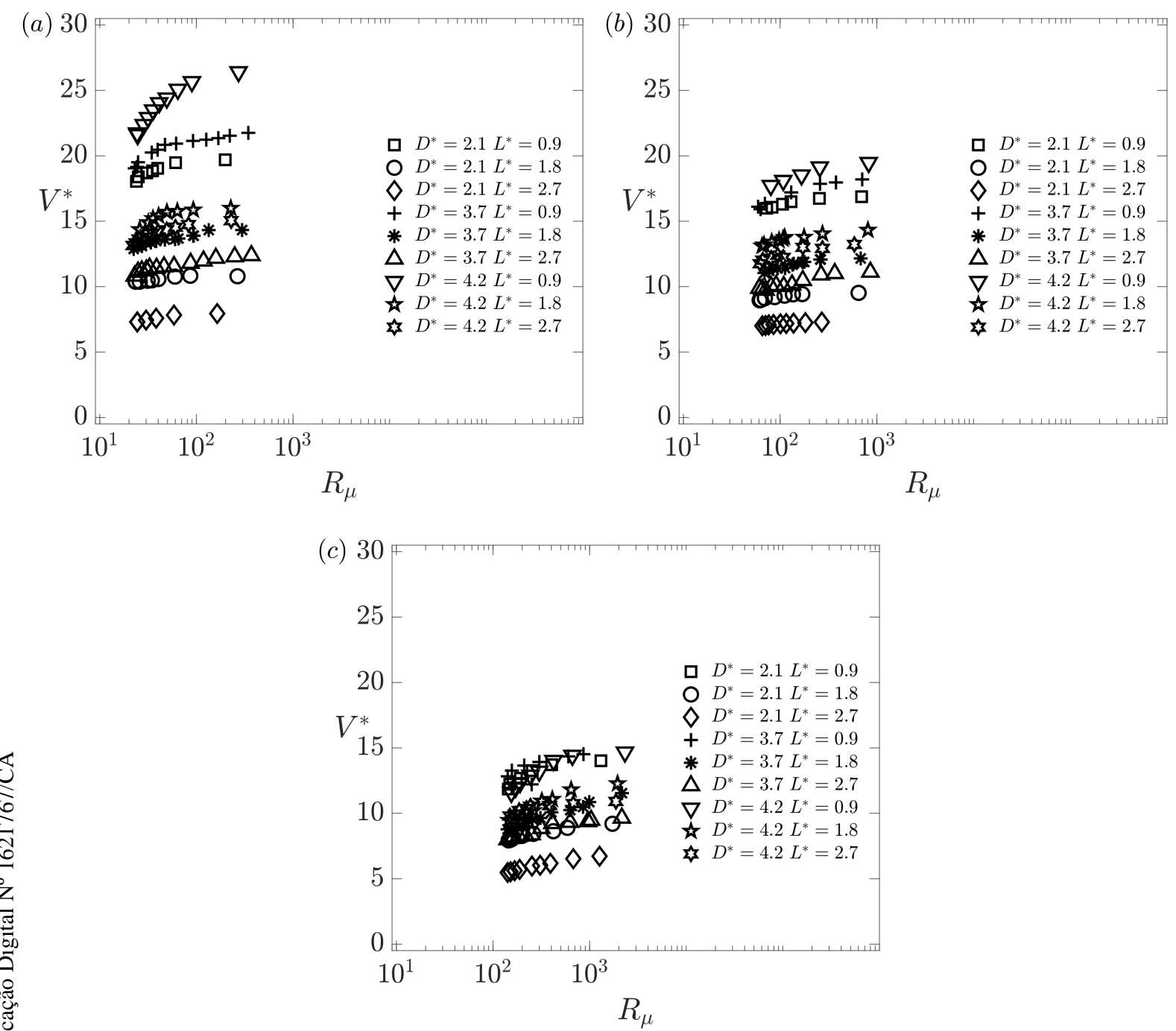

Figura 3.11: Volume $V^{*}$ em função da viscosidade $R_{\mu}$ para $\sigma^{*}=$ a) 0.088, b) 0.094 c) 0.157 .

Figura 3.11 mostra o volume $V^{*}$ em função da viscosidade $R_{\mu}$ para $\sigma^{*}=$ a) 0.088 , b) 0.094 c) 0.157 . De forma geral para viscosidade $R_{\mu}$ menores, observou-se volumes $V^{*}$ menores para todos os parâmetros geométricos testados. Os resultados concordam com os observados nas simulações realizadas por Naccache et al. (41). No trabalho referenciado, a autora atribuiu este comportamento à influência das forças inerciais. Ao aumentar $R_{\mu}$, aparentemente, o volume atinge um valor plateau. Isto indica que para um certo valor de viscosidade em diante, não existirá um variação do volume deslocado, na faixa estudada. Este comportamento também mostra dependente da tensão $\sigma^{*}$. Para menores $\sigma^{*}$, menor será o inicio do aparente plateau de $V^{*}$. 


\section{Considerações}

Diversos testes reológicos foram aplicados à soluções aquosa de Carbopol e mistura água/glicerina para obter suas características reológicas. Viscosidade newtoniana da mistura água/glicerina e uma função viscosidade de um fluido Herschel-Bulkley foram observadas para as soluções aquosas de Carbopol. Um aumento da concentração de polímero na solução aquosa mostra um aumento da tensão limite de escoamento aparente $\tau_{y}$, índice de consistência $k$ e um decrescemo do índice power law $n$.

Testes de varredura de tensão mostraram características elásticas e viscosas da solução aquosa quando esta se encontra na região viscoelástica linear (LVE). Foi observada um aumento dos módulos elástico e viscoso com o aumento da frequência testada e da concentração de polímero na solução aquosa.

Dependência do volume adimensional $V^{*}$ em função do número de Weissenberg para todos os parâmetros geométricos e reológicos estudados foi observado. Ao incrementar $W i, V^{*}$ diminuiu. Este comportamento pode ser interpretado como que para maiores números de $W i$ as forças inercias se tornam influenciáveis. Similar comportamento foi observado em simulações numéricas para deslocamentos imiscíveis realizadas por Nacccahe et al. (41) para uma geometria similar à usada na nossa pesquisa.

O volume adimensional mostrou dependência das características reológicas do fluido deslocado, da vazão de injeção e das características geométricas da seção de teste. Um aumento da concentração de polímero na solução aquosa, que representa em um aumento tanto da tensão limite de escoamento aparente como do módulo de elasticidade, mostrou a uma redução do volume de fluido deslocado para um mesmo número de Wi. O parâmetro da tensão adimensional $\sigma^{*}$ que mostra o grau de estruturação da solução aquosa interpreta o resultado obtido. Maior grau de estruturação (maior $\sigma^{*}$ ) aminora a capacidade da mistura água/glicerina de deslocar o fluido não newtoniano dentro da seção de teste.

Maior volumem adimensional $V^{*}$ foi deslocado para cavidades menos profundas (menores $D^{*}$ ) e mais compridas (maiores $L^{*}$ ) para o menor $\sigma^{*}$ testado. A combinação de fluidos não newtonianos com tensão limite de escoamento aparente alta (máximo $\sigma^{*}$ investigado) com cavidades estreitas mostraram que o volume deslocado independe da profundidade da cavidade. Isto mostra que o volume deslocado se mostra pouco influente da profundidade da cavidade quando o comprimento da mesma foi a maior testada e o fluido utilizado mostra o maior grau de estruturação (máximo $\sigma^{*}$ ).

Cabe enfatizar que os testes experimentais evidenciaram que para 
aumentar o volume de fluido residente deslocado, o que levaria a um aumento da eficiência de deslocamento, baixas taxas de injeção mostraram melhores resultados. Se o fluido possui alta tensão $\sigma^{*}$ (maior estruturação) a melhor combinação geométrica é uma cavidade menos profundas e menos compridas. Para fluidos com $\sigma^{*}$ baixos, cavidades menos profundidas mostrou ser a disposição ideal. Outra consideração que a literatura mostra que diminui o volume residente durante o deslocamento entre fluidos imiscíveis em geometrias complexas é utilizar um fluido deslocador com maior densidade em relação ao fluido deslocado (40). 


\section{Abordagem numérica}

\section{1}

\section{Descrição do problema}

A abordagem numérica considera o deslocamento de um fluido por outro através de um espaço confinado. O desenvolvimento do estudo numérico foi realizado em varias etapas sucessivas. Como primeiro passo foi realizada simulações em anulares contínuos (vide figura 4.1) entre fluidos newtonianos viscosamente estável e instável. A seguir foram desenvolvidas simulações quando um dos fluidos, podendo ser este injetado ou deslocado, possui função viscosidade não newtoniana. Finalmente deslocamentos newtonianos em uma geometria complexa constituído por um anular concêntrico que apresenta um alargamento abrupto centralizado na parede externa foram realizados. Foi atribuído o subíndice 1 às variáveis correspondentes ao fluido deslocador e 2 às do deslocado. Os fluidos foram considerados incompressíveis e as funções viscosidades foram modeladas como newtoniano ou Carreau-Yasuda. A equação de conservação de massa para um escoamento incompressível e axissimétrico em coordenadas cilíndricas de forma adimensional é dada por:

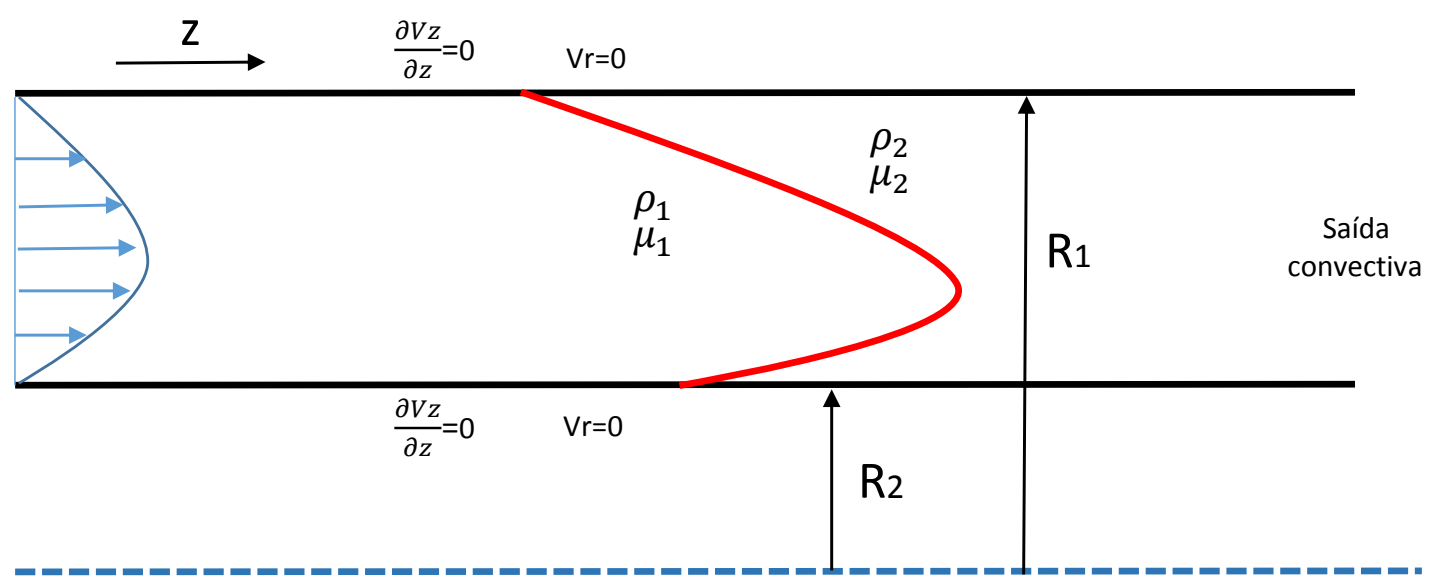

Figura 4.1: Figura esquemática mostrando a geometria do problema, as condições de contorno para as componentes do campo de velocidades $\vec{u}=(u, v)$ e a condição de velocidade média de injeção constante. 


$$
\frac{v}{r}+\frac{\partial v}{\partial r}+\frac{\partial u}{\partial z}=0
$$

e as equações de quantidade de movimento nas componentes $r$ e $z$ :

$$
\begin{gathered}
\frac{\partial v}{\partial t}+v \frac{\partial v}{\partial r}+u \frac{\partial v}{\partial z} \\
=\frac{1}{R e}\left(-\frac{\partial P}{\partial r}+\frac{1}{r} \frac{\partial}{\partial r} r\left(\mu \frac{\partial v}{\partial r}\right)+\frac{\partial}{\partial z}\left(\mu\left[\frac{\partial v}{\partial z}+\frac{\partial u}{\partial r}\right]\right)+\mu\left(\frac{v}{r^{2}}\right)-\frac{\kappa}{C a} \delta_{r}\right) \\
\frac{\partial u}{\partial t}+v \frac{\partial u}{\partial r}+u \frac{\partial u}{\partial z} \\
=\frac{1}{R e}\left(-\frac{\partial P}{\partial z}+\frac{1}{r} \frac{\partial}{\partial z} r\left(\mu\left[\frac{\partial v}{\partial z}+\frac{\partial u}{\partial r}\right]\right)+\frac{\partial}{\partial z}\left(2 \mu \frac{\partial u}{\partial z}\right)-\frac{\kappa}{C a} \delta_{z}-F \delta_{z}\right)
\end{gathered}
$$

onde $u$ e $v$ as componentes da velocidade da direção $z$ e $r$ do campo de velocidade $\vec{v}$, respectivamente. $P, t$ e $\rho$ são a pressão, tempo e a densidade. Foram usados como comprimento característico $L_{c}=R_{1}(1-w)$, sendo $R_{1}$ o raio externo do espaço anular e $w$ a razão entre o raio interno e externo $w=R_{2} / R_{1}$. A pressão característica é definida como $\mu U / L_{c}$. O tempo característico foi assumido como $T=L_{c} / U$, onde $U$ é a velocidade de injeção que foi definida como:

$$
U=\frac{-1+\frac{r^{2}}{R_{1}^{2}}-\frac{1-w^{2}}{\ln (1 / w)} \ln \left(r / R_{1}\right)}{\frac{1}{2} \frac{1}{1-w^{2}}\left(-1+w^{4}+\frac{\left(1-w^{2}\right)^{2}}{\ln (1 / w)}\right)}
$$

A velocidade $U$ é definida a expressão matemática que define o perfil de velocidade de um fluido newtoniano desenvolvido escoando em um espaço anular normalizado pela velocidade média de um fluido newtoniano escoando através de um espaço anular.

O número de Reynolds Re que aparece devido à adimensionalização é definido como:

$$
R e=\frac{\rho U L_{c}}{\eta_{c}}
$$

sendo $\eta_{c}$ a viscosidade do fluido newtoniano. Se os dois fluidos envolvidos são newtonianos, $\eta_{c}=\mu_{1}$. Para o caso que um dos fluidos possua características não newtonianas, $\eta_{c}=\mu$, sendo $\mu$ a viscosidade do fluido newtoniano.

Quando os fluidos imiscíveis possuem densidades diferentes, as forças de empuxo podem ser modeladas usando a aproximação de Boussinesq (79). 
Esta abordagem modela essas forças de corpo nas equações de quantidade de movimento, mas mantém inalterada a equação de conservação de massa. A força de empuxo $F$ é definida como:

$$
F=\frac{\Delta \rho L_{c}^{2}}{\eta_{c} U}
$$

sendo $\Delta \rho=\rho_{2}-\rho_{1}$. Valores positivos de $F$ correspondem ao deslocamento de um fluido mais denso por um menos denso. Para $F<0$, o fluido menos denso é o deslocador. O número capilar, que representa a razão entre as forças viscosas a força da tensão interfacial foi definido como:

$$
C a=\frac{\eta_{c} U}{\sigma}
$$

sendo $\sigma$ a tensão interfacial.

\subsection{1}

\section{Metodologia númerica}

Foi aplicado o método utilizado na pesquisa desenvolvida por Rai et al. (80). Utilizando diferenças finitas em uma discretização de três etapas Runge-Kutta/Crank-Nicolson, foram resolvidas as equações (4-2) e (4-3). Uma malha intercalada ou staggered grid foi escolhida para a discretização espacial. A figura 4.2 mostra uma malha intercalada regular para a discretização de equações bidimensionais. Para resolver Navier-Stokes incompressível na formulação de variavies primitivas $(\vec{u}, \varphi)$, as variáveis associadas à pressão, $\varphi$, são definidas no centro da célula e as componentes do campo de velocidade $\vec{u}$ nas faces $(81-83)$.

O esquema RK de três etapas para avançar as equações de quantidade de movimento do passo $n$ ao passo $n+1$ são:

Primeira etapa:

$$
\begin{gathered}
u_{i}^{a}=u_{i}^{n}+\Delta t\left(-\frac{2 \alpha_{1}}{R e} \frac{\partial p^{n}}{\partial i}+\gamma_{1} H_{u_{i}}^{n}+\frac{\alpha_{1}}{R e}\left(\frac{\partial}{\partial u_{i}} \mu\left(1+\delta_{i k}\right) \frac{\partial}{\partial u_{i}}\right)\left(u_{i}^{n}+u_{i}^{a}\right)\right) \\
\frac{\tilde{u}_{i}-u_{i}^{a}}{\Delta t}=-\frac{2 \alpha_{1}}{R e} G(\tilde{\varphi}) \\
D\left(\tilde{u}_{i}\right)=0
\end{gathered}
$$

Segunda etapa:

$$
u_{i}^{b}=\tilde{u}_{i}+\Delta t\left(-\frac{2 \alpha_{2}}{R e} \frac{\partial \tilde{p}}{\partial i}+\gamma_{2} \tilde{H}_{u_{i}}+\rho_{2} H_{u_{i}}^{n}+\frac{\alpha_{2}}{R e}\left(\frac{\partial}{\partial u_{i}} \mu\left(1+\delta_{i k}\right) \frac{\partial}{\partial u_{i}}\right)\left(\tilde{u}_{i}+v_{i}^{b}\right)\right)
$$




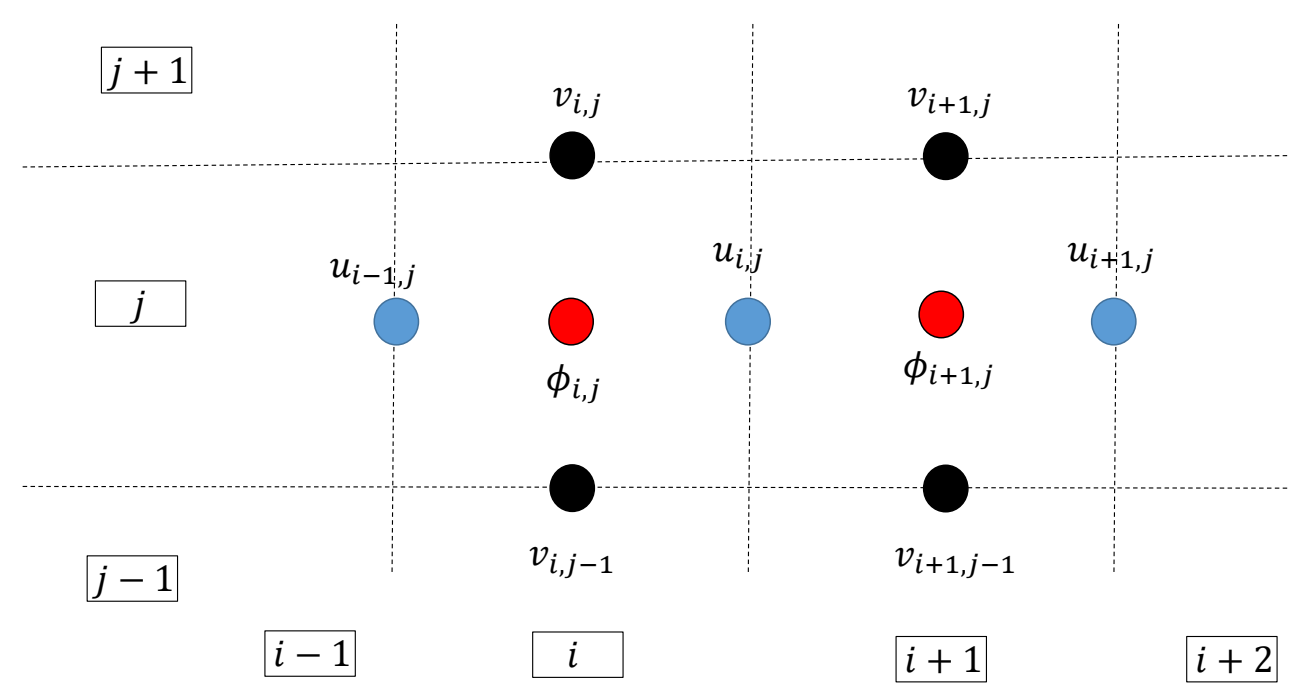

Figura 4.2: Posicionamento das componentes das velocidades e dos termos associado à pressão na malha intercalada

$$
\begin{gathered}
\frac{\tilde{\tilde{u}}_{i}-u_{i}^{b}}{\Delta t}=-\frac{2 \alpha_{2}}{R e} G(\tilde{\tilde{\varphi}}) \\
D\left(\tilde{\tilde{u}}_{i}\right)=0
\end{gathered}
$$

Terceira etapa:

$$
\begin{gathered}
u_{i}^{c}=\tilde{\tilde{u}}_{i}+\Delta t\left(-\frac{2 \alpha_{3}}{R e} \frac{\partial \tilde{\tilde{p}}}{\partial i}+\gamma_{3} \tilde{\tilde{H}}_{i}+\rho_{3} \tilde{H}_{i}+\frac{\alpha_{3}}{R e}\left(\frac{\partial}{\partial u_{i}} \mu\left(1+\delta_{i k}\right) \frac{\partial}{\partial u_{i}}\right)\left(\tilde{\tilde{u}}_{i}+u_{i}^{c}\right)\right) \\
\frac{u_{i}^{n+1}-u_{i}^{c}}{\Delta t}=-\frac{2 \alpha_{3}}{R e} G\left(\varphi^{n+1}\right) \\
D\left(u_{i}^{n+1}\right)=0
\end{gathered}
$$

para $i=r, z$. As constantes para as etapas intermediarias são definidas como:

$$
\begin{array}{ccc}
\alpha_{1}=4 / 15 & \gamma_{1}=8 / 15 & \rho_{1}=0 \\
\alpha_{2}=1 / 15 & \gamma_{2}=2 / 15 & \rho_{2}=-17 / 60 \\
\alpha_{3}=1 / 6 & \gamma_{3}=3 / 4 & \rho_{3}=-5 / 12
\end{array}
$$

Os operadores $H$ contêm os termos convectivos e difusivos que não pertencem à diagonal principal do tensor extra-tensão viscoso e são definidos como: 


$$
\begin{gathered}
H_{r}=-\left(v \frac{\partial v}{\partial r}+u \frac{\partial v}{\partial z}\right)+\frac{1}{R e}\left(\frac{\partial}{\partial z} \mu \frac{\partial}{\partial r} u+2 \mu \frac{v}{r^{2}}\right) \\
H_{z}=-\left(v \frac{\partial u}{\partial r}+u \frac{\partial u}{\partial z}\right)+\frac{1}{R e}\left(\frac{1}{r} \frac{\partial}{\partial r} r \mu \frac{\partial}{\partial z} v\right)
\end{gathered}
$$

$\frac{\delta}{\delta(i)}, G$, e $D$ são o operador discretizado, gradiente e divergente, respectivamente. O til e duplo til representa as etapas intermediárias do método Range-Kutta e $a, b$, e $c$ sobrescritos são as etapas intermediárias do método fractional-step de iterações do RK sucessivas. O escalar $\varphi$ se relaciona à pressão através de:

$$
p=\varphi-\frac{\alpha \Delta t}{R e} \frac{\partial}{\partial i}\left(\mu \frac{\partial \varphi}{\partial i}\right)
$$

É possível utilizar uma aproximação para os termos difusivos de modo que apenas sistemas lineares tridiagonais são resolvidos, (84). Isso se aplica às equações 4-8, 4-11 e 4-14 e resulta numa diminuição sustancial do custo computacional e de memória mantendo a precisão geral de segunda ordem do método (80). Para a primeira etapa RK, a equação 4-8 pode ser reescrita como:

$$
\begin{gathered}
\left(1-\Delta t \frac{\alpha_{1}}{R e} \frac{\delta}{\delta z} 2 \mu \frac{\delta}{\delta z}\right)\left(1-\Delta t \frac{\alpha_{1}}{R e} \frac{\delta}{\delta r} 2 \mu \frac{\delta}{\delta r}\right)\left(v_{i}^{a}-v_{i}^{n}\right)=-\frac{2 \alpha_{1}}{R e} \frac{\delta p^{n}}{\delta i} \\
+\Delta t \gamma_{1} H_{i}^{n}+\left(\Delta t \frac{\alpha_{1}}{R e} \frac{\delta}{\delta z} 2 \mu \frac{\delta}{\delta z}+\Delta t \frac{\alpha_{1}}{R e} \frac{\delta}{\delta r} \mu \frac{\delta}{\delta r}\right)\left(v_{i}^{n}\right)
\end{gathered}
$$

Os termos convectivos, tanto das equações de quantidade de movimento como da equação tipo Hamilton-Jacobi do método Level-Set, são calculados usando o método explicito de quinta ordem Weighted Essentially Non-Oscillatory (WENO) (85). Os termos viscosos, gradientes de pressão e termos associados à pressão foram resolvidos usando diferenças centrais de segunda ordem. As equações 4-10, 4-13 e 4-16, de cada uma das etapas RK, não podem ser resolvidas diretamente, mas podem ser combinadas com as equações 4-9,4-12 e 4-15 para obter equações de Poisson para $\varphi$. A estrategia é aplicar o divergente nos dois lados da equação 4-9, e nas equações semelhantes, em cada etapa de RK e usar a condição de divergente nulo. Para a primeira etapa RK, obtemos:

$$
\frac{\partial}{\partial_{i}} \frac{\partial}{\partial_{i}} \varphi=\frac{R e}{\left(2 \alpha_{1}\right) \Delta t} \frac{\partial u}{\partial i}
$$


O método desenvolvido por Rai et al. (80) sugere aplicar a transformada rápida de Fourier FFTW (86) para resolver a equação 4-22 a fim de obter uma equação diferencial ordinária de segunda ordem para a variável transformada. Uma vez resolvida a equação diferencial, e para obter a solução em função de $\varphi$, se aplica a transformada inversa. A velocidade corrigida é calculada usando equação a 4-9. Como última etapa do método, a pressão é atualizada. Para a primeira etapa de RK e para a componente $z$ temos:

$$
\frac{\partial \tilde{p}}{\partial z}=\frac{\partial p^{n}}{\partial z}+\frac{\partial \tilde{\varphi}}{\partial z}-\frac{\Delta t \alpha_{1}}{R e}\left(2 \frac{\partial}{\partial z}\left(\mu \frac{\partial}{\partial z}\right)+\frac{\partial}{\partial r}\left(\mu \frac{\partial}{\partial r}\right)\right) \frac{\partial \tilde{\varphi}}{\partial z}
$$

A condição de não escorregamento ou no-slip nas paredes para a componente axial da velocidade foi imposta (87). No caso da componente radial foi imposta a condição de não penetração .

\section{2}

\section{Level-set}

Uma das maiores adversidades numéricas ao capturar as interfaces móveis em problemas de deslocamento de fluidos imiscíveis deve-se ao fato da topologia ser influenciada pelas propriedades reológicas dos fluidos envolvidos, efeitos de tensão interfacial, condições de contorno, entre outras (88). A técnica numérica conhecida como Level-Set tem a capacidade de capturar a interface em múltiplas dimensões espaciais para diferentes cenários físicos (89).

\subsection{1}

\section{Método Level-Set}

Considerou-se uma interface contínua $\Gamma(t)$ (possivelmente multi-conectada) (90-95) e uma função auxiliar $\phi$ associada ao domínio $\Omega$ que satisfaz a condição:

$$
\phi(\vec{x}, t)= \begin{cases}\phi(\vec{x}, t)<0 & \Omega \\ \phi(\vec{x}, t)=0 & \Gamma(t) \\ \phi(\vec{x}, t)>0 & \Omega\end{cases}
$$

onde $\vec{x} \in R^{n}$ e $t \in R^{+}$e que possui a propriedade de $|\nabla \phi|=1$. Se $\phi(\vec{x}, t)$ é conhecido, a interface pode ser localizada encontrando o nível zero de $\phi$. Isto é $\Gamma(t)=\{\vec{x}: \phi(\vec{x}, t)=0\}$.

Supondo que a velocidade em cada ponto do domínio é dada por $\vec{u}$, sendo no nosso caso um campo de velocidades está composto pelas componentes $\vec{u}=(u, v)$, todos os pontos que pertencem à interface $\phi(\vec{x}, t)=0$ se movem com 
dita velocidade. A maneira mais simples de computar o movimento é resolvendo a equação diferencial:

$$
\frac{d \vec{x}}{d t}=\vec{u}(x)
$$

para cada ponto $\vec{x}$ da interface onde $\phi(\vec{x})=0$. Esta é a formulação lagrangiana da evolução da interface. Desafortunadamente, mesmo os campos de velocidade mais triviais, a solução da equação diferencial pode envolver adversidades númericas infranqueáveis (96). A equação tipo Hamilton-Jacobi usada para o deslocamento da função auxiliar $\phi$ :

$$
\phi_{t}+\vec{u} \cdot \nabla \phi=0
$$

resolve o problema da abordagem Lagrangiana (97), onde o sub-índice $t$ representa a derivada parcial com respeito ao tempo. Cabe enfatizar que o segundo termo representa a parte convectiva da equação:

$$
\vec{u} \cdot \nabla \phi=v \phi_{r}+u \phi_{z}
$$

sendo $\phi_{z}=\partial \phi / \partial z$ e $\phi_{r}=\partial \phi / \partial r$. A equação 4-26 é uma equação diferencial parcial que define o deslocamento da função auxiliar $\phi$ com velocidade $\vec{u}$. Esta é a formulação eureliana da evolução da interface, desde que a interface seja capturada pela função implícita $\phi(97)$. Esta, por precisão numérica, deve permanecer bem comportada, no entanto, a solução da equação 4-26 muitas vezes torna muito plano ou íngreme a função auxiliar $\phi$. Portanto, é necessário um procedimento para redistanciamento os valores de $\phi(\vec{x}, t)$ de modo que este seja o mais próximo da propriedade $|\nabla \phi|=1$. O procedimento é comumente chamado de reinicialização (89).

\section{3}

\section{Inicialização e Reinicialização da função level-set}

Como primeiro passo é necessário que a função auxiliar $\phi$ seja definida de acordo com 4-24. A principal razão para utilizar esta condição é que o método Level-Set é mais preciso quando uma função auxiliar $\phi$ sinalizada é usada, principalmente $(98,99)$ em aplicações onde a espessura da interface é restrita, caso de deslocamentos imiscíveis (91). Não é difícil inicializar a função auxiliar $\phi$ para ser a função distância, no entanto, devido a evolução da equação 4-27, a condição $|\nabla \phi|=1$ se perde. Portanto, em momentos posteriores da simulação, é necessário recompor a função auxiliar $\phi$.

O primeiro trabalho em reconhecer e explorar a necessidade da reinicialização foi desenvolvido por Chopp et al. (100). Reinicialização é o processo utilizado para manter $\phi(\vec{x}, t)$ com as mesmas características de $\phi(\vec{x}, 0)(89,91)$. É difícil prever a frequência com que a reinicialização deve ser 
aplicada (91). Tipicamente, os pontos próximos de $\phi(\vec{x}, t)=0$ precisam manter a propriedade $|\nabla \phi|=1$.

Uma maneira simples de reinicializar é resolver uma equação diferencial que tem como solução estacionária a função de distância, como sugerido por Sussman et al. (89). Esta abordagem tem a vantagem de não mover a interface. A desvantagem é seu alto custo e a probabilidade de introduzir dados espúrios, fazendo que parâmetros baseados na função auxiliar $\phi$, como a curvatura, forneçam resultados não acurados (91). A equação do tipo Hamilton-Jacobi utilizada nesse processo de reinicialização é

$$
\phi_{t}=S\left(\phi_{0}\right)(1-|\nabla \phi|) .
$$

Devemos evoluir a equação até que $\phi(\vec{x}, t)$ atinga as características de $\phi(\vec{x}, 0)$.

\subsection{1}

\section{Level-Set rápido}

A abordagem de Level-Set rápido limita a solução da equação tipo Hamilton-Jacobi e a reinicialização a uma região em torno do conjunto $\phi(\vec{x}, t)=0$. O método utilizado na presente pesquisa foi desenvolvido por Peng et al. (91), inspirada no trabalho de Chopp et al. (100) e de Osher et al. (101). A principal vantagem é a economia no tempo computacional. O uso de métodos do tipo Level-Set rápido permite que as simulações de mais de uma dimensão sejam tratáveis $(88,91,98,102)$.

\subsubsection{1}

\section{Tubo}

Para executar a abordagem do método Level-Set rápido é necessário a construção de um tubo, em torno de $\phi(\vec{x}, t)=0$, onde a função auxiliar $\phi$ será definida com a propriedade $|\nabla \phi|=1$. Em vez de calcular a equação tipo Hamilton-Jacobi e reinicialização em todo o domínio, elas serão executadas apenas nessa região. A função auxiliar $\phi$ é inicializada para ser a função distância. À medida que o nível zero correspondente à interface se desloca, devemos garantir que fique dentro do tubo. Uma maneira de fazer isso será reconstruir um novo tubo ao redor de $\phi(\vec{x}, t)=0$ a cada passo do tempo. Isto é um procedimento demorado de realizar, mas necessário. Foi definido um tubo de largura $\gamma$ de modo que:

$$
T^{0}=x:\left|d^{0}(x)\right|<\gamma
$$

Para a evolução da função auxiliar $\phi$ com o método Level-Set clássico, resolve-se a equação 4-26 com um passo de tempo que desloque a interface uma distância menor que um $\Delta z$ da malha para obter a nova posição da 
função distância, i.e. $\phi^{1}(x)$. Esta condição é equivalente a $\Delta t|u|<\Delta z$. A fim de evitar oscilações nas bordas do tubo, foi definida a função de suavização cut-off (101) como:

$$
c(\phi)=\left\{\begin{array}{llc}
1 & \text { se } & |\phi|<\beta \\
(|\phi|-\gamma)^{2}(2|\phi|+\gamma-3 \beta) /(\gamma-\beta)^{3} & \text { se } \beta<|\phi|<\gamma \\
0 & \text { se } \quad|\phi|>\gamma
\end{array}\right.
$$

Para o uso do método Level-Set rápido, a posição de $\Gamma^{0}$, é atualizada resolvendo a equação:

$$
\phi_{t}=-c(\phi)(\vec{v} \cdot \nabla \phi)
$$

para $T^{0}$ com dados iniciais de $\phi^{0}$ e para um passo no tempo, obtendo $\tilde{\phi}^{1}$. A nova posição da interface é dada por $\Gamma^{1}=\left\{x: d^{1}(x)=0\right\}$, sendo $d^{1}(\vec{x})$ a função distância de $\Gamma^{1}$. Enfatizando que $d^{1}$ é desconhecido e só se conhece $\tilde{\phi}^{1}$. Para obter $d^{1}$ é necessário que a seguinte condição se cumpra:

$$
T^{1}=\left\{x:\left|d^{1}\right|<\gamma\right\}
$$

Para construir a nova função distância $d^{1}$ a partir de $\tilde{\phi}^{1}$ de modo que $\phi^{1}=d^{1}$ para $\left|d^{1}\right|<\gamma$ envolve várias etapas que são descritas a seguir. A equação tipo Hamilton-Jacobi é resolvida dentro do tubo de raio $\beta$. Na região $\left\{x: \beta<\left|\phi^{0}\right|<\gamma\right\}$, o deslocamento é modificado pela função de suavização cut-off. No espaço fora do tubo $\gamma$ a função auxiliar $\phi$ não é modificada, e continua com valores constantes. Obviamente, $\tilde{\phi}^{1}$ não é $d^{1}$ de $\Gamma^{1}$ como é representada de forma esquemática na Fig. 4.4. Para que a condição 4-32 se cumpra, a etapa de reinicialização da função distância deve ser efetuada. Desde que $\phi$ se desloque menos de $\Delta z$, define-se a região para o tubo $N^{0}$ :

$$
N^{0}=\left\{x:\left|\phi^{0}(x+y)\right|<\gamma\right\} \quad \text { quando } \quad|y|<\Delta z
$$

Uma vez definido o tubo $N^{0}$, aplica-se a reinicialização em $\tilde{\phi}^{1}$ a fim de obter $d^{1}$. Finalmente a função auxiliar $\phi^{1}$ é definida como:

$$
\phi^{1}(x)=\left\{\begin{array}{lll}
-\gamma & \text { se } & d^{1}(x)<-\gamma \\
d^{1}(x) & \text { se } & d^{1}(x) \leq \gamma \\
\gamma & \text { se } & d^{1}(x)>\gamma
\end{array}\right.
$$

onde $d^{1}(x)$ é uma função distância.

Os valores numéricos de $\beta$ e $\gamma$ são definidos de acordo com o método de discretização espacial usado. Para nosso caso foi usado o método explicito WENO de quinta ordem para a discretização espacial. Portanto, $\beta=3 \Delta z \mathrm{e}$ 
$\gamma=6 \Delta z$ foram escolhidos $(91,103)$. Uma representação esquemática dessa descrição é mostrada na figura 4.4.

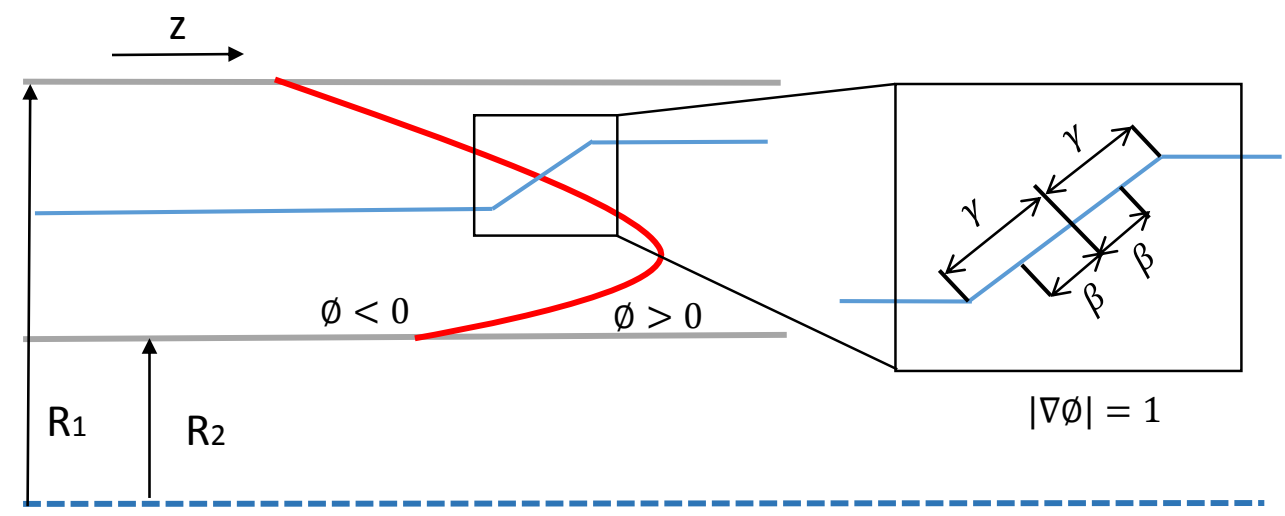

Figura 4.3: Largura dos tubos $\gamma$ e $\beta$ para a implementação do método Level-Set rápido.

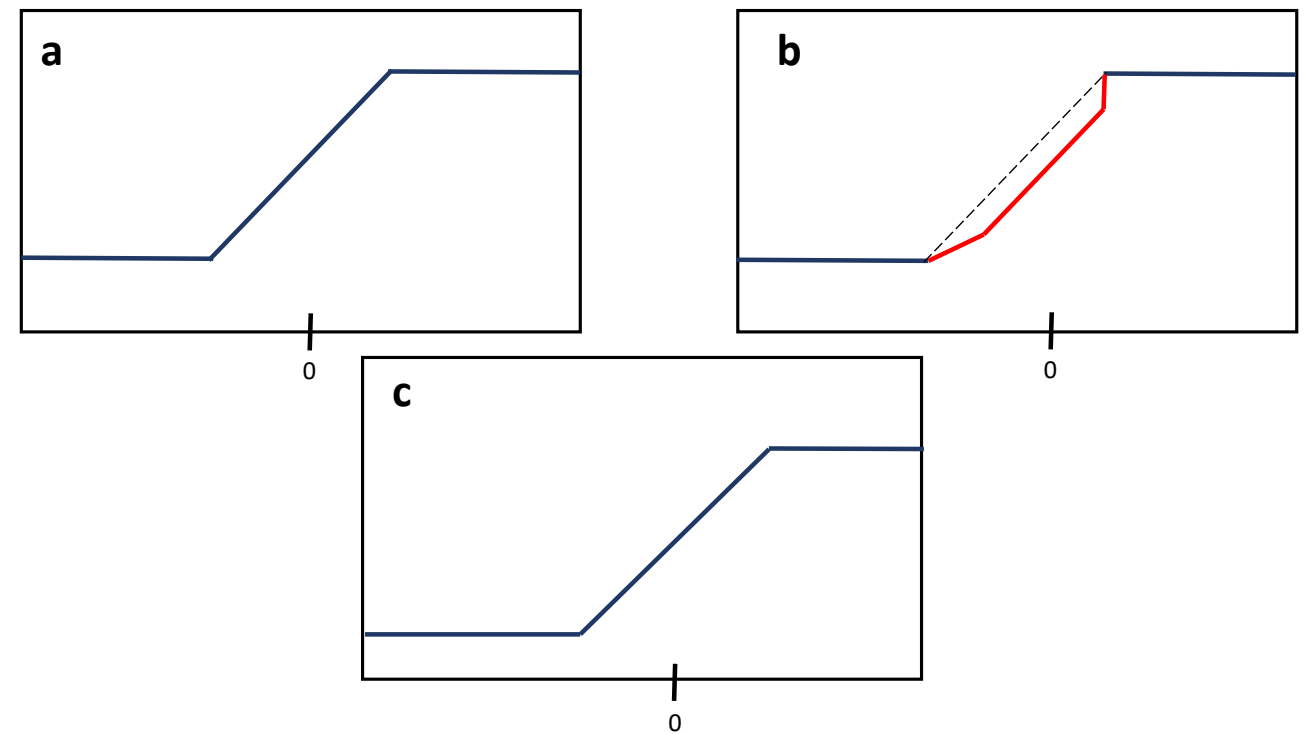

Figura 4.4: a) Localização da função distância em $t=t_{1}$. b) Depois de um passo de tempo $t_{2}=t_{1}+\Delta t$. c) Posição final da função distância depois da reinicialização. 


\subsubsection{2}

\section{Reinicialização}

A aproximação da função sinal $S(\phi)$, utilizada na nossa pesquisa, depende da inclinação local de $\phi$ e foi definida como:

$$
S(\phi)=\frac{\phi}{\sqrt{\phi^{2}+|\nabla \phi|^{2} \epsilon^{2}}}
$$

sendo

$$
|\nabla \phi|=\sqrt{\phi_{z}^{2}+\phi_{r}^{2}} \quad \text { e } \quad \epsilon=\sqrt{\Delta z^{2}+\Delta r^{2}}
$$

sugerida por Sethian et al. (88). Baseado na análise acima, foi usada a equação tipo Hamilton-Jacobi:

$$
\phi_{t}=S(\phi)(1-|\nabla \phi|)
$$

até atingir a condição $\phi(\vec{x}, t)=\phi(\vec{x}, 0)$. A fim de obter a norma do gradiente da função auxiliar $\phi$, o esquema Godunov foi utilizado $(97,101,104)$. De acordo com o sinal de $S(\phi)$, a equação 4 -36 pode se tornar:

$$
\left.\phi^{n+1}=\phi^{n}-\left(S(\phi)^{+} G(\phi)_{z, r}-1\right)\right) \Delta p d t
$$

ou:

$$
\phi^{n+1}=\phi^{n}-S(\phi)^{-}\left(\left(G(\phi)_{z, r}-1\right)\right) \Delta p d t
$$

sendo:

$$
G(\phi)_{z, r}=\left\{\begin{array}{c}
\sqrt{\max \left(\left(a^{+}\right)^{2},\left(b^{-}\right)^{2}\right)+\min \left(\left(c^{+}\right)^{2},\left(d^{-}\right)^{2}\right)} \\
\text { se } \quad \phi_{z, r}>0 \\
\sqrt{\max \left(\left(a^{-}\right)^{2},\left(b^{+}\right)^{2}\right)+\min \left(\left(c^{-}\right)^{2},\left(d^{+}\right)^{2}\right)} \\
\text { se } \quad \phi_{z, r}<0 \\
0 \quad \text { caso contrario }
\end{array}\right.
$$

onde o sobrescrito + representa a parte positiva e o sobrescrito - a parte negativa. As aproximações das derivadas direcionadas $(a, b, c, d)$ foram definidos como:

$$
\begin{aligned}
a & =D_{z}^{-} \phi_{z, r} \\
b & =D_{z}^{+} \phi_{z, r} \\
c & =D_{r}^{-} \phi_{z, r} \\
d & =D_{r}^{+} \phi_{z, r}
\end{aligned}
$$


Em (89) foi demonstrado que é possível calcular a expressão matemática 4-36 usando um esquema de primeira ordem para a discretização espacial. Apesar de ter a vantagem de fácil implementação de um esquema de primeira ordem, sua desvantagem é a precisão. Osher et al. $(90,97,101)$ manifestaram melhoria nos resultados quando é usado uma aproximação de ordem maior para as derivadas de $\phi$. O mesmo esquema WENO de quinta ordem usado na discretização dos termos convectivos das equaçõoes de movimento foi utilizado na discretização espacial de $\phi$. Para a evolução temporal da reinicialização, um esquema de primeira ordem foi usado.

\subsubsection{3}

\section{Frequência da reinicialização}

Pesquisas realizadas em $(89,91,101,105,106)$ implementaram o processo de reinicialização em cada passo de tempo $\Delta t$ para todos os valores da função auxiliar $\phi$ no tubo $\gamma$, o que aumenta consideravelmente o custo computacional. Um novo processo é proposto no presente trabalho.

Como passo inicial, antes de iniciar a reinicialização comparamos o desvio de $|\nabla \phi|$ em relação a um erro $E$, usando o esquema 4-39. Quando a norma do gradiente da função auxiliar $\phi$ que pertencem ao tubo $\beta$ ultrapassa o desvio com respeito a $E$, o processo de reinicialização é iniciado. Após sucessos tentativas e erros, o maior erro possível de se usar tem o valor de $E=0.35$ sendo $E=1-|\nabla \phi|$. A figura 4.5 mostra esquematicamente o desvio de $|\nabla \phi|$.

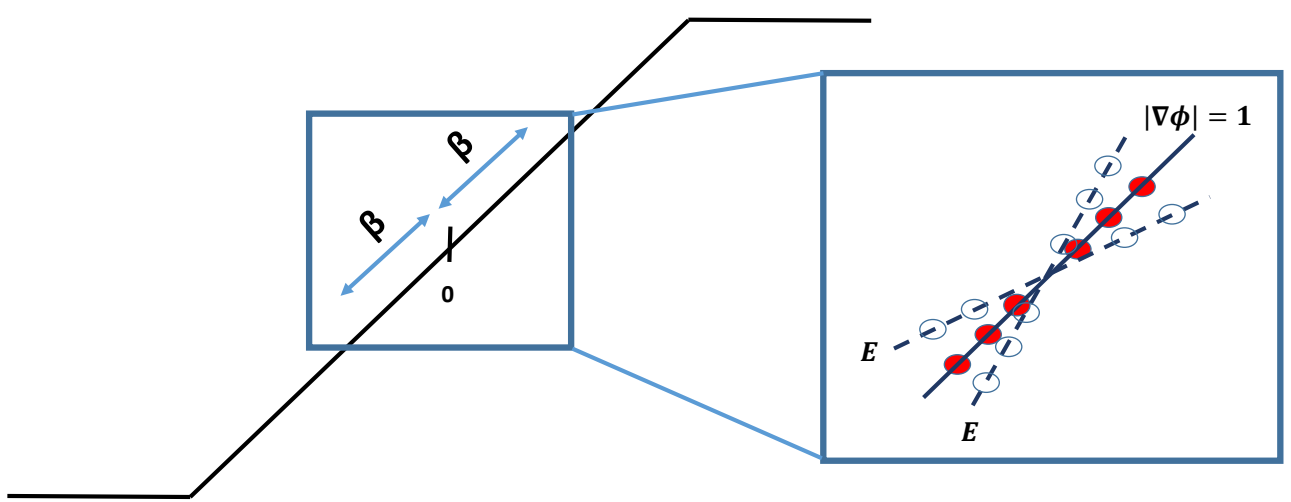

Figura 4.5: Representação esquemática do desvio de $\phi$ dentro do tubo $\beta$.

Entre os valores de $\phi$ mais próximos de $\phi(\vec{x})=0$, se escolhe aquele que possui um valor absoluto maior (veja figura 4.6) e o processo de reinicialização 
é aplicado para aquele único ponto até atingir o critério de parada sugerida por Sussman et al. (89):
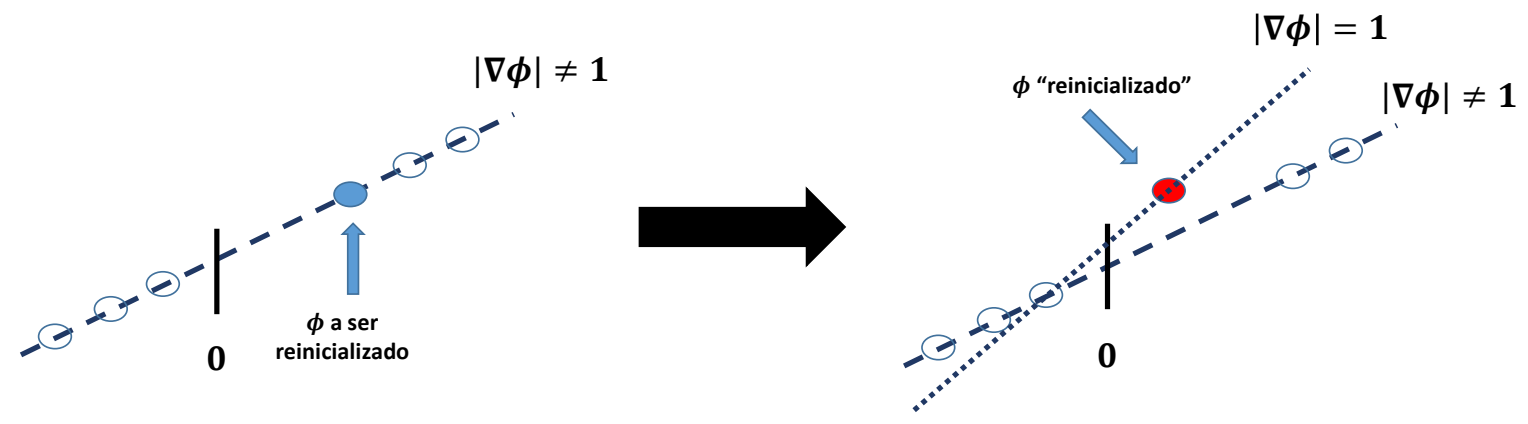

Figura 4.6: Reinicialização da função auxiliar $\phi$.

$$
\left|\phi_{z, r}^{N+1}-\phi_{z, r}^{N}\right|<h,
$$

sendo $h=\Delta z^{2} \Delta r^{2}$. Uma vez que o critério de parada foi atingido, é necessário construir a função $\phi$ dentro do tubo $\gamma$ de modo que $\phi=d$ utilizando a condição:

$$
\frac{\partial^{2} \phi}{\partial z^{2}}=0
$$

Note que, uma vez normalizada, a função $\phi$ precisa se tornar uma reta com $|\nabla \phi|=1$. Então, se o processo da reinicialização for implementado com precisão em um único ponto dessa função distância, os demais pontos do tubo $\beta$ podem ser reposicionados usando a equação 4-41. Isso evita que uma equação diferencial parcial seja resolvida para esses pontos. Finalmente, a condição algébrica 4-42 foi aplicada:

$$
\phi^{1}(x)=\left\{\begin{array}{lll}
-\gamma & \text { se } & d^{1}(x)<-\gamma \\
d^{1}(x) & \text { se } & d^{1}(x) \leq \gamma \\
\gamma & \text { se } & d^{1}(x)>\gamma
\end{array}\right.
$$

\subsection{2}

\section{Modelagem da função viscosidade e tensão superficial}

O método Level-Set permite relacionar as funções viscosidades dos fluidos envolvidos no deslocamento. A viscosidade em função de $\phi$ pode ser expressada como: 


$$
\mu(\phi)=\mu_{1}+\left(\mu_{2}-\mu_{1}\right) H(\phi) .
$$

Para o caso em que os dois fluidos possuem viscosidades newtonianas, a equação pode ser expressa como uma razão entre elas:

$$
\mu(\phi)=1+(M-1) H(\phi)
$$

onde $M=\mu_{2} / \mu_{1}$. A função heaviside suavizada (101) foi definida como:

$$
H_{\epsilon}(\phi)= \begin{cases}0 & \phi<-\epsilon \\ \frac{1}{2}\left[1+\frac{\phi}{\epsilon}+\frac{1}{\pi} \sin (\pi \phi / \epsilon)\right] & |\phi| \leq \epsilon \\ 1 & \phi>\epsilon\end{cases}
$$

sendo $\epsilon=1.5 \Delta z$. Para o caso de $M>1$, o fluido deslocado possui uma viscosidade maior que o deslocador. O caso contrário acontece quando $M<1$, sendo o fluido deslocado menos viscoso que o deslocador.

As equações constitutivas que modelam fluidos não newtonianos são tipicamente governados por um número bastante grande de parâmetros. Portanto, deve-se adimensionalizar de forma que os parâmetros reológicos independam entre eles e que o comportamento da viscosidade só dependa da variação da taxa de cisalhamento. Usando os parâmetros característicos propostos por de Souza Mendes (107), foi feita a adimensionalização dos parâmetros da equação 4-46 como:

$$
\eta_{0}=\eta_{0}{ }^{*} \eta_{c}, \quad \eta_{\infty}=\eta_{\infty}^{*} \eta_{c} \quad \dot{\gamma}=\dot{\gamma}^{*} L_{c} / U \quad \lambda=\lambda^{*} /\left(L_{c} / U\right)
$$

Preliminarmente a função viscosidade do fluido não newtoniano foi modelada como um fluido com tensão limite de escoamento, como foi realizado na seção experimental (vide figura 2.4), usando a equação proposto por Siqueira et al. (108). A expressão matemática usa patamares newtonianos para altas e baixas taxas de cisalhamento para modelar o comportamento da viscosidade para estas faixas de cisalhamento. Resultados preliminares mostraram que ainda com a máxima razão entre os patamares simulados não foi possível modelar corretamente o comportamento de um fluido com tensão limite de escoamento. Portanto a função viscosidade escolhida para representar un fluido não newtoniano foi de Carreau-Yasuda. A viscosidade descrita a seguir $\eta(\dot{\gamma})$ encontra-se de forma adimensional e é definida como: 


$$
\eta(\dot{\gamma})=\eta_{\infty}+\left(\eta_{0}-\eta_{\infty}\right)\left(1+(\lambda \dot{\gamma})^{a}\right)^{n-1 / a}
$$

sendo o tempo de relaxação $\lambda$, índice power law $n$, parâmetro $a$. Para a presente pesquisa, serão simulados um fluido newtoniano deslocando um não newtoniano, ou vice-versa. Portanto, $\eta_{0}$ e $\eta_{\infty}$ representam as razões de viscosidade entre os plateaus newtonianos para baixas e altas taxas de cisalhamento do fluido de Carreau e a viscosidade newtoniana característica $\eta_{c}$. A viscosidade característica é representada pelo fluido newtoniano, podendo ser este deslocado o deslocador. Para o caso que o fluido newtoniano seja o deslocador $\eta_{c}=\mu_{1}$. Caso contrario, quando o fluido newtoniano é deslocado $\eta_{c}=\mu_{2}$. A equação que modela a viscosidade em função de $\phi$ quando um fluido não newtoniano desloca um newtoniano é definida como:

$$
\mu(\phi)=R \mu+(1-R \mu) H(\phi)
$$

sendo:

$$
R \mu=\eta_{\infty_{1}}+\left(\eta_{0_{1}}-\eta_{\infty_{1}}\right)\left(1+(\lambda \dot{\gamma})^{a}\right)^{n-1 / a}
$$

Quando um fluido não newtoniano é deslocado por um fluido newtoniano, a equação que modela a viscosidades em função de $\phi$ é definida como:

$$
\mu(\phi)=1+\left(R_{\mu}-1\right) H(\phi)
$$

sendo:

$$
R_{\mu}=\frac{1}{\eta_{\infty_{2}}+\left(\eta_{0_{2}}-\eta_{\infty_{2}}\right)\left(1+(\lambda \dot{\gamma})^{a}\right)^{n-1 / a}}
$$

Figura 4.7 mostra o comportamento da viscosidade de um fluido Carreau Yasuda para três diferentes tempos de relaxação $\lambda$ e $\left(\eta_{0}, \eta_{\infty}, n, a\right)=(20,0.25,0.9,0.88)$. 


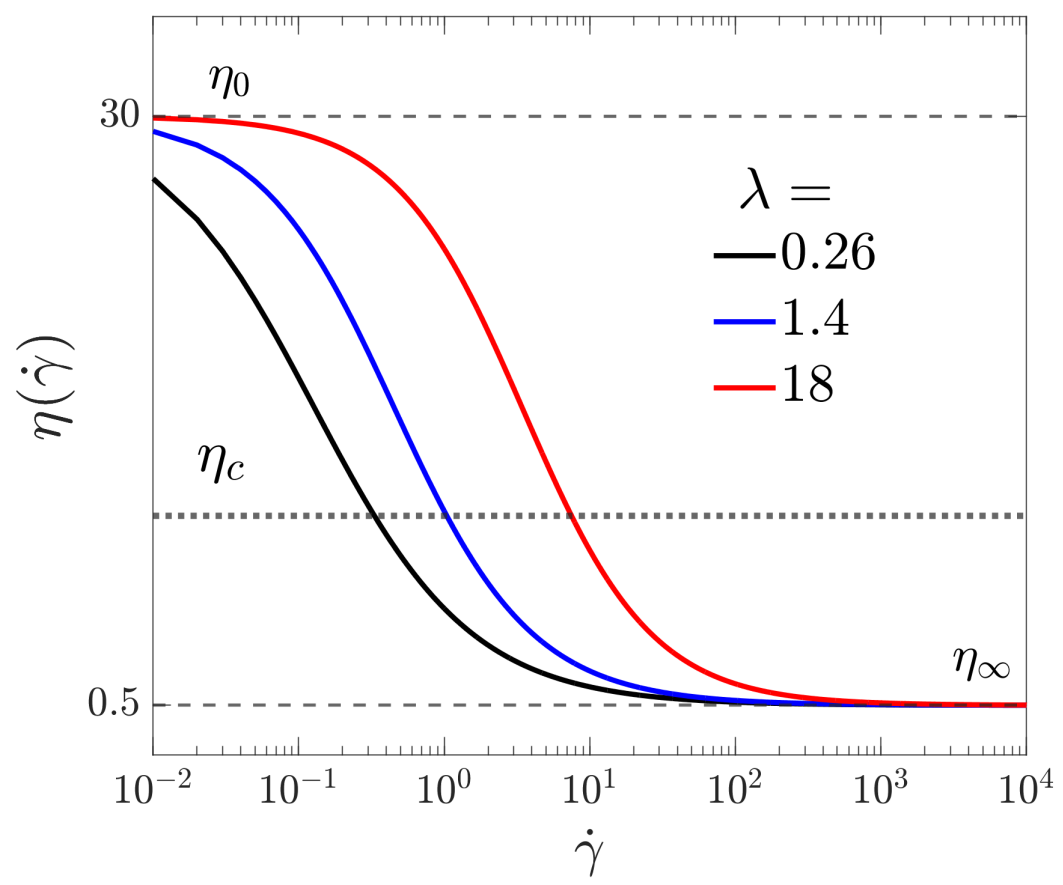

Figura 4.7: Viscosidade de um fluido Carreau Yasuda para $\left(\eta_{0}, \eta_{\infty}, n, a\right)=(20,0.25,0.9,0.88)$.

A tensão interfacial pode ser modelada como uma força de corpo que atua apenas na interface entre os fluidos. Para isso, definimos a função auxiliar $\phi$ do método Level-Set (92). Esta abordagem foi utilizada também por vários autores na literatura (109-111). As forças de tensão superficial é definida como

onde a curvatura é:

$$
\frac{k}{C a} \delta_{i}=\frac{k(\phi)}{C a} \delta_{i}(\phi) \nabla \phi
$$

$$
\kappa(\phi)=\nabla \cdot\left(\frac{\nabla \phi}{|\nabla \phi|}\right)
$$

É possível aproximar numericamente $\delta(\phi)$ por uma função delta modificada $(89), \delta_{\epsilon}(\phi)$ suavizada como:

$$
\delta_{\epsilon}(\phi)=\left\{\begin{array}{lc}
\frac{1}{2}\left[1+\frac{1}{\pi} \cos (\pi \phi / \epsilon)\right] & |\phi|<\epsilon \\
0 & \text { caso contrario }
\end{array}\right.
$$

A taxa de cisalhamento $\dot{\gamma}$ foi definida como:

$$
\dot{\gamma}=\left[2\left(\frac{\partial v_{z}}{\partial z}\right)^{2}+2\left(\frac{\partial v_{z}}{\partial r}+\frac{\partial v_{r}}{\partial z}\right)+2\left(\frac{v_{r}}{r}\right)^{2}+2\left(\frac{\partial v_{r}}{\partial r}\right)^{2}\right]^{1 / 2}
$$




\section{4}

\section{Limitações do método númerico: $A$ abordagem Level-set rápido sem reinicialização}

Como discutido anteriormente, o método Level-Set rápido apresentado por Peng et al. (91) requer que a solução das equações Hamilton-Jacobi modificada e reinicialização sejam unicamente aplicadas em uma região denominada tubo $\gamma$ ao redor de $\phi(\vec{x}, t)=0$.

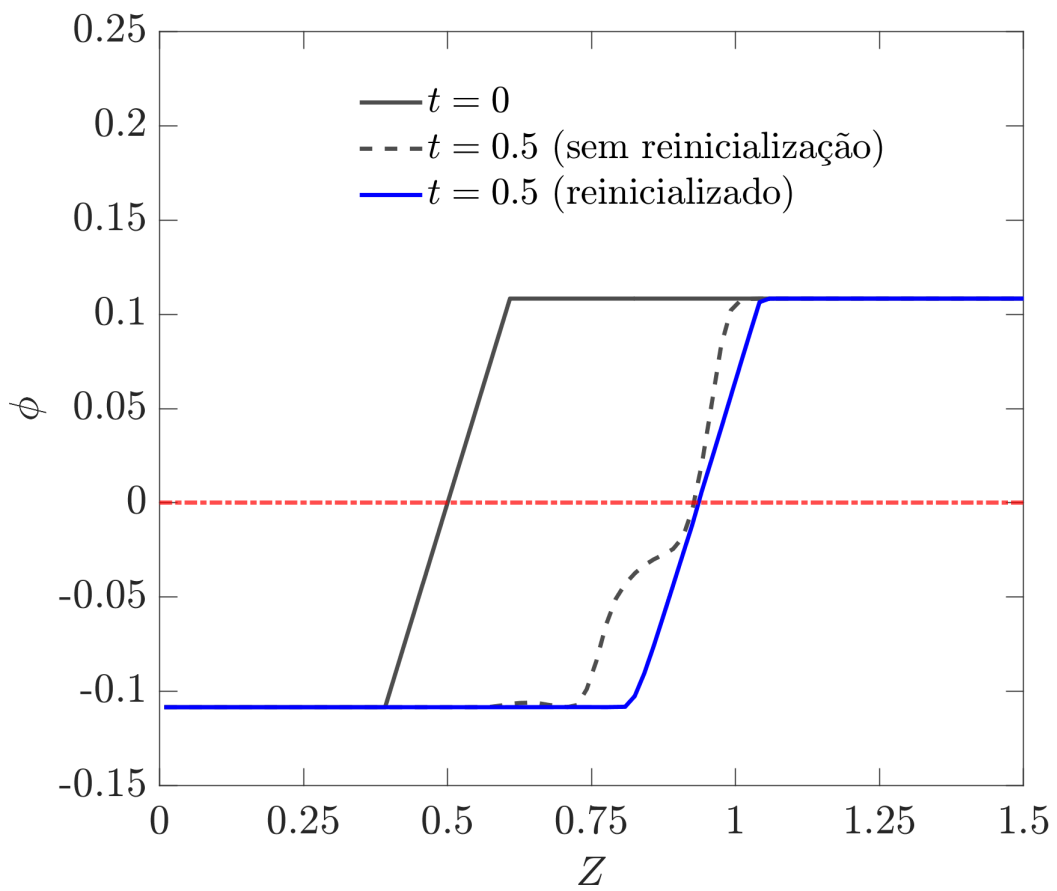

Figura 4.8: Função auxiliar $\phi$ em função da posição $Z$ para $(w, R e, M)=(0.75,1,0.25)$ na posição radial 0.75 .

A figura 4.8 mostra a função auxiliar $\phi$ para tempos adimensionais $t=0 \mathrm{e}$ 0.5 , quando se aplica a reinicialização ou se omite. Note que $\phi(\vec{x}, 0.5)=\phi(\vec{x}, 0)$ quando o reinicialização foi aplicada. Não obstante, o método possui restrições que limitam seu uso. Para deslocamentos em geometrias complexas é possível o surgimento de interfaces com funções auxiliares $\phi$ de larguras menores às do tubo $\gamma$. Devido ao método de discretização espacial utilizado na implementação da reinicializção da função auxiliar $\phi$, se requer minimamente o espaçamento de um tubo $\gamma$ para ser aplicada. A figura 4.9 mostra a função auxiliar $\phi$ para $(w, l, \delta, R e, M, t)=(0.75,3,0.1,1,0.25,1.1)$ para uma geometria anular de paredes paralelas que possui uma expansão-contração abrupta. Pode-se observar a aparição de curvas de nível com larguras menores a $\gamma$, tornando inviável o uso da reinicialização.

Uma abordagem usando o método Level-Set evitando o processo de reinicialização restringe o conjunto de parâmetros já que pesquisas feitas 


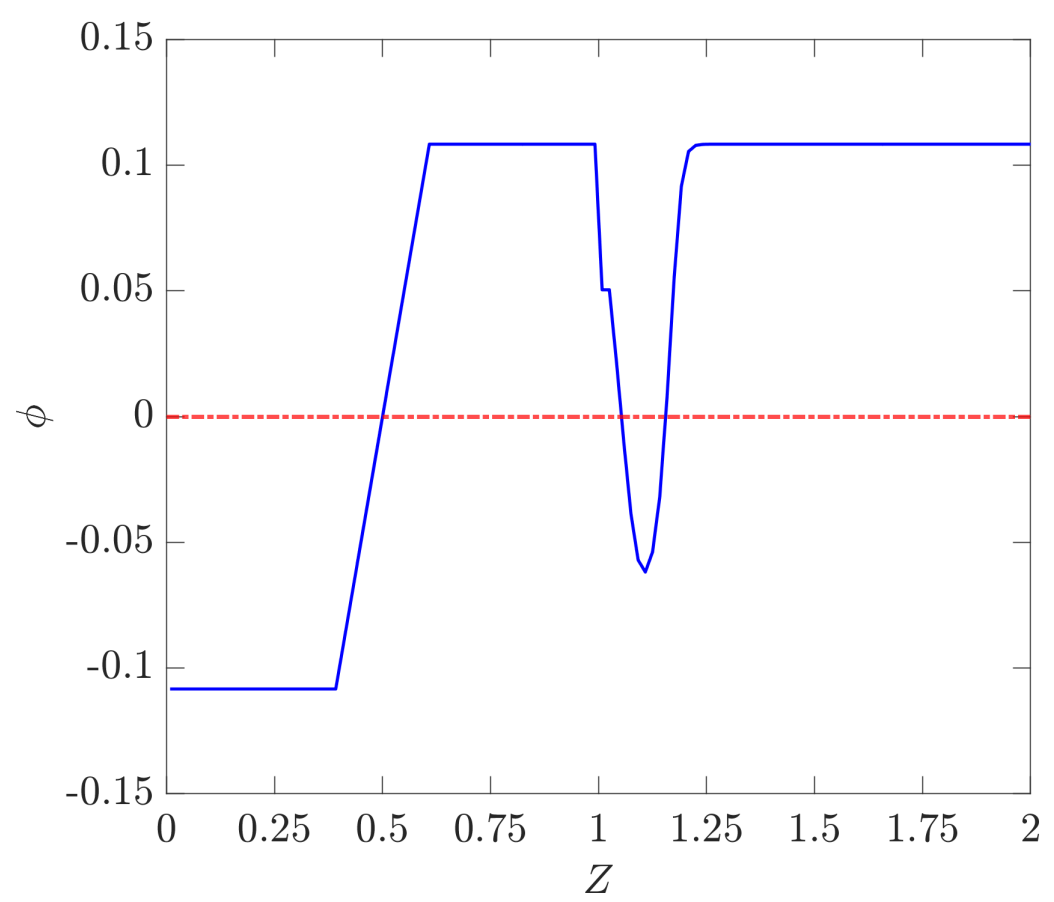

Figura 4.9: Função auxiliar $\phi$ em função da coordenada axial $z$ para $(w, l, \delta, R e, M, t)=(0.75,3,0.1,1,0.25,1.1)$.

por Osher, Sussman, Peng entre outros $(90,91,97,101)$, mostraram que a discretização espacial da função auxiliar $\phi$ não preserva a massa ao longo do tempo de simulação. Os resultados obtidos para simulações entre fluidos imiscíveis com funções viscosidade newtonianas através de um espaço anular concêntrico com expansão-contração abrupta usando o método Level-Set foram desenvolvidas sem o uso da função reinicialização. 


\section{Resultados das simulações}

\section{1}

\section{Teste de malha}

Foram testadas quatro malhas simétricas com refinamentos distintos para uma razão de diâmetros $w=0.5$, número de Reynolds $R e=10$, razão de viscosidade $M=2$ e tempo adimensional. As malhas testadas foram $60 x 20$, $120 x 40,180 x 60$ e $240 x 80$. Figura 5.1 apresenta a interface de deslocamento para as diferentes malhas testadas.

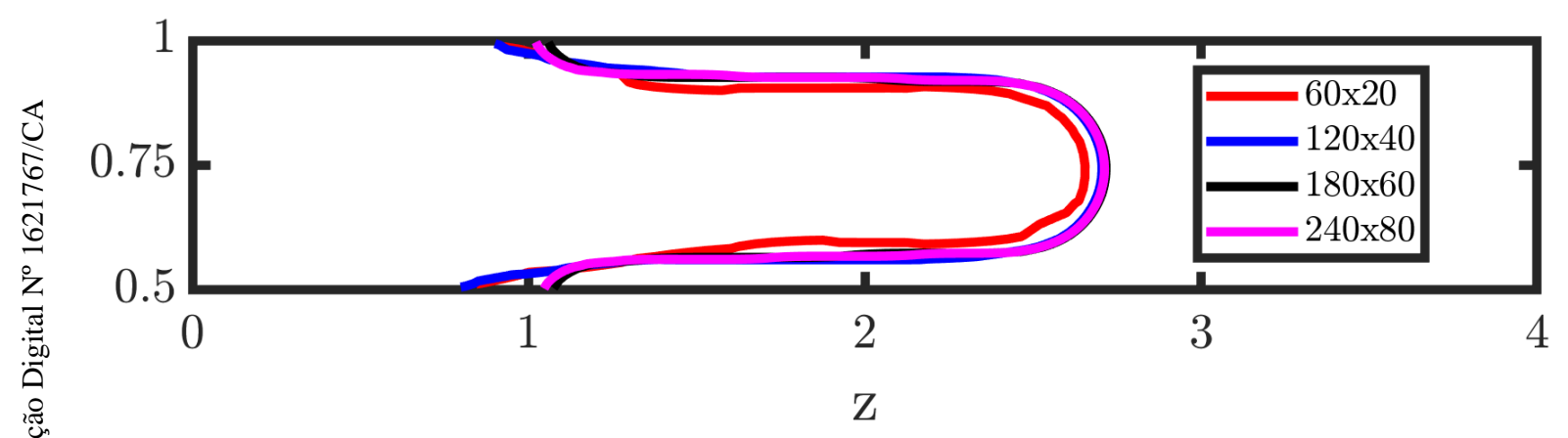

Figura 5.1: Interface de deslocamento para diferentes resoluções de malha para $(w, R e, M, t)=(0.5,10,2,1.7)$.

Foi computado, para um tempo $t=1.7$, o erro relativo sugerido em (89):

$$
E=\frac{\left|f_{240 \times 80}-f_{n}\right|}{f_{240 x 80}}
$$

sendo $f$ a velocidade tip ou sua posição e $n$ a resolução da malha. Tabela 5.1 contem os erros relativos. Foi escolhida a malha com resolução $180 x 60$ por mostrar os erros relativos menores.

Tabela 5.1: Erros relativos entre malhas estruturadas.

\begin{tabular}{cccc}
\hline & $E_{60 \times 20,240 \times 80}$ & $E_{120 \times 40,240 \times 80}$ & $E_{180 \times 60,240 \times 80}$ \\
\hline Posição & 0.165 & 0.042 & 0.0021 \\
\hline Velocidade tip & 0.0107 & 0.00623 & 0.00350 \\
\hline
\end{tabular}




\section{2}

\section{Validação}

A pesquisa desenvolvida por Szabo et al. (1) abordou o deslocamento de um fluido newtoniano por outro em uma geometria anular com diferentes densidades. A condição inicial de velocidade média foi definida como $\bar{u}=Q / \pi R_{2}^{2}\left(1-k^{2}\right)$, sendo $R_{2}$ o raio externo e $k=R_{2} / R_{1}$, i.e, a razão da vazão volumétrica e a área da seção transversal do espaço anular. Cabe enfatizar que as simulações em (1) tem como parâmetro fixo $M=1$, ou seja, fluidos com a mesma viscosidade. No trabalho de referência foi feito o deslocamento de dois fluidos com os seguintes parâmetros $(w, R e, F)=(0.8,128,-0.4)$. Para este caso o fluido mais denso é o deslocador. Enfatizamos que nas simulações realizadas por Szabo et al. (1) não foram definidos os efeitos da tensão interfacial. Em nossas simulações, o número de capilaridade foi definido como $C a=0.1$. Foram comparados dois tempos adimensionais $t=4.5$ e 8.3. Os resultados mostrados na figura 5.2 revelam uma similaridade qualitativamente boa para os dois tempos adimensionais $t$ simulados.

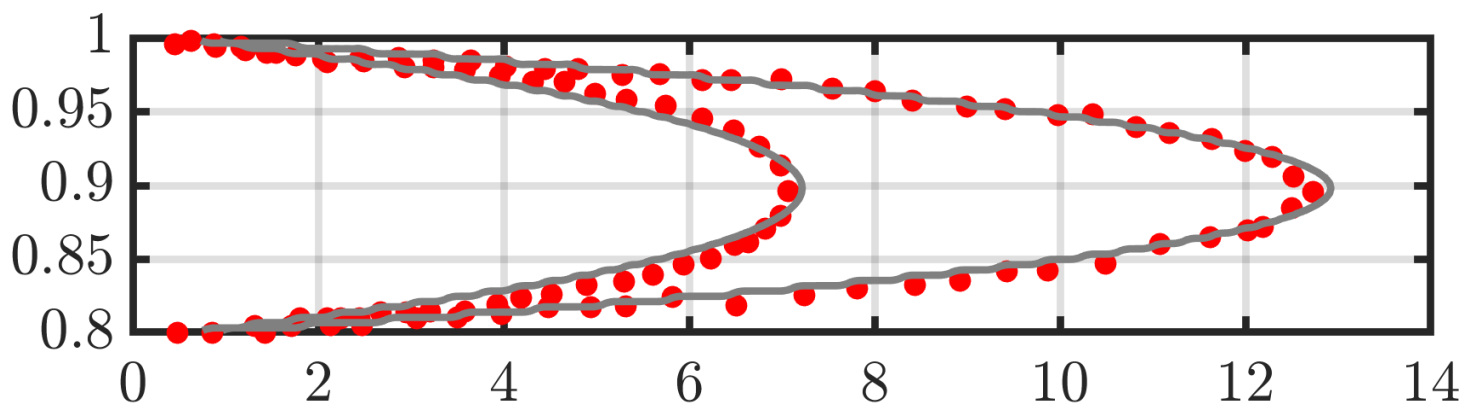

Figura 5.2: Comparação da forma da interface para $(w, R e, F)=(0.8,128,-0.4)$ e $t=4.5,8.3$. A linha continua representa os resultados obtidos com as simulações do presente trabalho. Os marcadores vermelhos são os dados obtidos na pesquisa de Szabo et. al (1).

\section{3}

\section{Fluido newtoniano deslocando outro newtoniano}

\subsection{1}

\section{Forma da interface quase estacionaria}

Nesta seção foi realizada a análise das características da interface que se forma quando um fluido newtoniano é deslocado por outro newtoniano. O deslocamento se desenvolve através de um anular delimitado por paredes paralelas sólidas. O fluido deslocador foi injetado a uma velocidade de um escoamento desenvolvido, como foi mencionado no capítulo 4, e o deslocado 
foi considerado em estado quiescente. Os fluidos são imiscíveis e portanto forças interfaciais foram impostas. Para todos os casos simulados, foi definido $C a=0.1$. Nosso estudo se limitou para razões de diâmetros $w=0.25,0.5,0.75$, números de Reynolds $R e=1,10,100$, e razões de viscosidade $M=0.25,0.5$, 20, e 30. As razões de viscosidade menores que um são viscosamente estáveis, ou favoráveis, pois para esta configuração um fluido mais viscoso desloca um menos viscoso. Para o caso contrário, quando $M>1$, o deslocamento é viscosamente instável ou desfavorável.

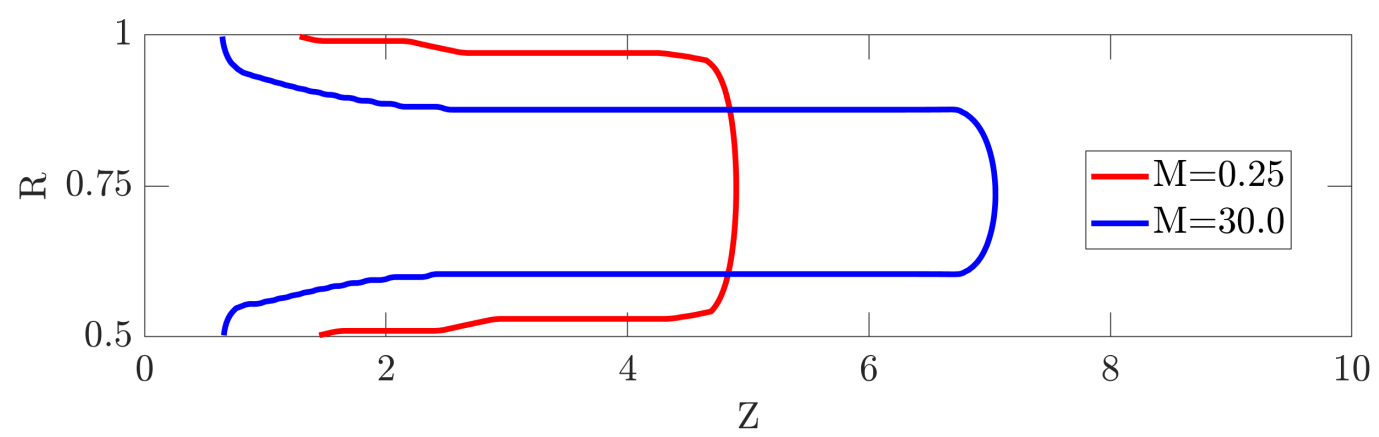

Figura 5.3: Interfaces pseudo estáveis de deslocamento bidimensional entre dois fluidos newtonianos a velocidade constante para $(w, R e, t)=(0.5,10,4.0)$.

A figura 5.3 mostra as interfaces para $(w, R e, t)=(0.5,10,4.0)$ e duas razões de viscosidade. Para $M=30$, a interface mostra-se menos larga e com um maior avanço que $M=0.25$. Comportamentos similares foram avistados em trabalhos de deslocamentos envolvendo fluidos newtonianos imiscíveis (vide (112)). Devido aos efeitos da curvatura da geometria anular, foi observado também uma assimetria radial da interface. Este fenômeno será discutido com mais detalhes posteriormente.

Foi definido a posição de maior avanço da interface como $z_{t i p}$, para um tempo adimensional $t$. Figura 5.4 mostra $z_{t i p}$ em função do tempo adimensional $t$, para $(w, R e)=(0.5,100)$ e $M=0.25,0.5,20$, e 30 .

A posição da interface $z_{\text {tip }}$ mostra uma taxa de avanço quase constante, para a faixa de tempo $t$ estudado. A mesma tendência se mostrou para todo $w \mathrm{e}$ $R e$ investigado. Isso sugere que esses deslocamentos axissimétricos rapidamente alcançam um estado quase estacionário. Dois comportamentos bem definidos e dependentes de $M$ podem ser observados. Para $M>1, z_{t i p}$ mostra avanços maiores em comparação com os casos $M<1$ para o mesmo tempo adimensional t. Portanto, um maior avanço da ponta da interface quanto maior é a razão de viscosidades $M$, para $R e$ constante, foi observado.

Pesquisas como as realizadas por Homsy et al. (113) mostraram que durante deslocamentos considerados como viscosamente instáveis (fluidos 


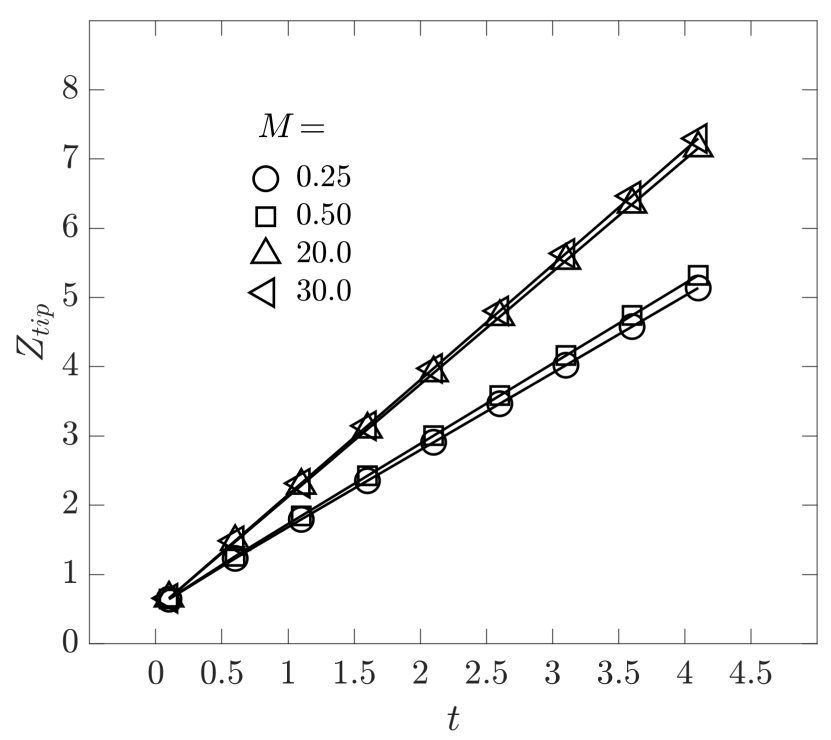

Figura 5.4: Posição da ponta da interface $z_{t i p}$ em função do tempo adimensional $t$ para os parâmetros $(w, R e)=(0.5,1)$.

menos viscosos deslocando mais viscosos) envolvendo fluidos newtonianos imiscíveis, divisões sucessivas da interface podem ocorrer. O fenômeno é inerente à instabilidade viscosa que ocorre em várias escalas, tanto micro como macroscopicamente $(114,115)$. Apesar de estudos numéricos tridimensionais mostrarem que essa abordagem é necessária para modelar todos os fenômenos que ocorrem durante um deslocamento viscosamente instável, simulações bidimensionais (116), (103), (117), (118), (26), (19) e axissimétricas (1), (119), (27) mostraram que resultados relevantes podem ser obtidos, cientes que não se consegue capturar os viscous fingers que poderiam aparecer.

A figura 5.5 mostra a velocidade da ponta da interface $u_{t i p}$ em função do número de Reynolds Re para todos os parâmetros estudados. Foi observado um aumento de $u_{t i p}$ quando $R e$ aumenta, para deslocamentos considerados viscosamente estáveis. O contrário foi observado para deslocamentos viscosamente instáveis, sendo que a velocidade $u_{\text {tip }}$ diminui com o aumento de $R e$. De forma geral, para menores $w$ (menor $w$ corresponde a uma folga anular maior), maior foi a velocidade $u_{t i p}$, tanto para deslocamentos estáveis e instáveis. Isso reflete o fato de que as propriedades geométricas e reológicas dos fluidos newtonianos em que se desenvolve o deslocamento tem um forte efeito na velocidade de avanço da ponta da interface.

A figura 5.6 mostra o desenvolvimento temporal das interfaces para $(w, R e)=(0.75,1.0)$. Figuras $(a, b)$ representam simulações de deslocamentos para $M=0.25,0.5$, enquanto $(c, d)$ mostram deslocamentos para razões de 


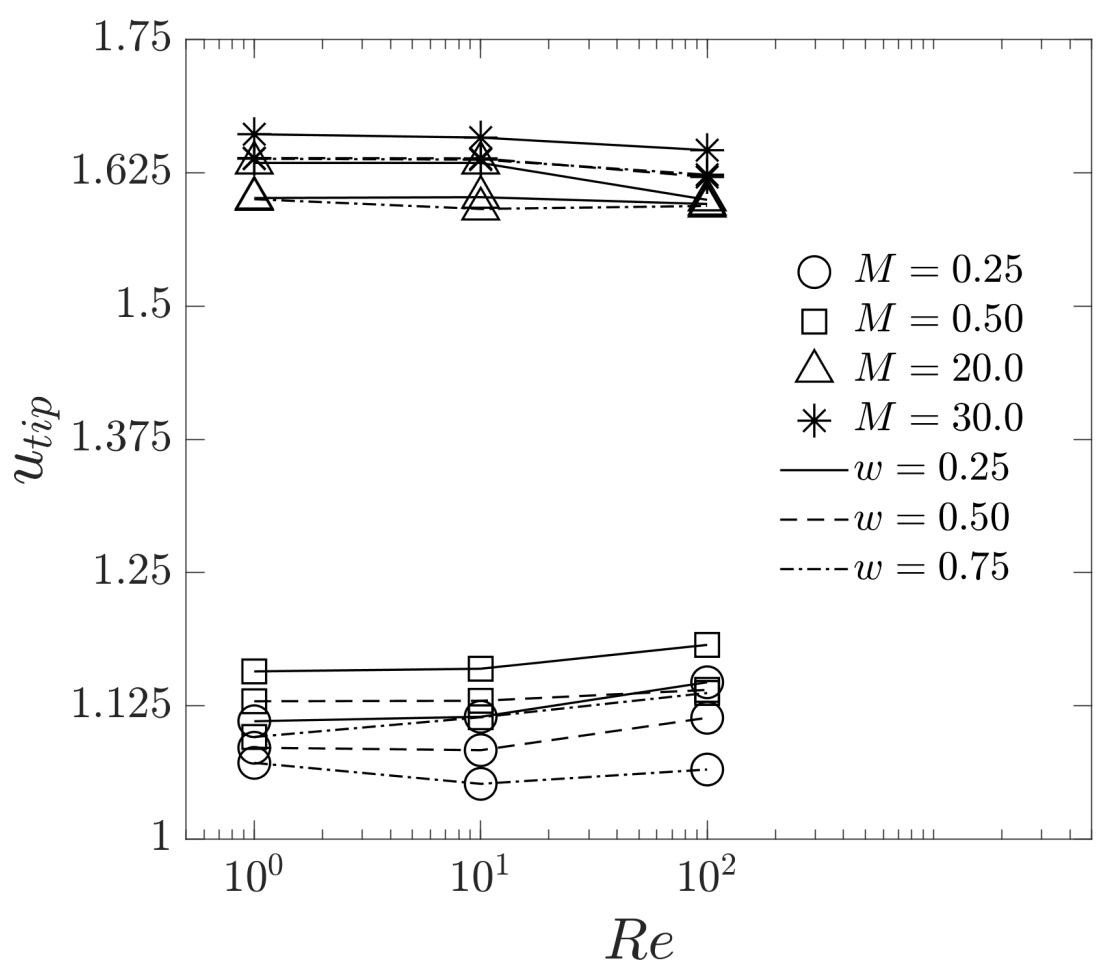

Figura 5.5: Velocidade da ponta $u_{t i p}$ em função de $R e$.

viscosidade $M=20$ e 30 , respetivamente. Os tempos adimensionais $t$ foram $t=0,0.5, \ldots .5$. É notório que para os casos de deslocamentos viscosamente estáveis, interfaces mais largas com menor avanço aparecem. Maiores velocidades, como as obtidas para deslocamentos viscosamente instáveis, mostram interfaces de larguras menores, deixando uma camada maior de fluido sem ser deslocado perto das paredes. Isto indica que a razão de viscosidades entre os fluidos deslocador e deslocado têm um forte efeito na largura da interface e na eficiência de deslocamento. À primeira vista, em todos os casos, a interface atinge uma largura constante. Posteriormente será verificada esta suposição.

Figura 5.7 a) mostra a interface de deslocamento axissimétrico quase estacionário para $(w, M, t)=(0.75,0.5,3.6)$ e $R e=1,10,100$. Para diferentes valores de $R e$, a interface mostra diferentes posições da sua frente. Esse comportamento também foi observado anteriormente na figura 5.5. A influência da razão de viscosidade $M$ na largura da interface pode ser avaliado na figura 5.7 b). Aqui, Re, w e $t$ são mantidos constantes em $(10,0.75,3.6)$. A interface, para todos os casos, mostra uma largura constante $\zeta$ através de várias posições axiais $z$. Isto sugere que pode ser calculado uma razão entre a largura da interface e do espaço anular definida como: 
(a)
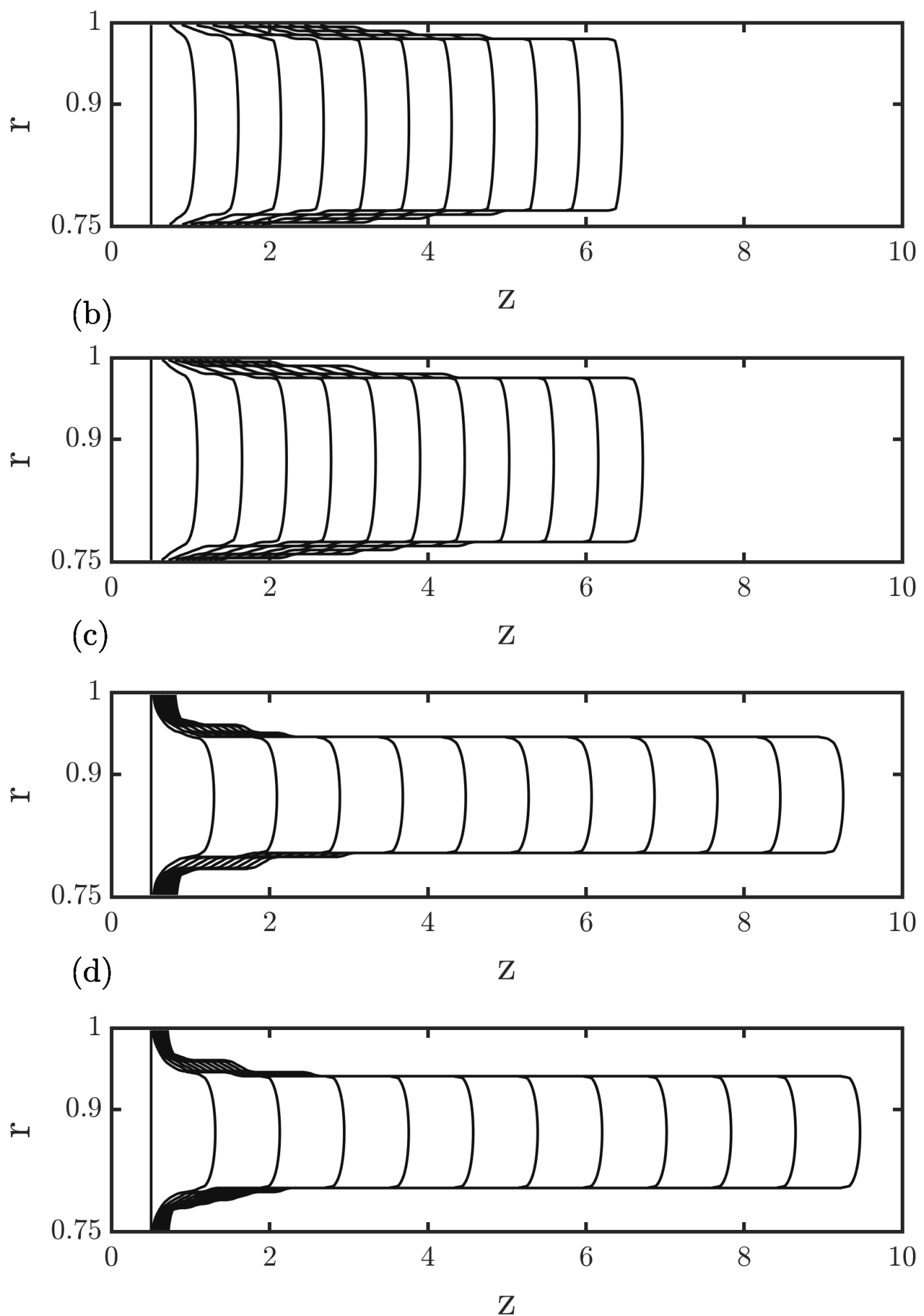

Figura 5.6: Deslocamento temporal entre fluidos newtonianos. Os parâmetros são $(w, R e)=(0.75,10)$ para $t=0,0.5, \ldots .5$ e $M=\mathrm{a}) 0.25, \mathrm{~b}) 0.5$, c) 20 , d) 30 . 

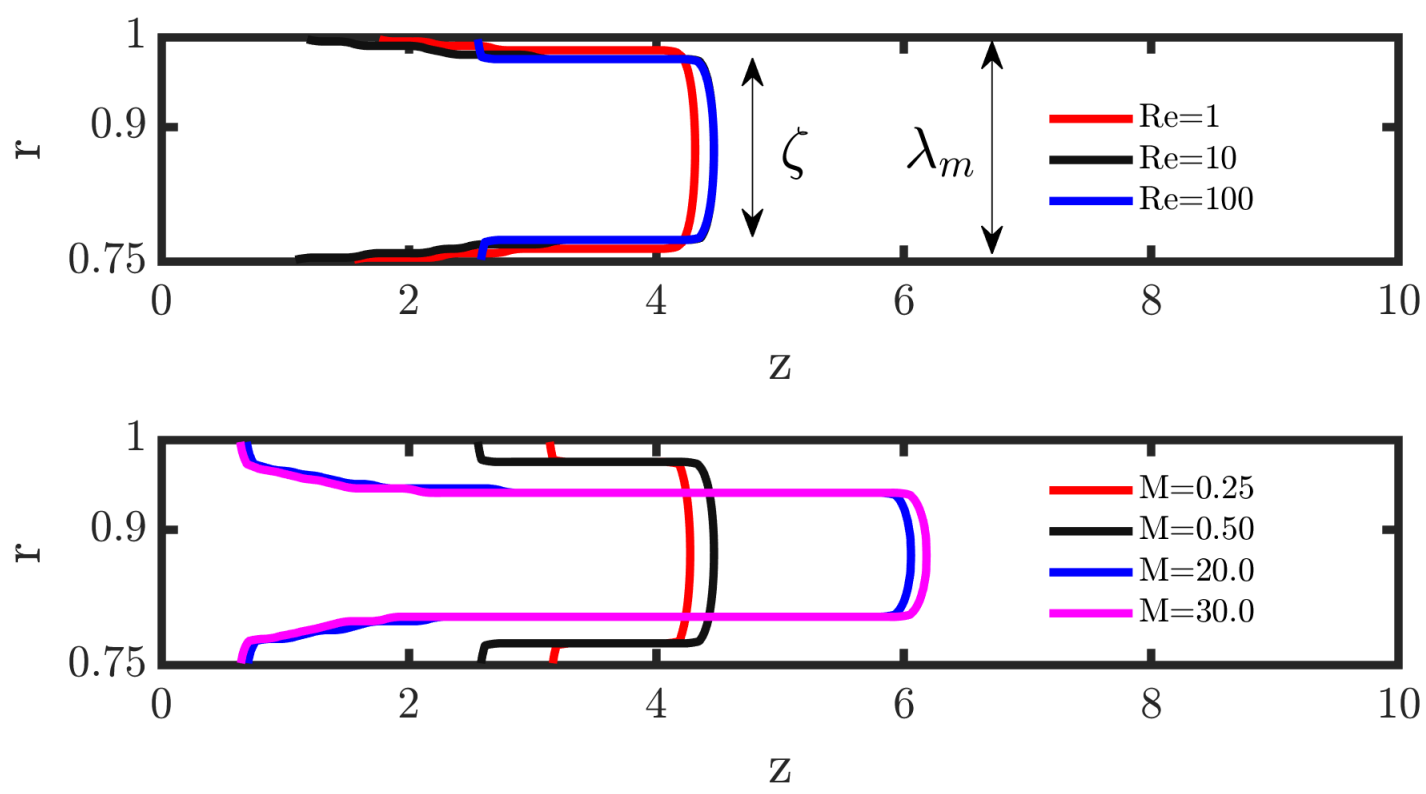

Figura 5.7: Interfaces geradas durante o deslocamento para a) $R e=1,10,100$ e b) $M=0.25,0.50,20,30$ para $(w, t)=(0.75,3.6)$.

$$
m=\frac{\zeta}{\lambda_{m}}
$$

sendo $\lambda_{m}=1-w$ (vide Fig. 5.7).

A figura 5.8 mostra a razão de larguras $m$ em função do tempo $t$ para $(w, R e)=(0.25,1.0)$ e $M=0.25,0.5,20,30$. Note que para todos os casos, $m$ se mostra constante para um tempo adimensional posterior a $t=3.6$. Para tempos menores, variações do parâmetro $m$ podem ser observados, as quais se atenuam com o avanço de $t$. A transição para uma interface com largura constante ocorre em um período relativamente curto, indicando, mais uma vez, que essas interfaces atingem um estado quase estacionário.

Figura 5.9 mostra a largura $m$ em função de $R e$ para $M=0.25,0.5,20,30$ e $w=0.25,0.5,0.75$. Note que em todos os valores mostrados de viscosidade $M$, a largura $m$ mostra um comportamento que independe de Re. Outros dois comportamentos bem notórias da largura $m$ da interface são observados. Deslocamentos viscosamente instáveis $(M>1)$ produzem larguras menores que as geradas por deslocamentos estáveis. O parâmetro $w$ também influencia no comportamento de $m$. Razões de diamêtros menores geram interfaces com larguras maiores, para deslocamentos instáveis. Comportamento contrário foi observado para razões de viscosidades $M=(0.25,0.50)$, em que larguras menores se formaram.

A figura 5.10 mostra o comportamento de $m$ em função de $M$ para todos os parâmetros estudados. A formação de interfaces mais ou menos largas 


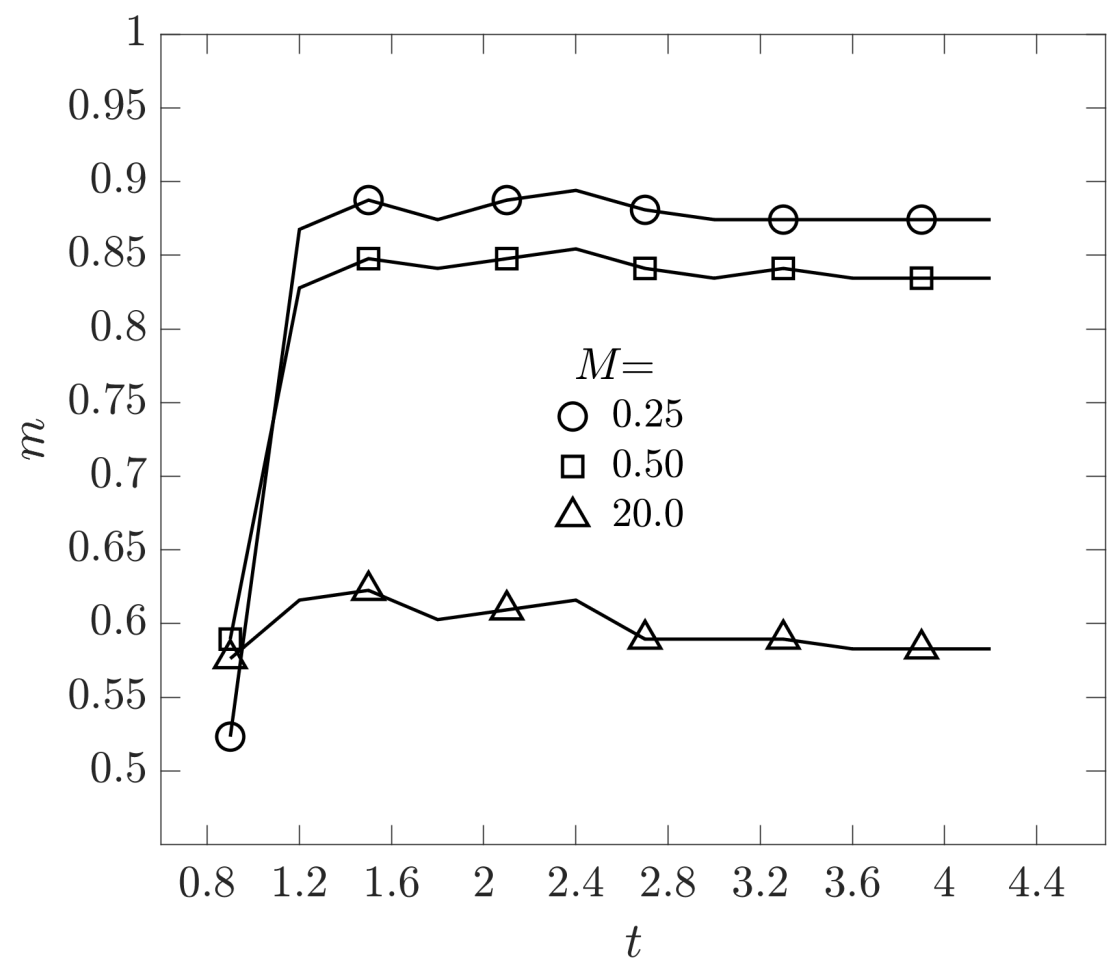

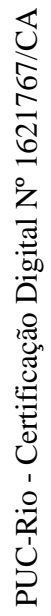

Figura 5.8: Largura $m$ em função do tempo $t$ para $(w, R e)=(0.25,1.0) \mathrm{e}$ $M=0.25,0.5,20,30$.

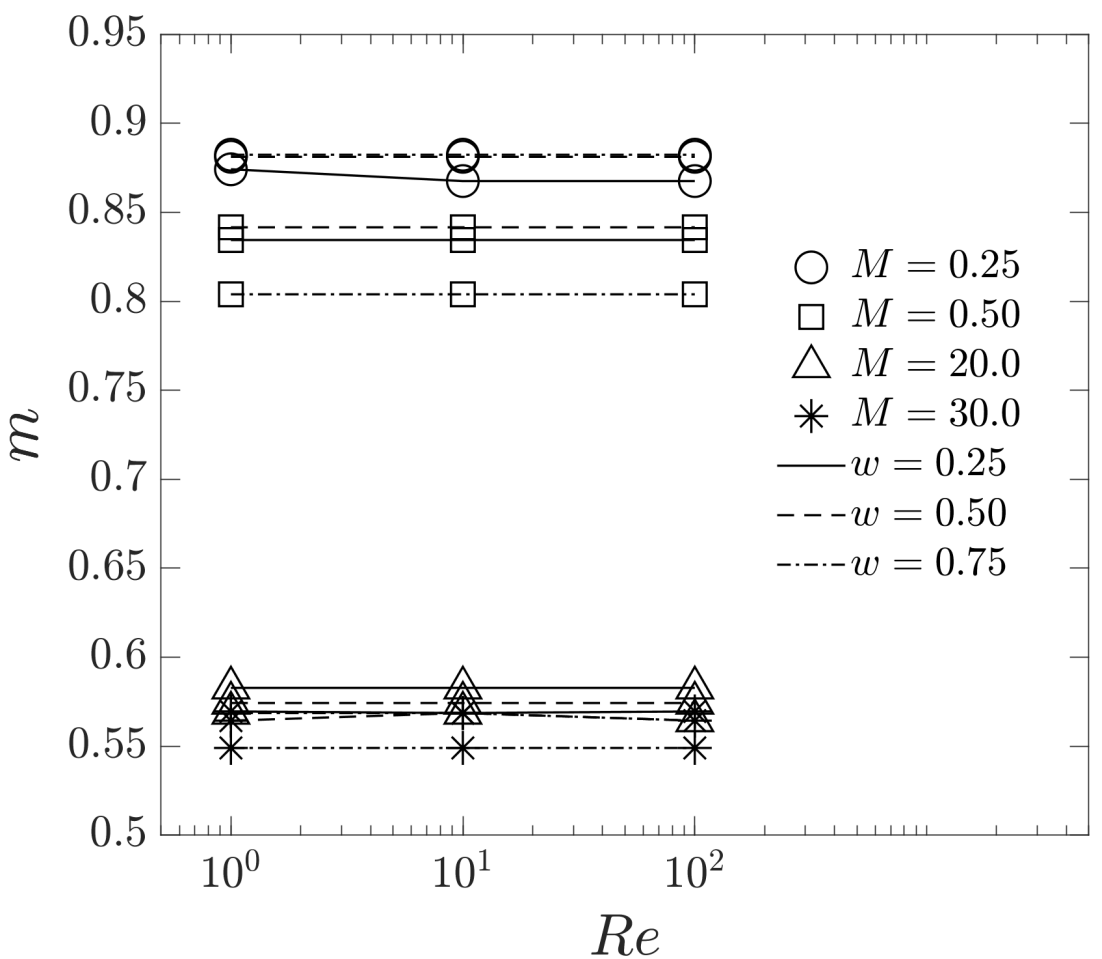

Figura 5.9: Razão e larguras $m$ em função do número de Reynolds $R e$ para $w=0.25,0.5,0.75$ e $M=0.25,0.50,20,30$. 
depende fortemente da razão de viscosidade $M$. Quando um fluido mais viscoso é injetado obtemos as maiores razões de largura $m$. Por outro lado, $m$ diminuiu consideravelmente quando $M$ aumenta.

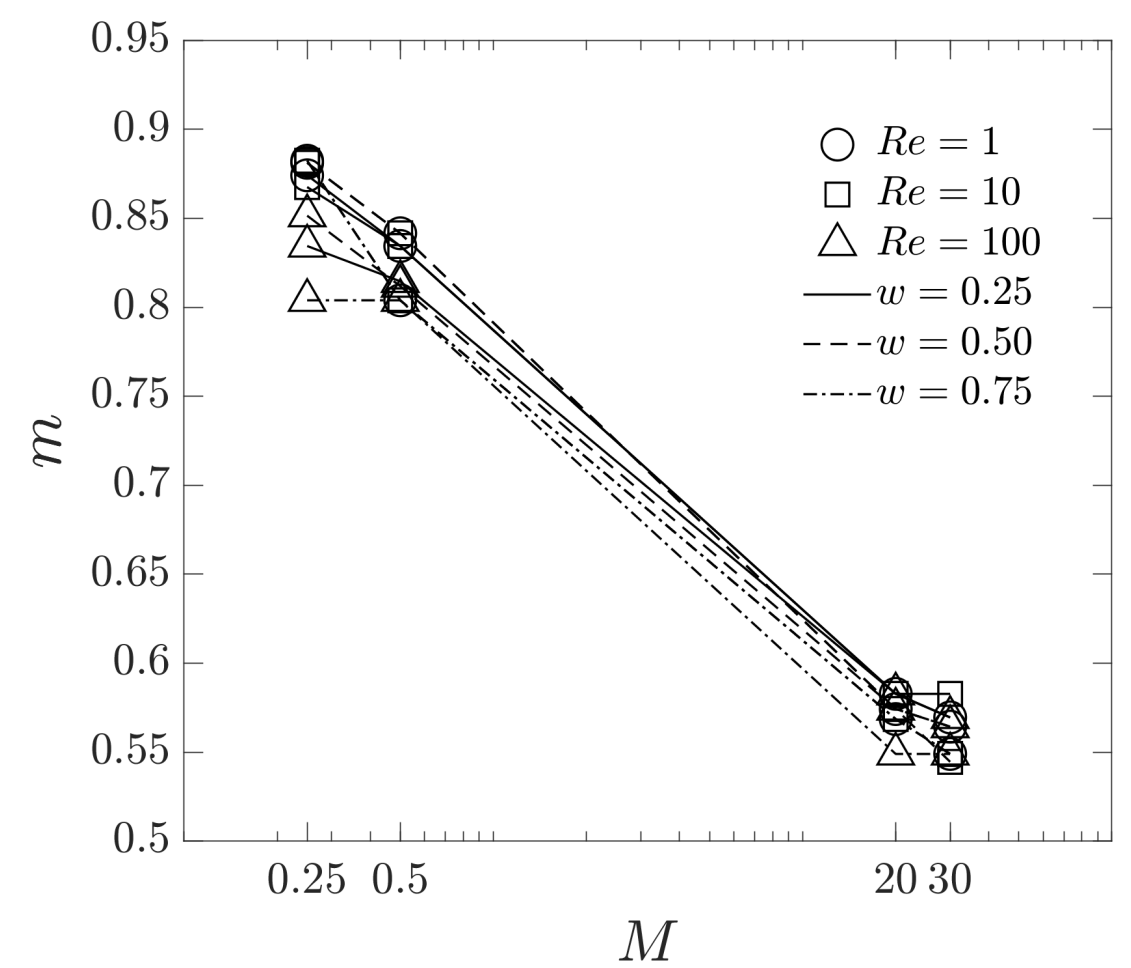

Figura 5.10: Largura $m$ em função da viscosidade $M$ para $w=(0.25,0.5,0.75)$ e $R e=(1,10,100)$.

O desvio radial da ponta da interface $r_{t i p}$ com relação ao eixo longitudinal do espaço anular é representado na figura. 5.11. A posição do eixo longitudinal ao longo de $\lambda_{m}$ é definida como:

O parâmetro $r_{t i p}$ foi definido como:

$$
e=\frac{(1+w)}{2}
$$

$$
r_{t i p}=r\left(z_{t i p}\right)-e
$$

A figura 5.12(a) mostra o desvio radial da ponta da interface $r_{t i p}$ em função de $R e$ para todos os $w$ e $M$ investigados. Uma independência de $r_{t i p}$ em função do número de Reynolds Re foi observada. Para deslocamentos viscosamente estáveis e $w=0.75$, a posição radial da ponta da interface $r_{t i p}$ encontra-se no plano central. Isto sugere que a aproximação de deslocamentos entre placas planas paralelas para deslocamentos estáveis em espaços anulares com a maior razão de diamêtros investigada pode ser assumida. Para os casos de menores razões de diamêtros, observa-se que $r_{\text {tip }}$ se afasta do eixo central 


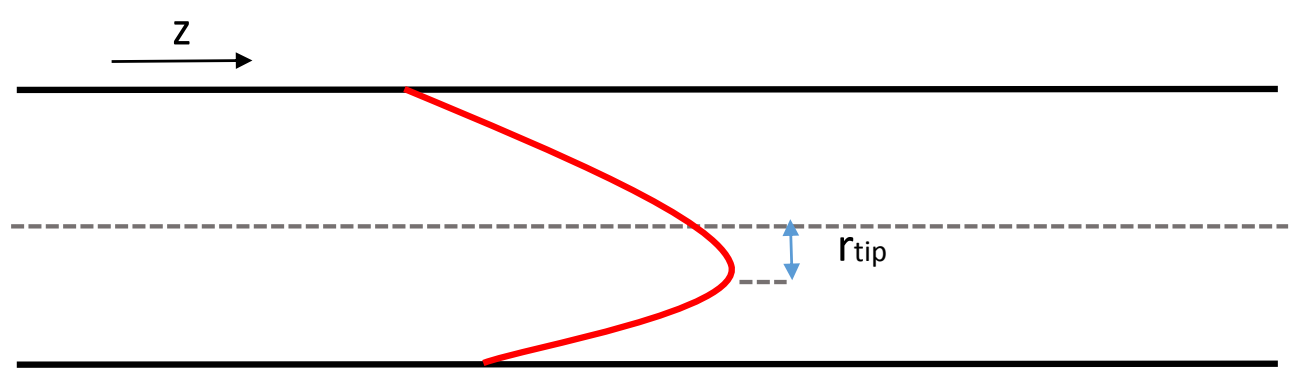

Figura 5.11: Representação esquemática da definição de $r_{\text {tip }}$.

em direção à parede interna do anular, tanto em casos viscosamente estáveis quanto instáveis.

A figura 5.12(b) mostra o desvio radial da ponta da interface $r_{t i p}$ em função de $M$ para todos os $w$ e Re investigados. Menores desvios radiais foram observados para deslocamentos estáveis e maiores razões de diamêtros. Note que o maior desvio radial ocorre para deslocamentos viscosamente instáveis e menores razões de diâmetros.

(a)

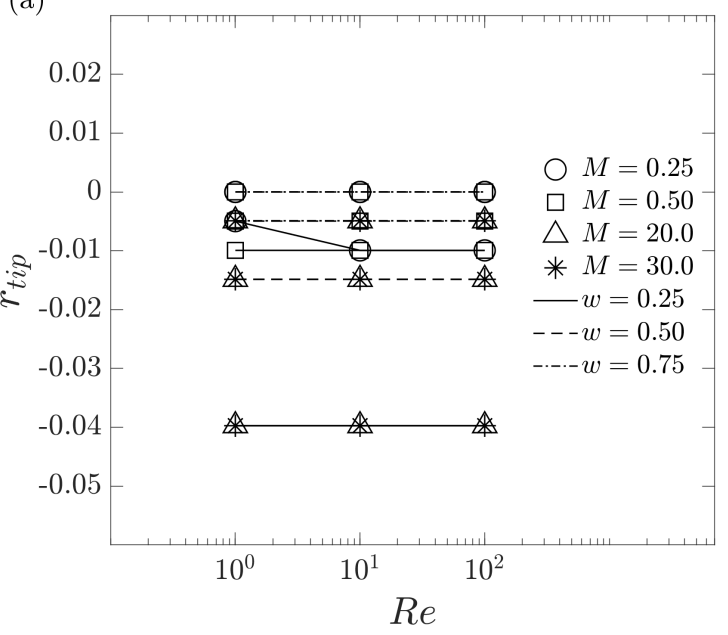

(b)

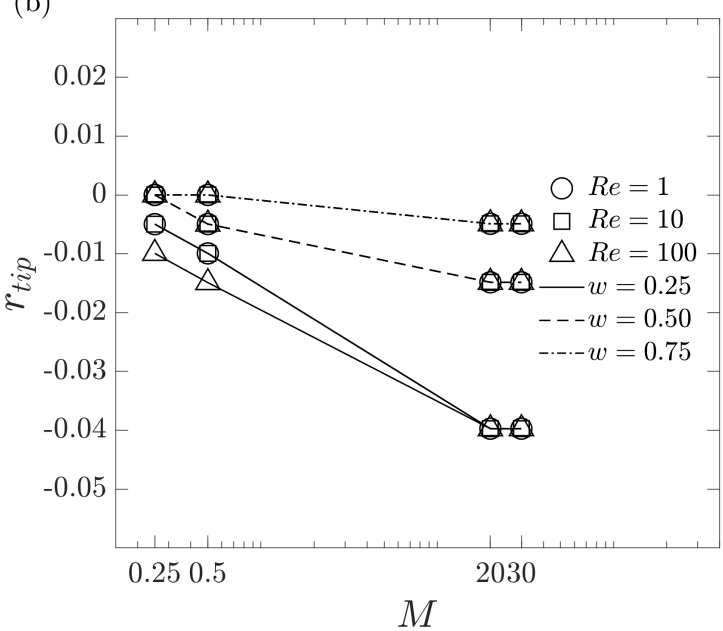

Figura 5.12: Desviação radial da ponta da interface $r_{\text {tip }}$ em função de a) Re b) $M$.

A velocidade $u_{f}$ é definida como a velocidade máxima do fluido na posição radial $r_{t i p}$, i.e. $U_{f}=\max \left(u\left(r_{\text {tip }}\right)\right)$. A figura 5.13 mostra $u_{f}$ em função do tempo adimensional $t$ para os parâmetros $(w, R e)=(0.25,1.0)$ e $M=0.25,0.5,20,30$. Para comparação, a velocidade quase constante da ponta da interface $u_{t i p}$ 
foi representada, no mesmo marcador que a velocidade $u_{f}$ em cada razão de viscosidades $M$. Observamos que após um período transitório inicial, a velocidade do fluido $u_{f}$ se mostra quase constante ao longo do tempo. Dois comportamentos bem definidos foram obtidos. Para deslocamentos viscosamente estáveis, a velocidade $u_{f}$ é maior que a velocidade da ponta. Para os casos instáveis, $u_{t i p} \approx u_{f}$. Em outras palavras, para deslocamentos estáveis a ponta da interface se desloca mais lentamente que a velocidade máxima das partículas na posição $r_{t i p}$. Para o caso instável, as velocidades são muito próximas.

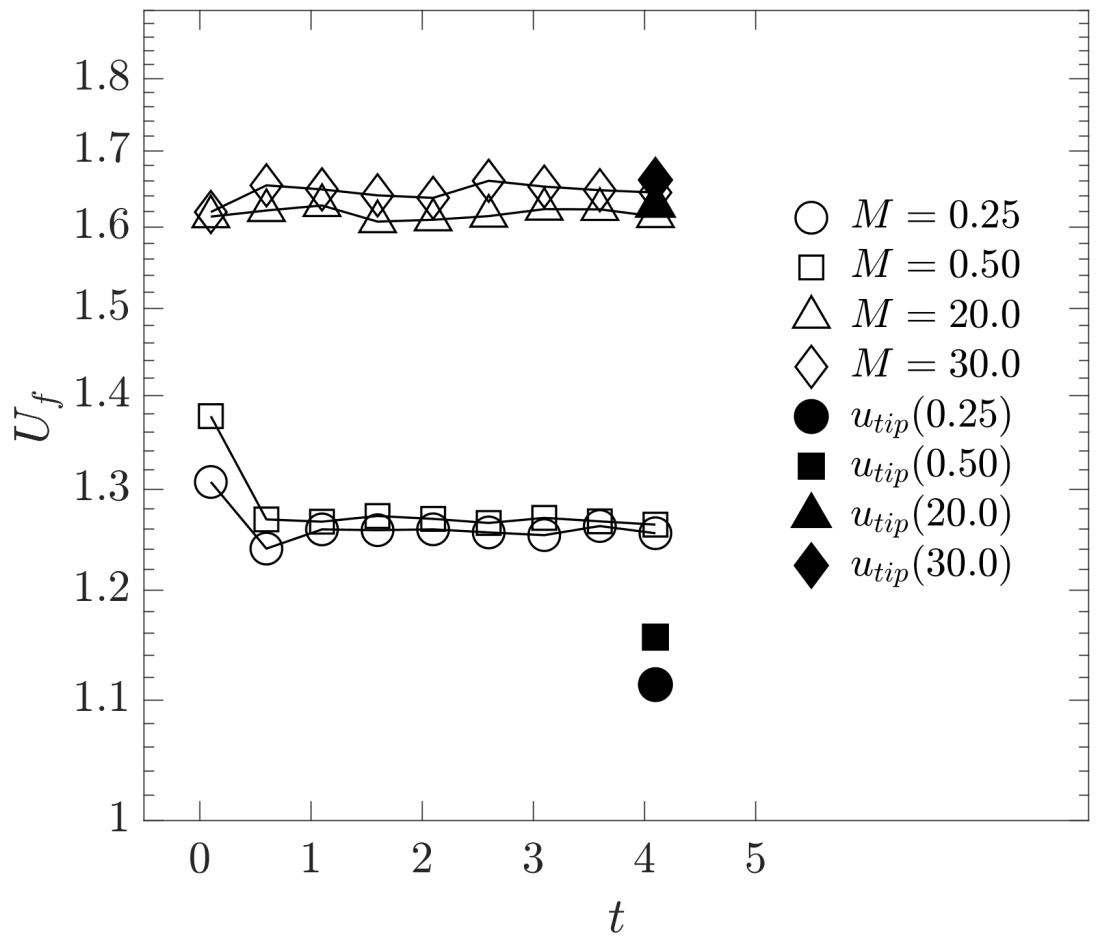

Figura 5.13: Velocidade $u_{f}$ em funcão do tempo $t$. Os parâmetros são $(w, R e)=(0.25,1.0)$ e $M=0.25,0.5,20,30$. A velocidade da ponta da interface $u_{f}$ são mostradas no mesmo marcador para cada $M$.

A figura 5.14 mostra o módulo do campo de velocidades $|\vec{u}|$ para um tempo adimensional $t=4$.0. Os parâmetros são $(w, R e)=(0.25,1)$ para todos os casos. O módulo do campo de velocidade foi definido como $|\vec{u}|=\left(u^{2}+v^{2}\right)^{1 / 2}$, e as componentes do campo de velocidades foram determinadas como $V_{z}=u-u_{\text {tip }}$ e $V_{r}=v$. Isso corresponde a um sistema de referência seguindo a frente da interface. As figuras $5.14(a, b)$ mostram $|\vec{u}|$ para $M=0.25,0.5$, enquanto $(c, d)$ representam $M=20$, e 30, respectivamente. A figura 5.14 a) mostra uma região de velocidades baixas que se forma a uma curta distância atrás da interface de deslocamento. Pode-se observar uma menor região de baixas velocidades para razões de viscosidades $M=0.5$ (vide figura $5.14 \mathrm{~b}$ ), induzindo a interfaces 
menos largas e maiores velocidades de avanço, como também observado na figura 5.4. As figuras $5.14 \mathrm{c}$ ) e d) mostram as simulações para deslocamentos considerados viscosamente instáveis. A ausência da região de fluido estagnado atrás da interface, diferente do encontrado em deslocamentos estáveis, foi observado. Observamos também que o módulo do campo de velocidade mostra uma região de velocidade com maior intensidade atrás da interface. Além disso, também encontramos velocidades com alta intensidade entre a interface de deslocamento e as paredes do anular. No entanto, na frente da interface, em posições radiais próximas a $r_{t i p}$, as velocidades para os casos $M>1$ são menores que as velocidades dos casos $M<1$.

Figura 5.15 ilustra o campo de velocidade próximo à interface para $(w, R e, M, t)=(0.25,1,0.25,4.4)$. A definição do campo de velocidades é o mesmo utilizado na figura 5.14. Foram observadas recirculações que se formam na frente da interface que transportam o fluido da região próxima das paredes para o centro do espaço anular, enquanto as recirculações atrás da interface mostram um sentido contrário. A causa dos escoamentos de recirculação podem ser interpretados usando a conservação de massa. A montante da interface, próximo à região de injeção, o perfil de velocidade está desenvolvido, enquanto na posição de $z_{\text {tip }}$ o campo de velocidade mostra um ponto de estagnação. Por conseguinte se induz necessariamente o escoamento do plano central em direção às paredes. Um argumento similar mostra que há escoamento das paredes em direção ao plano central diante da interface.

A figura 5.16 mostra as linhas de corrente para uma razão de viscosidades $M=20$ com parâmetros $(w, R e, t)=(0.25,1.0,4.4)$. O valor de $M$ implica um deslocamento viscosamente instável. Figura 5.16 a) ilustra as linhas de corrente ao longo de todo o domínio de deslocamento. A topologia das linhas de corrente mostram o ponto de estagnação na posição de $z_{\text {tip }}$. O padrão é claramente assimétrico, tanto na região atrás como na frente da interface. Uma característica notável é a ausência de escoamentos de recirculação a jusante da interface ocupado pelo fluido mais viscoso. As linhas de corrente que pertencem ao fluido deslocado se espalham em direção às paredes sólidas do anular em presença da interface imiscível próximas de $z_{t i p}$. Na figura 5.16 b) observamos que o sentido do movimento das partículas do fluido deslocador localizadas próximas às paredes do anular se opõem ao sentido imposto pela condição inicial, induzindo à geração de vórtices assimétricos toroidais atrás da interface. A conjunção dos vórtices incrementam a velocidade das partículas na posição de $r_{\text {tip }}$ (vide figura 5.14), produzindo $u_{\text {tip }}$ maiores (cf. figura 5.5).

Uma configuração de deslocamentos viscosamente estáveis levou a mudanças na topologia das linhas de corrente. Figura 5.17 mostra o 
(a)

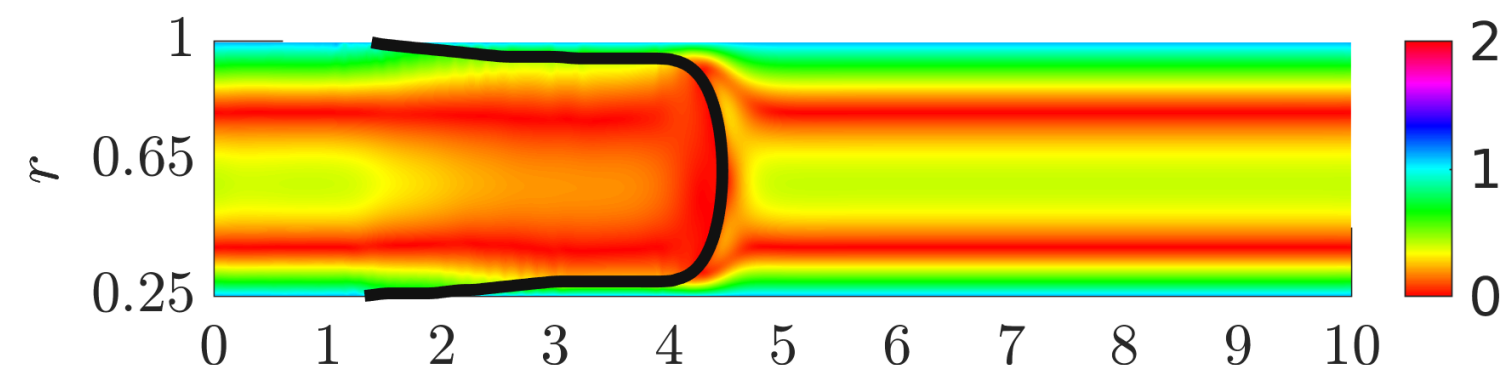
$z$
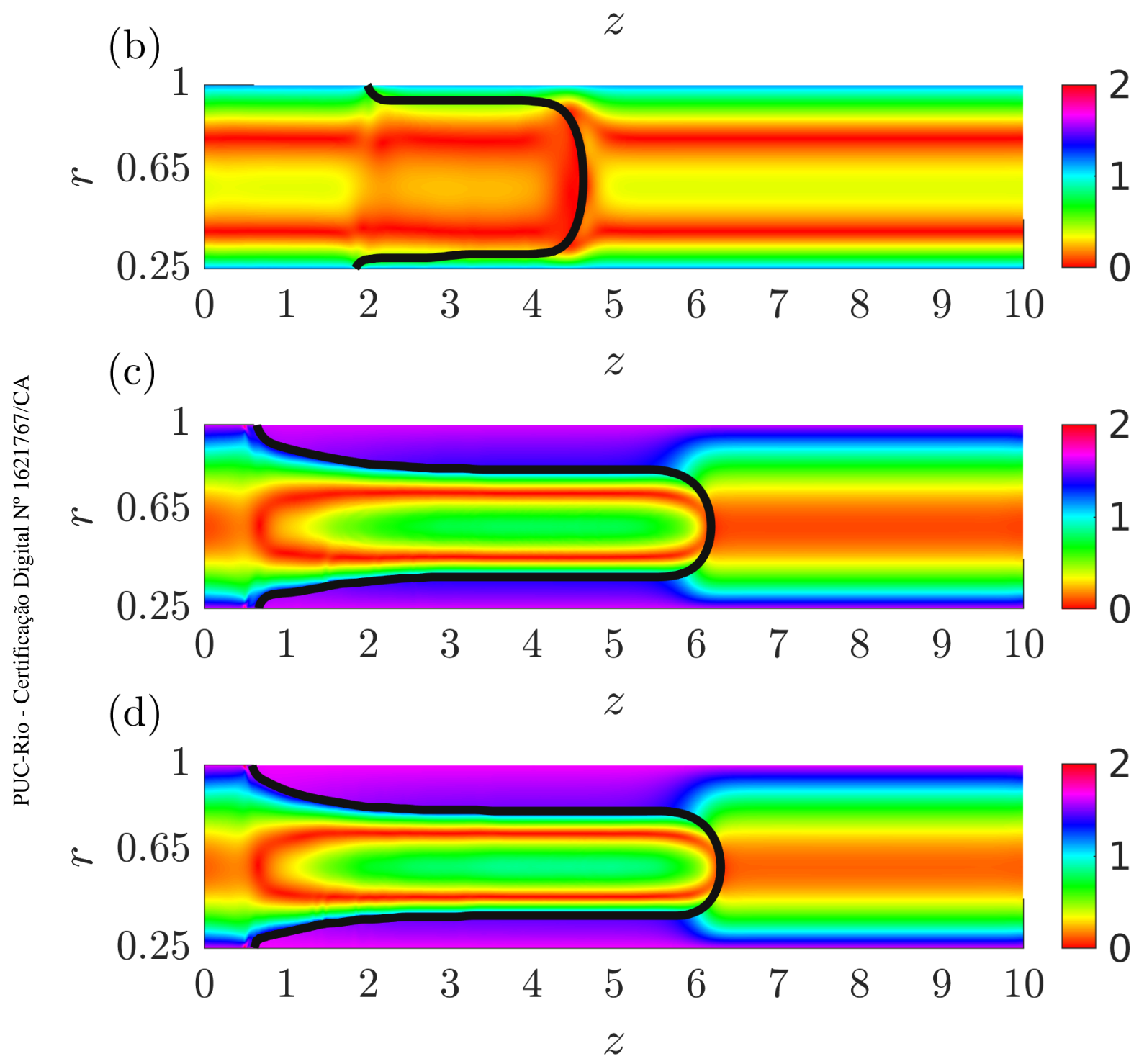

Figura 5.14: Módulo do campo de velocidade $|u|$ para $(w, R e, t)=$ $(0.25,1.0,4.0)$ e $M=(a, b, c, d)=(0.25,0.5,20,30)$

deslocamento para os parâmetros fixos $(w, R e, M, t)=(0.25,1.0,0.25,4.4)$. O crescimento da largura da interface e diminuição da velocidade é notória, 


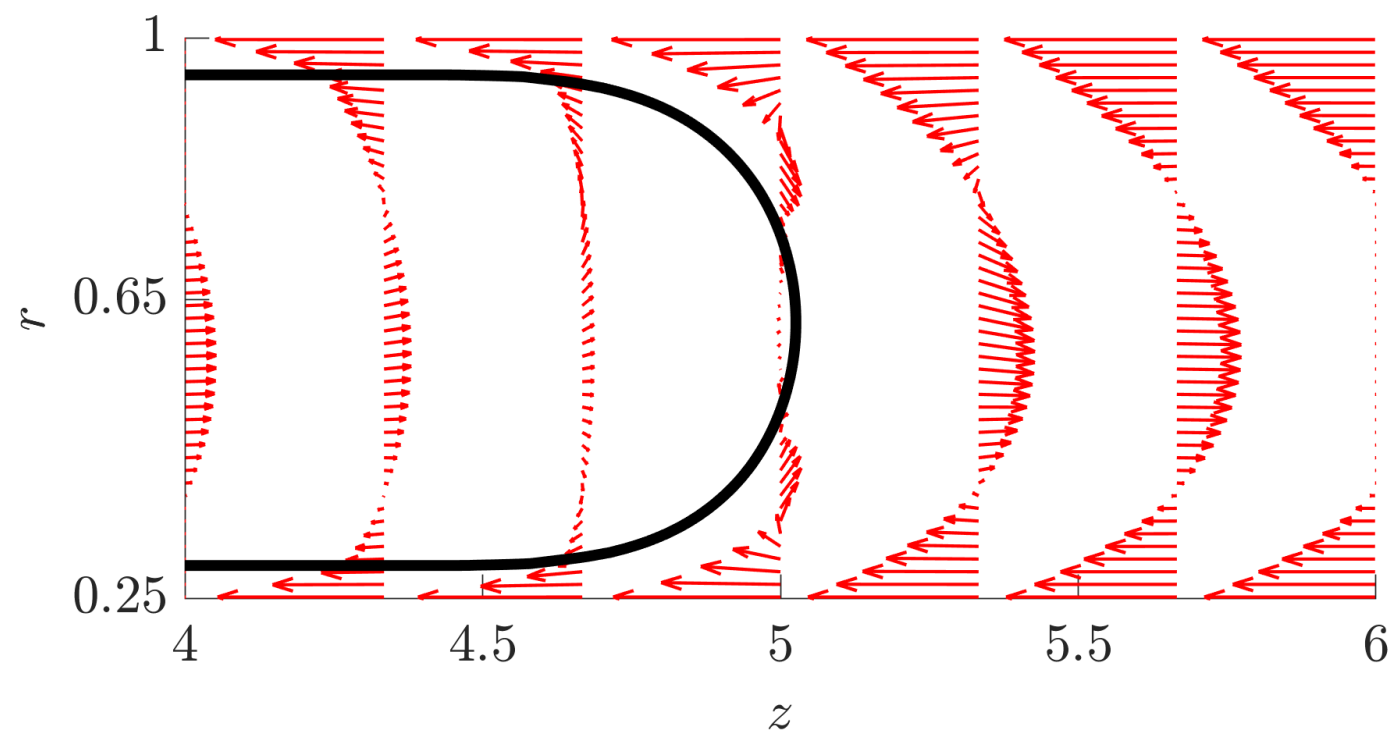

Figura 5.15: Campo de velocidade para um sistema de referência utilizado na figura 5.14 para $(w, R e, M, t)=(0.25,1.0,0.25,4.4)$.
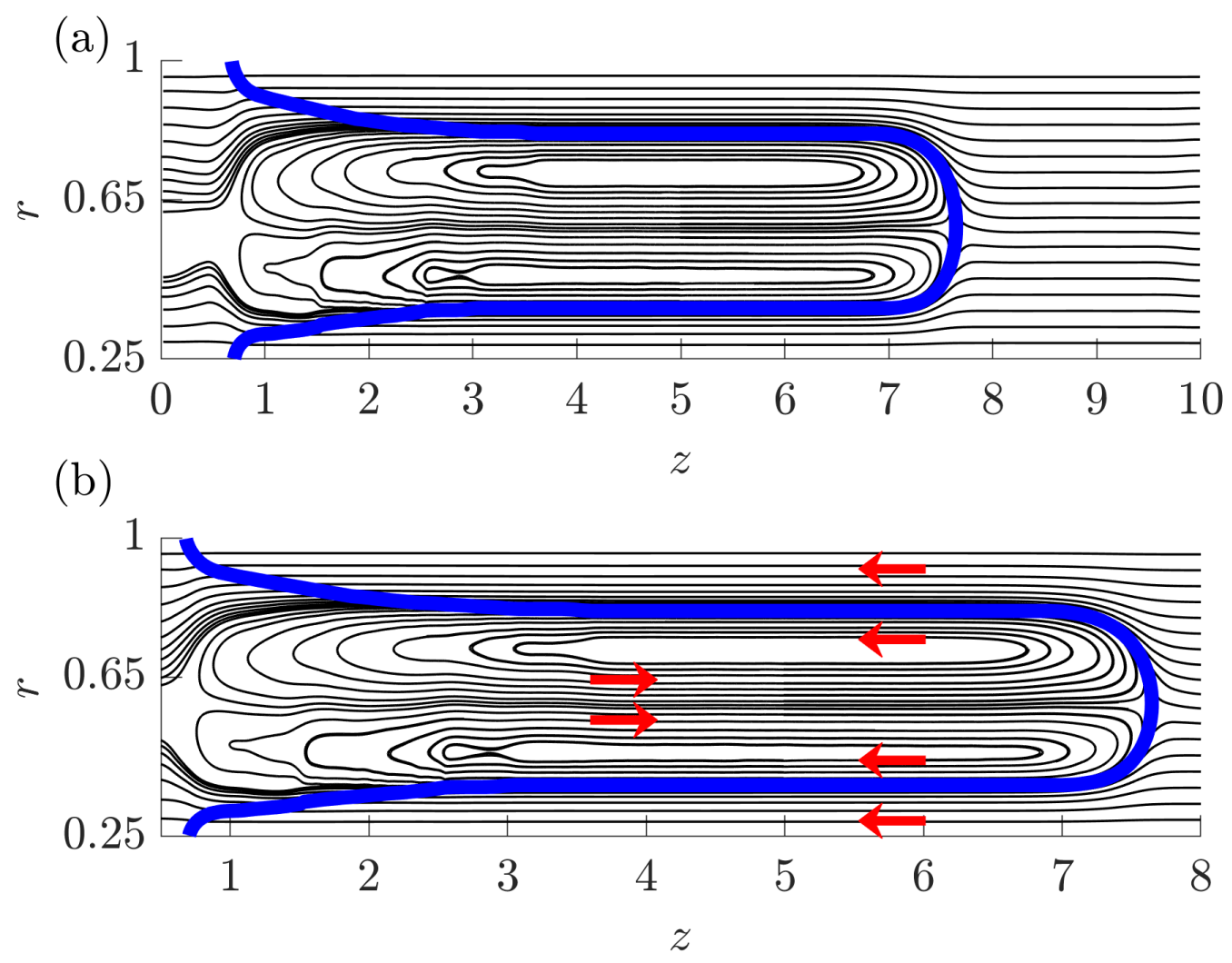

Figura 5.16: Linhas de corrente para $(w, R e, C a, M, t)=(0.25,1.0,0.1,20,4.4)$. comparado com o caso mostrado na figura 5.16. Figura 5.17 a) mostra, a jusante da interface, recirculações onde o fluido perto das paredes é transportado à 
seção interna do espaço anular. Estes escoamentos de recirculação se mostram assimétricos. Figura 5.17 b) mostra que existem escoamentos de recirculação que transportam o fluido da região central, interna à interface para regiões próximos às paredes. Além disso, vórtices toroidais a uma curta distância atrás da interface foram observadas. Esta topologia mostra similitude com as obtidas por Long et al. (120) e Rasmussen et al. (121).

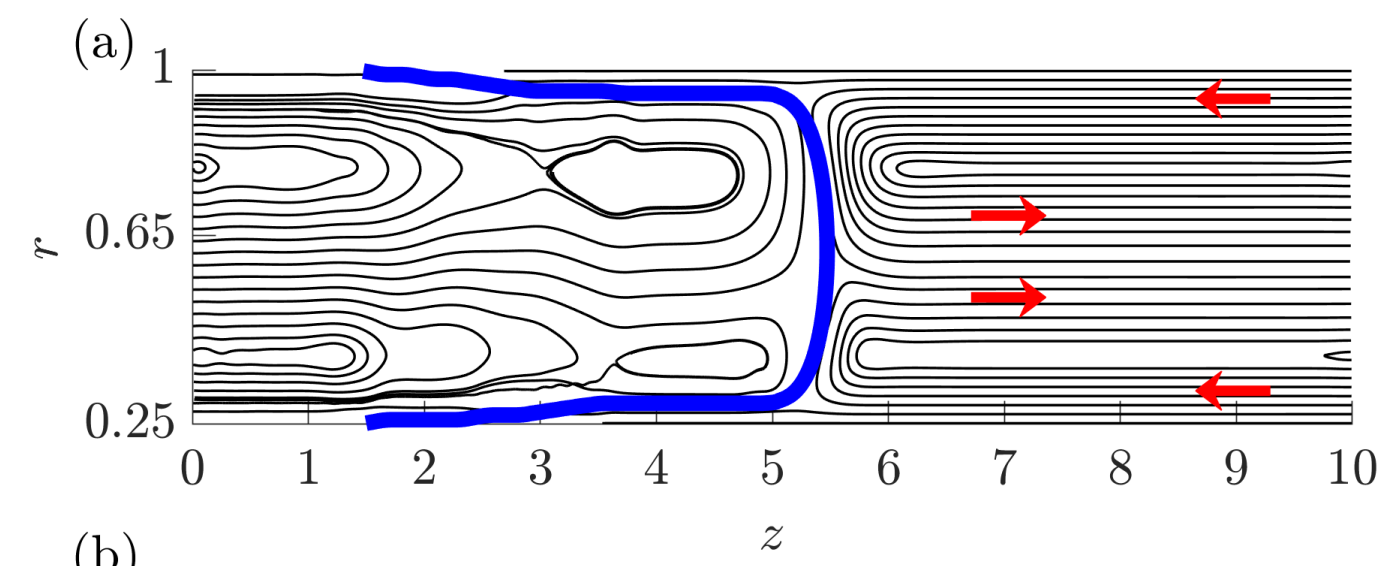

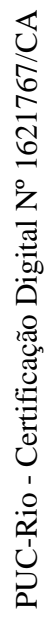

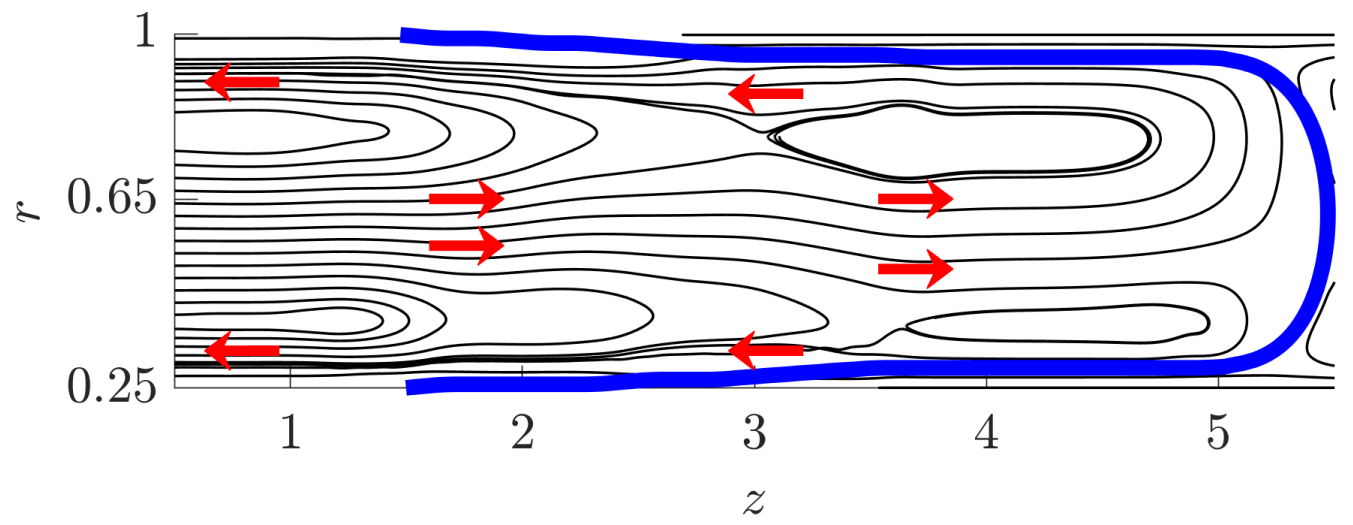

Figura 5.17: Linhas de corrente para $(w, R e, C a, M, t)=$ $(0.25,1.0,0.1,0.25,4.4)$. 


\section{4}

\section{Fluido não newtoniano deslocando newtoniano e vice-versa}

\subsection{1}

\section{Características da interface quase estacionário}

Para um valor constante de $R e=1$, foram estudadas as características da interface que se forma quando um fluido Carrreau-Yasuda desloca um newtoniano ou vice-versa, através de um espaço anular contínuo para razões de diamêtros $w=0.25,0.5,0.75$. Foram mantidas, para todas as simulações, os paramêtros reológicos adimensionais do fluido não newtoniano em $(a, n)=(0.88,0.9)$. Os tempos de relaxação $\lambda$ simulados foram $0.26,1.43$ e 18. Como definido na equação constitutiva $4-46, \eta_{\infty}$ e $\eta_{0}$ representam as viscosidades para altas e baixas taxas de cisalhamento, normalizadas pela viscosidade do fluido newtoniano. Em outras palavras, para definir $\eta_{0}=\eta_{0}{ }^{*} \eta_{c}$ e $\eta_{\infty}=\eta_{\infty}^{*} \eta_{c}$, foi escolhido $\eta_{c}=\mu_{1}$ ou $\eta_{c}=\mu_{2}$, dependendo se o fluido newtoniano foi o fluido deslocador ou deslocado, respectivamente, cf. figura 4.1. Para comparar deslocamentos distintos que envolvem fluidos não newtonianos, foram escolhidas as viscosidades de forma adimensional $R_{\eta}=1 \equiv\left(\eta_{0}, \eta_{\infty}\right)=(20,0.25)$ e $R_{\eta}=2 \equiv\left(\eta_{0}, \eta_{\infty}\right)=(30,0.5)$, respetivamente.
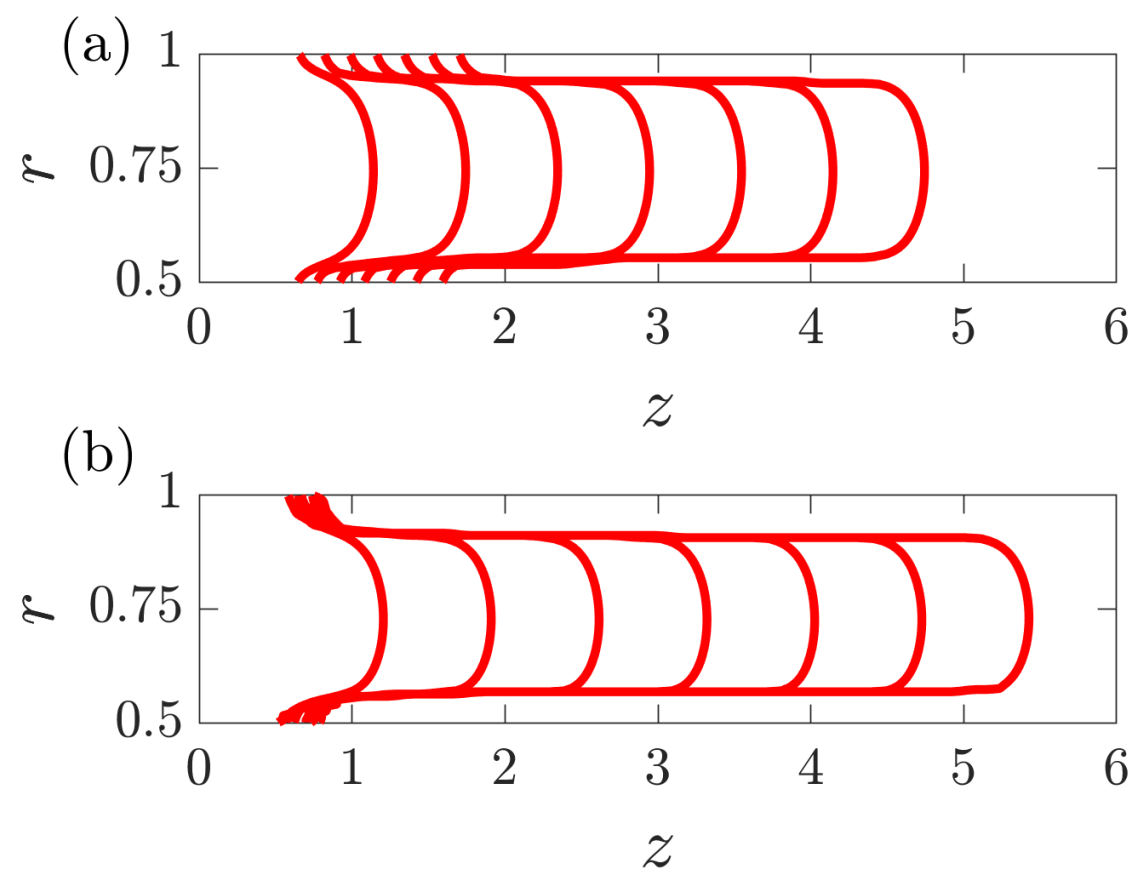

Figura 5.18: Evolução temporal da interface durante o deslocamento de um fluido não newtoniano deslocando um newtoniano para $\lambda=$ a) 0.26 e b) 18 e $\left(w, R_{\eta}\right)=(0.5,2)$. Os tempos são $t=0.5,1.0 \ldots 3.5$.

Figura 5.18 mostra a evolução temporal da interface de deslocamento 
de um fluido não newtoniano por um newtoniano para $\left(w, R_{\eta}\right)=(0.25,2)$. Os tempos mostrados são $t=0.5,1.0 \ldots 3.5$. Para $\lambda=0.26$, figura 5.18 (a), a interface se mostra mais larga e com menor avanço do que a simulação com o tempo de realxação $\lambda=18$, mostrada na figura 5.18(b). Aparentemente, a interface se desenvolve até atingir uma largura constante, para os dois casos. Estas características serão discutidas posteriormente.

Como foi feito anteriormente, definimos a posição mais a jusante da interface como $z_{\text {tip }}$. Figura 5.19(a) mostra o avanço da ponta da interface próxima de uma taxa constante para os parâmetros $\left(w, R_{\eta_{1}}\right)=(0.25,1)$ e $\lambda=0.26,1.43,18$ em função do tempo adimensional $t$, quando o fluido deslocador é não newtoniano. O tempo de relaxação tem pouca influência na taxa de avanço da ponta da interface, e apresenta uma leve diminuição da taxa de avanço quando $\lambda$ aumenta. Figura 5.19 b) mostra o comportamento de $z_{\text {tip }}$ para os mesmos parâmetros reológicos e geométricos quando o fluido deslocado é não newtoniana. Um aumento da taxa de avanço quase constante foi observado, e uma maior sensibilidade a variações de $\lambda$ é obtida.
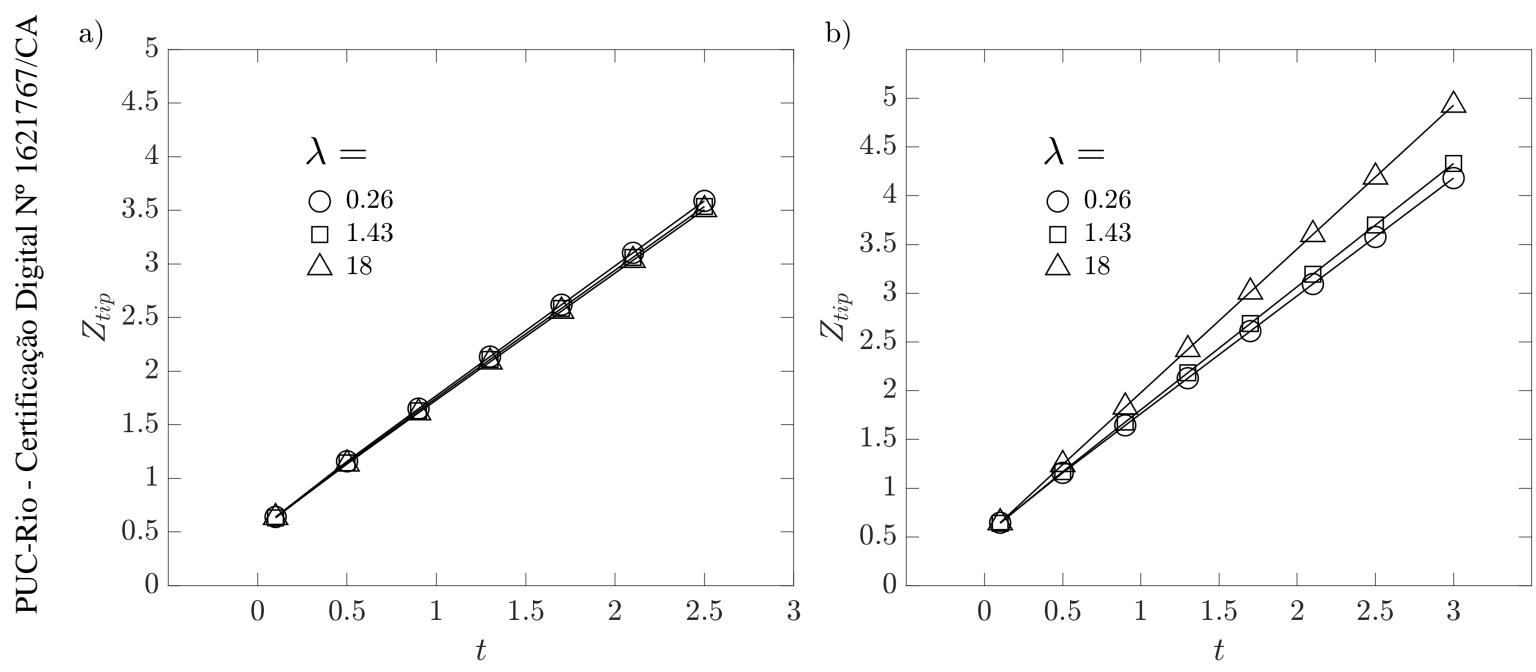

Figura 5.19: Posição da ponta da interface $z_{\text {tip }}$ em função do tempo adimensional $t$. Os parâmetros foram fixados em $\left(w, R_{\eta_{1}}\right)=(0.25,1)$ quando o fluido não newtoniano é a) injetado b) deslocado.

A figura 5.20 mostra a velocidade da ponta da interface $u_{t i p}$ em função do tempo de relaxação $\lambda$ para todos os parâmetros simulados. A figura 5.20(a) exibe uma velocidade $u_{\text {tip }}$ menor quando o tempo de relaxação $\lambda$ aumenta, para fluidos não newtonianos deslocando newtonianos. Subsequentemente, uma diminuição mais acentuada de $u_{\text {tip }}$ entre $\lambda=0.26$ e 1.43 foi observada. Note que para o menor $w$ simulado, foram obtidas velocidades maiores da ponta da interface, para todo $\lambda$. Figura 5.20 b) mostra que a velocidade da 
ponta da interface $u_{t i p}$ aumenta quando o tempo de relaxação aumenta, sendo que o fluido não newtoniano é o deslocado. A maior variação de $u_{t i p}$ dá-se entre $\lambda=1.43$ e 18 , caso contrário do que foi observado na figura 5.20(a). Mais uma vez, o maior $w$ gerou a maior velocidade da ponta. Os resultados refletem que a escolha da viscosidade do fluido deslocador influencia na velocidade de avanço da ponta da interface.
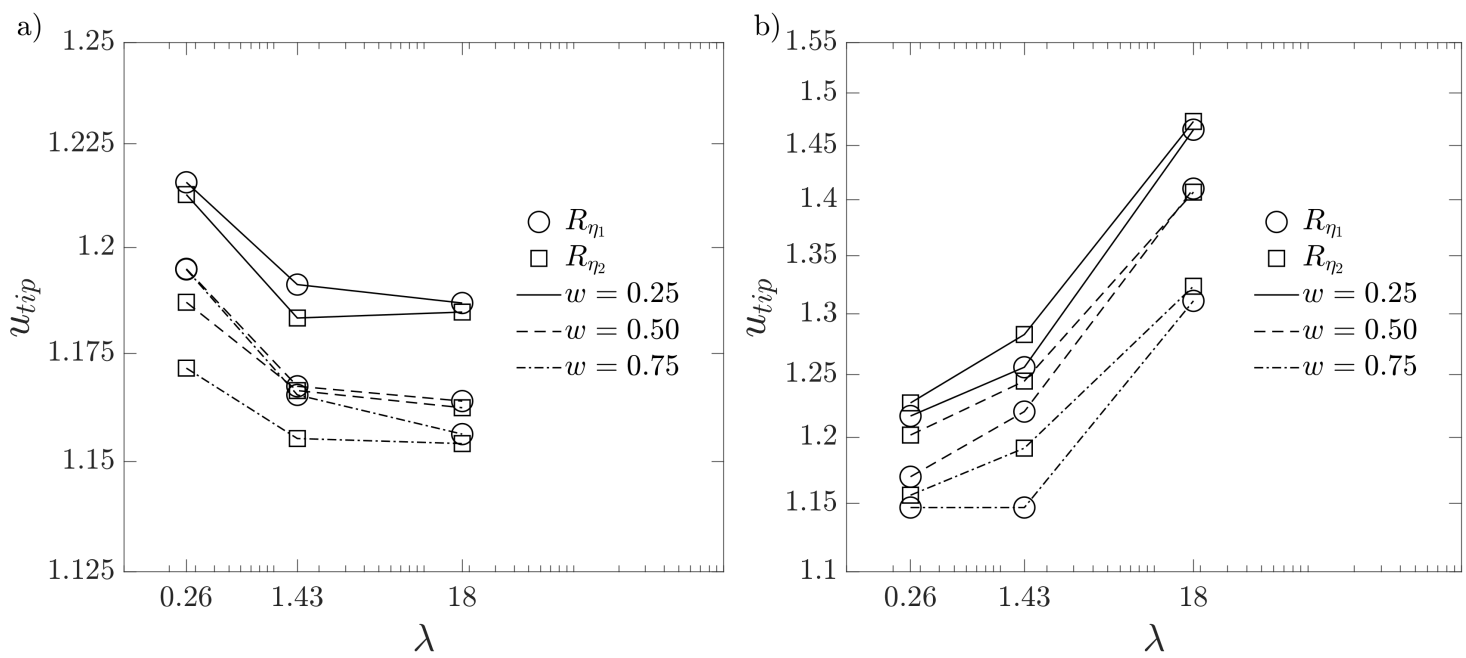

Figura 5.20: Velocidade da ponta da interface de deslocamento $u_{t i p}$ em função do tempo de relaxação $\lambda$. Os parâmetros são $w=0.25,0.50,0.75$ e $R_{\eta}=1,2$ quando a viscosidade é não newtoniana do fluido a) deslocador b) deslocado.

A figura 5.21 mostra o desvio radial da ponta da interface, $r_{t i p}$, em função do tempo de relaxação $\lambda$. Na figura 5.21(a) observa-se que para o maior $w$, i.e., para a menor folga anular estudada, $r_{t i p}$ depende do tempo de relaxação. Para os demais casos, i.e. $w=0.25$ e $w=0.50, r_{\text {tip }}$ independe tanto do tempo de relaxação quanto das viscosidades $R_{\eta}$. Devido a simetria radial, a aproximação do espaço anular como sendo placas planas paralelas se mostra viável para a menor distância anular $w=0.75$. A figura 5.21(b) mostra o desvio radial da ponta da interface, $r_{t i p}$, em função do tempo de relaxação quando o fluido deslocado é não newtoniano. De modo geral, ao aumentar $\lambda, r_{\text {tip }}$ se afasta do eixo de simetria em direção à parede interna do espaço anular. A consideração de um deslocamento entre placas paralelas será factível para a combinação da maior razão de diâmetros e menor tempo de relaxação simulados. As viscosidades $R_{\eta}$ influenciam o sistema apenas para a combinação do maior $\lambda$ e o menor $w$ investigados.

A velocidade quase estacionária da ponta da interface, $u_{t i p}$, para cada um dos tempos de relaxação $\lambda$ (vide figura 4.7) e viscosidades, $R_{\eta}$, quando o fluido deslocador é não newtoniano é mostrada na figura 5.22(a) em 

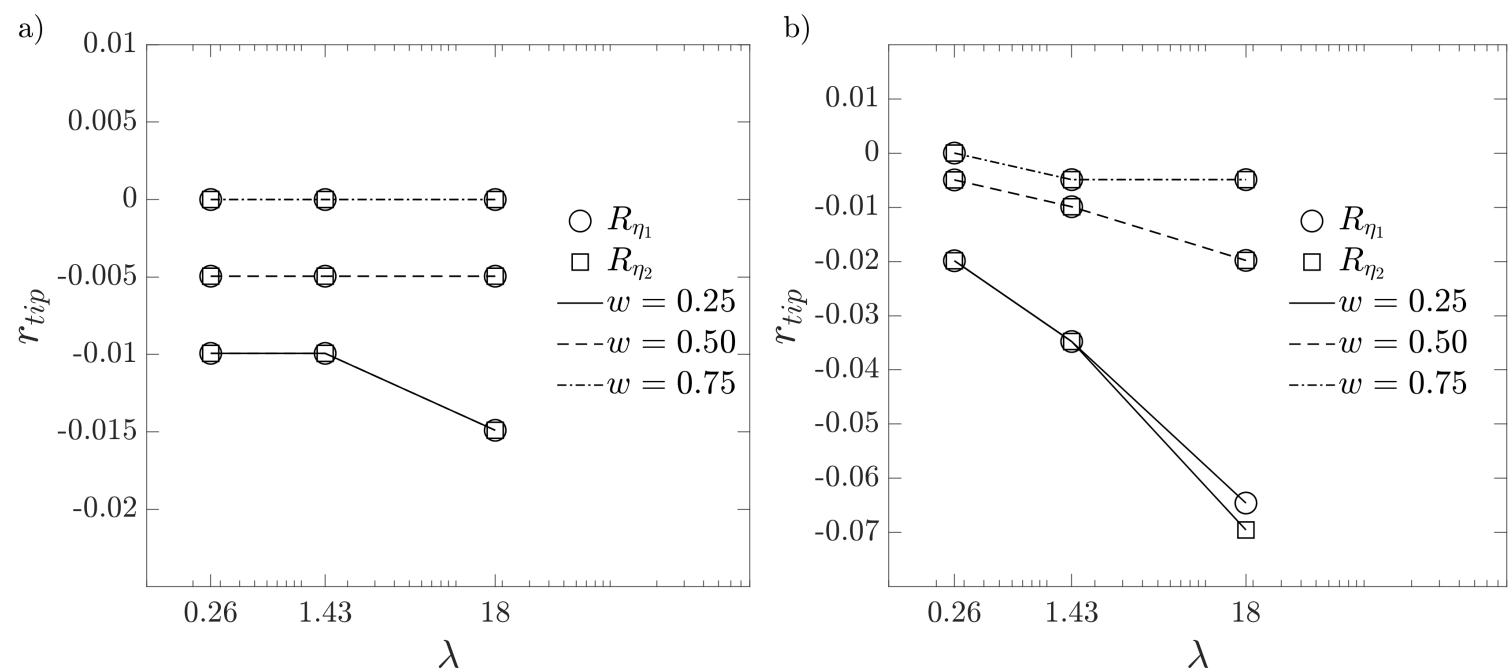

Figura 5.21: Desvio radial $r_{\text {tip }}$ em função de $\lambda$, para todos os parâmetros investigados.

símbolos abertos. Aqui, mantemos fixo o tempo adimensional $t=3.8$ e a razão de diâmetros $w=0.5$. As viscosidades $\eta_{0}$ e $\eta_{\infty}$, que representam os plateaus newtonianos do fluido de Carreau, foram usadas como razões de viscosidades em simulações com dois fluidos newtonianos. Esses resultados de $u_{t i p}$ com fluidos newtonianos são representados por símbolos fechados. Observamos que as velocidades das interfaces quando o fluido não newtoniano é injetado são maiores que a velocidade do deslocamento viscosamente estável envolvendo fluidos newtonianos. Observamos também que essas velocidades são menores do que as velocidades dos deslocamentos newtonianos viscosamente instáveis. Em outras palavras, um fluido não newtoniano, para diferentes $\lambda$, deslocando um newtoniano tem uma velocidade $u_{t i p}$ maior que um deslocamento estável entre dois newtonianos de razão de viscosidade $\eta_{\infty}$ e menor que um deslocamento instável com razão de viscosidade $\eta_{0}$. A figura $5.22(b)$ mostra a velocidade da ponta $u_{t i p}$ quando o fluido deslocado é não newtoniano, para os mesmos parâmetros da figura 5.22(a). Para todos os casos, foram observadas velocidades $u_{t i p}$ comparáveis com a configuração anterior, i.e., a velocidade $u_{t i p}$ do deslocamento com um fluido não-newtoniano apresenta valores intermediários entres as velocidades $u_{t i p}$ esperadas dos deslocamentos entre fluidos newtonianos. Além disso, o tempo de relaxação $\lambda$ manifesta uma maior influência na velocidade $u_{t i p}$.

A figura 5.23 mostra a evolução das interfaces para $\left(w, R_{\eta}\right)=(0.5,1)$ e $t=0,0.5 \ldots .5 .5$. Os deslocamentos quando um fluido não newtoniano é injetado são apresentadas nas figuras $5.23(a, b)$ para $\lambda=0.26$ e 18, respectivamente. Nas figuras, a largura da interface atinge um valor constante $\zeta$, para os dois 

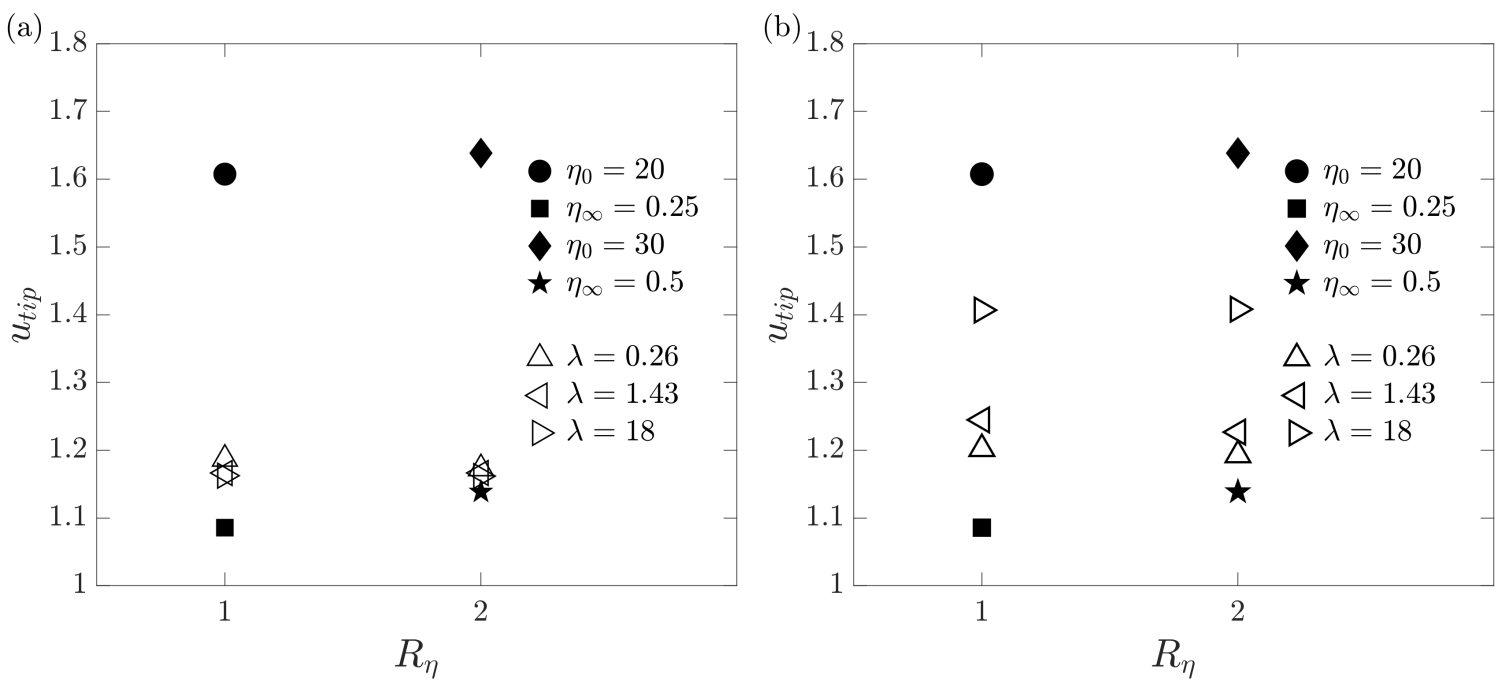

Figura 5.22: Velocidade da ponta da interface $u_{t i p}$ em função da razão de viscosidade $R_{\eta}$ para $(w, t)=(0.5,3.8)$ e $\lambda=0.26,1.43,18$. A figura representa o deslocamento quando um fluido não newtoniano foi considerado como $a$ ) deslocador $b$ ) deslocado.

tempos de relaxação $\lambda$. Além disso, os diferentes avanços da frente da interface, descritos na figura 5.19(a), também podem ser observados. Por outro lado, as figuras 5.23 (c,d) mostram as interfaces do deslocamento quando um fluido não newtoniano é o fluido deslocado para $\lambda=0.26$ e 18, respectivamente. Mais uma vez, a interface atinge uma largura constante posterior a um tempo de transição. O comportamento da velocidade da ponta $u_{\text {tip }}$, em todos os casos, concorda com o descrito na figura 5.20(b).

Analogamente, como foi realizado com o deslocamento entre fluidos newtonianos (vide figura 5.8), a figura 5.24 mostra a largura $m$ em função do tempo $t$. Os parâmetros são $\left(w, R_{\eta}\right)=(0.25,1)$ e $\lambda=0.26,1.43,18$. Para todos os tempos de relaxação, a largura $m$ apresenta um valor constante após de um tempo de transição. Isto permite realizar uma análise do parâmetro $m$ usando a abordagem sugerida na equação 5-2. Note que quanto menor é $\lambda$, a interface atinge uma largura $m$ constante com maior celeridade.

A figura 5.25(a) mostra a largura $m$ em função do tempo de relaxação $\lambda$ quando o fluido deslocador é não newtoniano. Note que quando $\lambda$ aumenta, maiores $m$ se geram, indicando que a largura da interface aumenta dentro do espaço anular. Além disso, a razão de diâmetros $w$ e as viscosidades $R_{\eta}$ também mostraram-se influentes. A maior largura $m$ foi obtida para o maior $w$ e $R_{\eta}=2$ quando $\lambda=18$. A figura 5.25(b) mostra a influência de $\lambda$ na largura $m$ quando o fluido deslocado é o não newtoniano. Para todas as configurações geométricas e parâmetros reológicas, $m$ diminui com o aumento de $\lambda$, indicando 
(a)

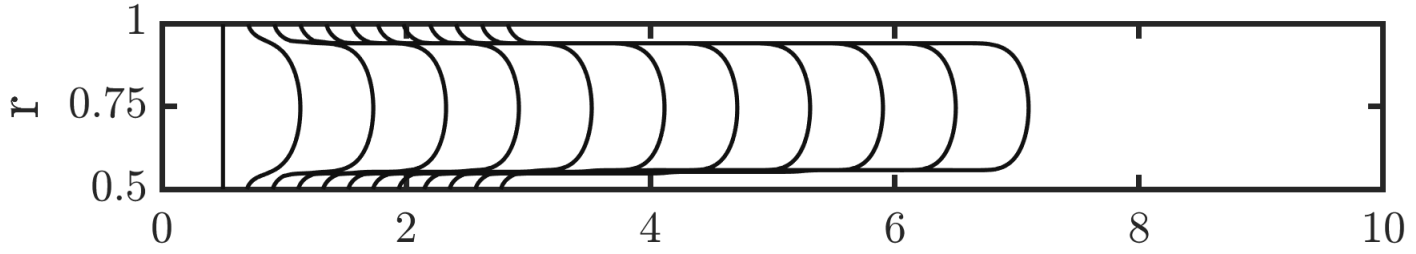

(b)

$\mathrm{Z}$

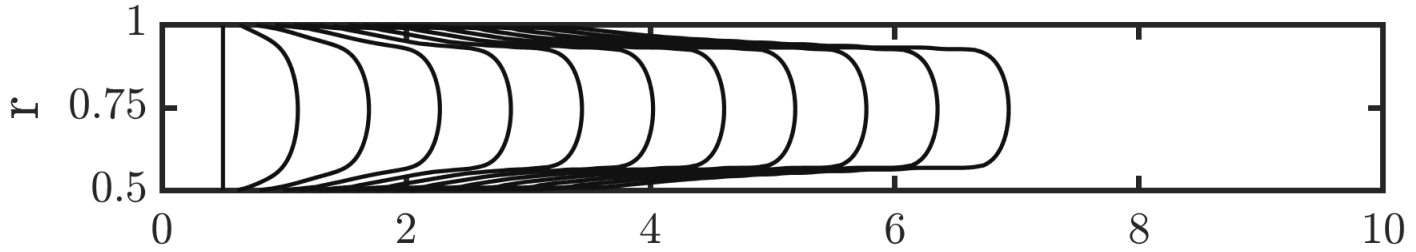

(c)

$\mathrm{Z}$

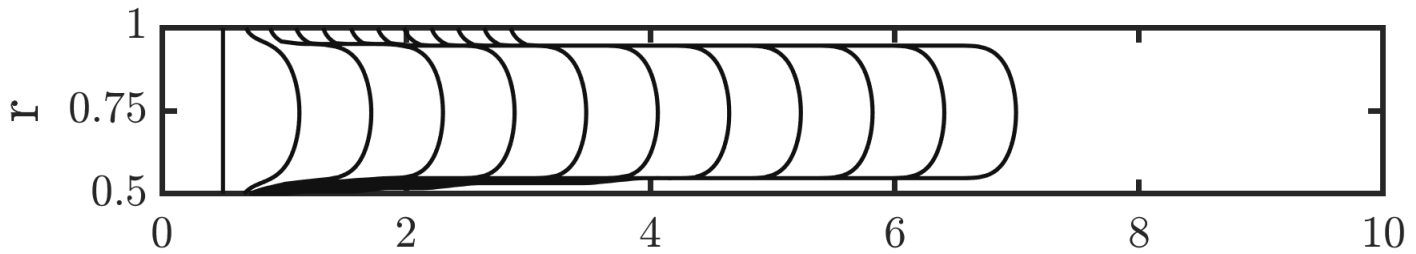

(d)

$\mathrm{Z}$

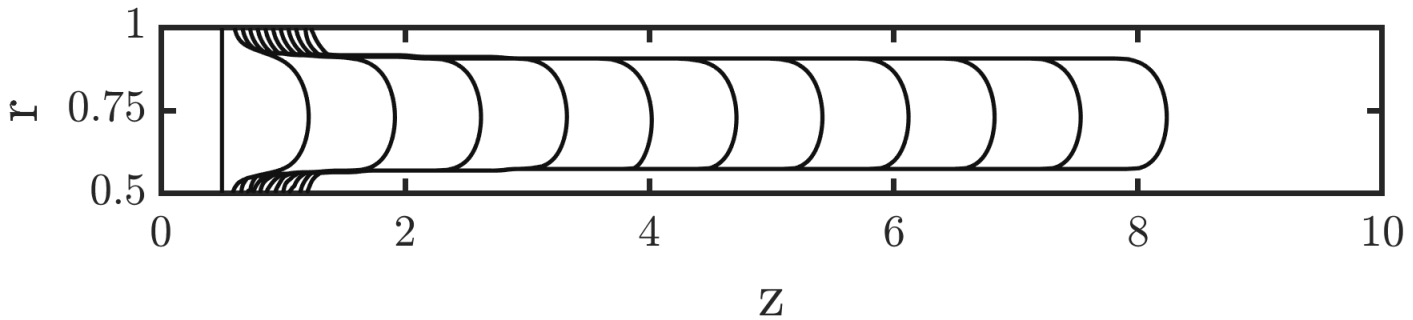

Figura 5.23: Desenvolvimento temporal da interface de deslocamento para $\left(w, R_{\eta}\right)=(0.5,1)$ e $t=0,0.5 \ldots .5 .5$. Figuras $(a, b)$ são representações quando o fluido deslocador para $\lambda=0.26$ e 18 , respetivamente. Figuras $(c, d)$ mostram as interfaces quando o fluido não newtoniano foi deslocado. Os tempos de relaxação simulados foram $\lambda=0.26$ e 18 , respetivamente.

que o tempo de relaxação ingere fortemente na largura. De acordo com esses resultados, a largura da interface depende não somente do tempo de relaxação $\lambda$. Menores razões de diâmetros e a viscosidade $R_{\eta_{1}}$ desenvolvem maiores $m$.

A figura 5.26(a) mostra o módulo do campo de velocidades $|\vec{u}|$ e o campo de velocidade $\vec{u}$ para deslocamentos quando o fluido não newtoniano é o deslocador e parâmetros $\left(w, R_{\eta}, \lambda, t\right)=(0.75,1,0.26,4.3)$. O sistema de referência foi o mesmo utilizado no deslocamento entre fluidos newtonianos das figuras 5.14 e 5.15, e move-se com a velocidade da ponta da interface. Para todos os casos, o ponto de estagnação foi observado na posição de $z_{\text {tip. }}$. O campo de velocidade a jusante da interface mostra que o fluido perto das paredes tem 


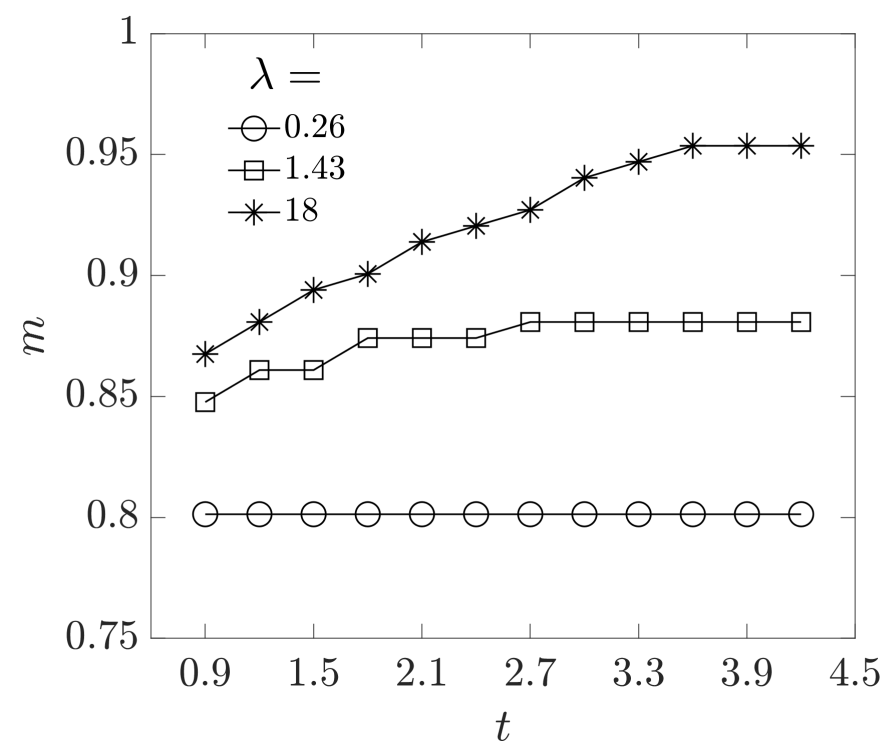

Figura 5.24: Largura $m$ em função do tempo adimensional $t$ para $\left(w, R_{\eta}\right)=$ $(0.25,1)$ e $\lambda=0.26,1.43,18$.
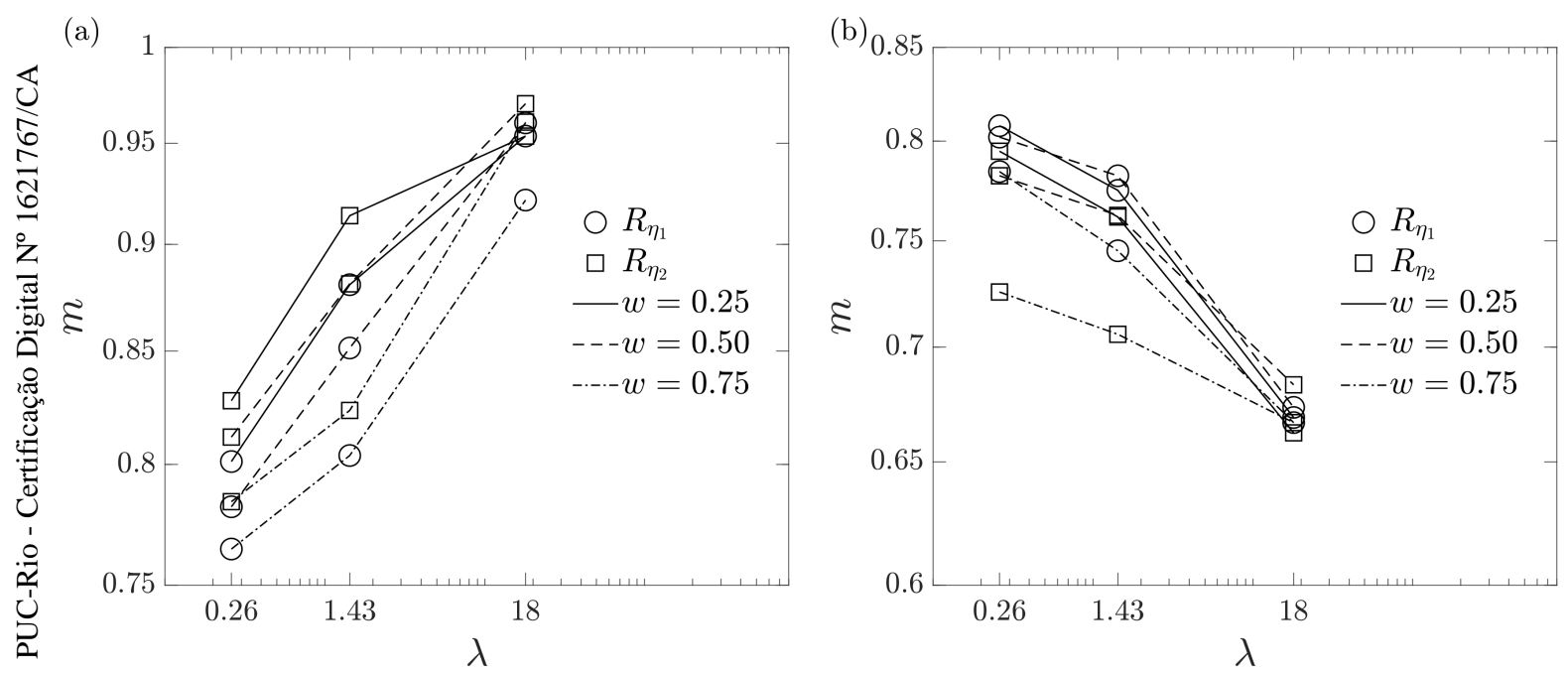

Figura 5.25: Largura $m$ em função do tempo de relaxação $\lambda$ para $w=0.25,0.5,0.75$ e $R_{\eta}=1,2$. A figura representa um deslocamento quando o fluido não newtoniano é $a$ ) deslocador $b$ ) deslocado.

um sentido contrario à do sentido do deslocamento, e no mesmo sentido na parte central do espaço anular. Cabe enfatizar que esta configuração do campo de velocidade do fluido deslocado é similar para todos os casos simulados, onde a maior intensidade foi observado próximo das paredes. A figura 5.26(b) mostra o deslocamento para os mesmos parâmetros que os simulados na figura 5.26(a) para $\lambda=1.43$. Note que uma região de mobilidade reduzida aparece atrás da interface, induzido pelo aumento do tempo de relaxação. Ademais, 
(a)

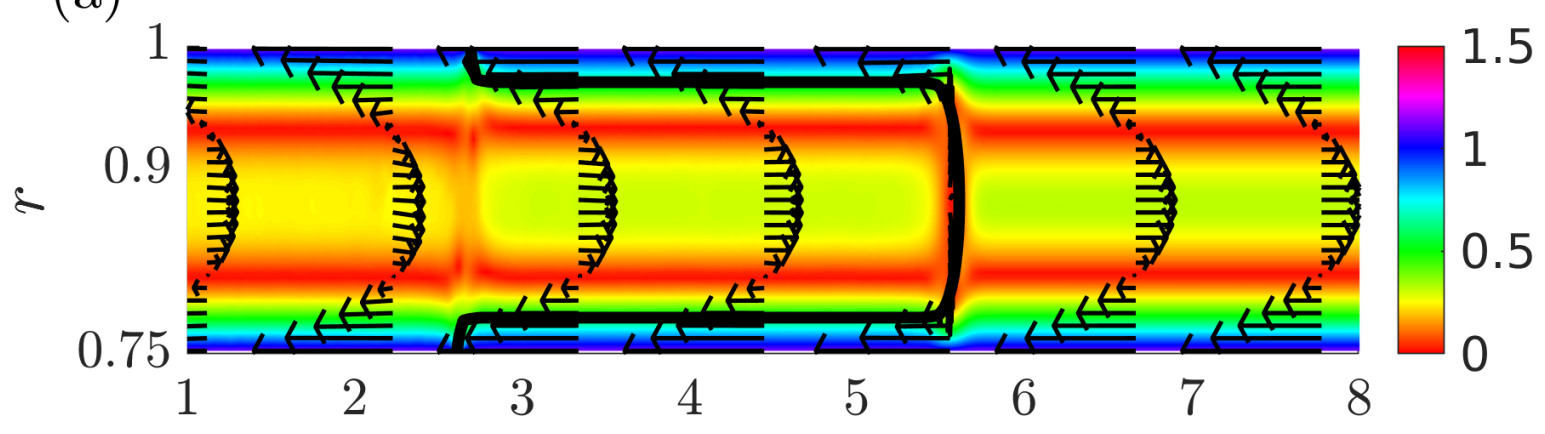

(b)

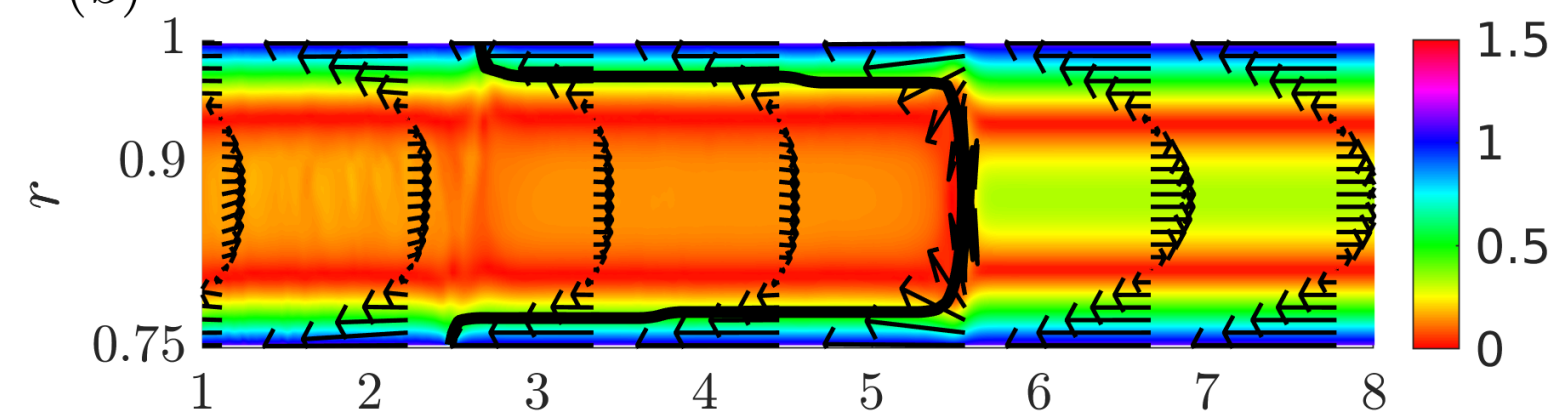

(c)

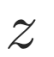

\&

0.9

1

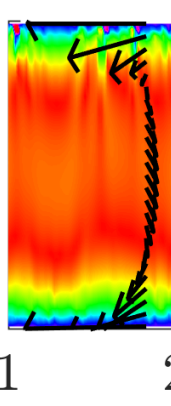

0.75

12

23

34

$z$

Figura 5.26: Módulo do campo de velocidades $|\vec{u}|$ e campo de velocidades $\vec{u}$ quando o fluido não newtoniano é deslocador, para tempos de relaxação $\lambda=$ a) 0.26 , b) 1.43 , c) 18 para $\left(w, R_{\eta}, t\right)=(0.75,1,4.3)$.

uma interface de largura maior que o caso anterior é observado. A figura 5.26(c) mostra o deslocamento quando $\lambda=18$. A interface com uma largura que abrange quase a totalidade do espaço anular e regiões de baixa velocidade atrás da interface são observadas.

A figura 5.27(a) mostra o campo de velocidades $\vec{u}$ e o módulo do campo de velocidade $|\vec{u}|$ quando um fluido não newtoniano é deslocado para um tempo de relaxação $\lambda=0.26$ e $\left(w, R_{\eta}, t\right)=(0.75,1,4.3)$. Foi observado um campo e módulo de velocidade semelhante à da figura $5.26 a$ ). Atrás da interface, escoamentos 


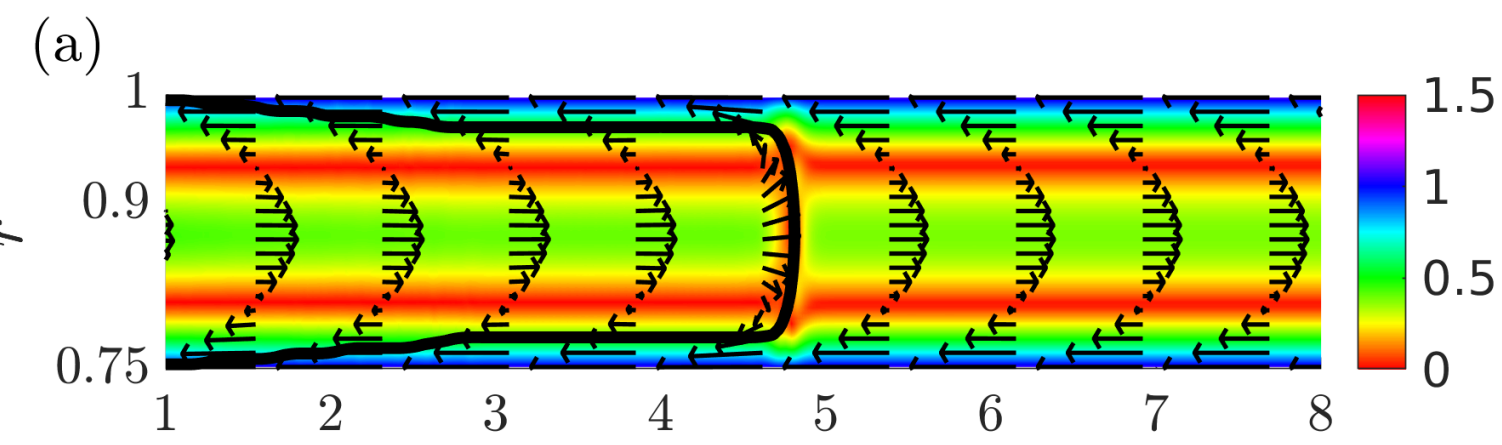

(b)

$z$

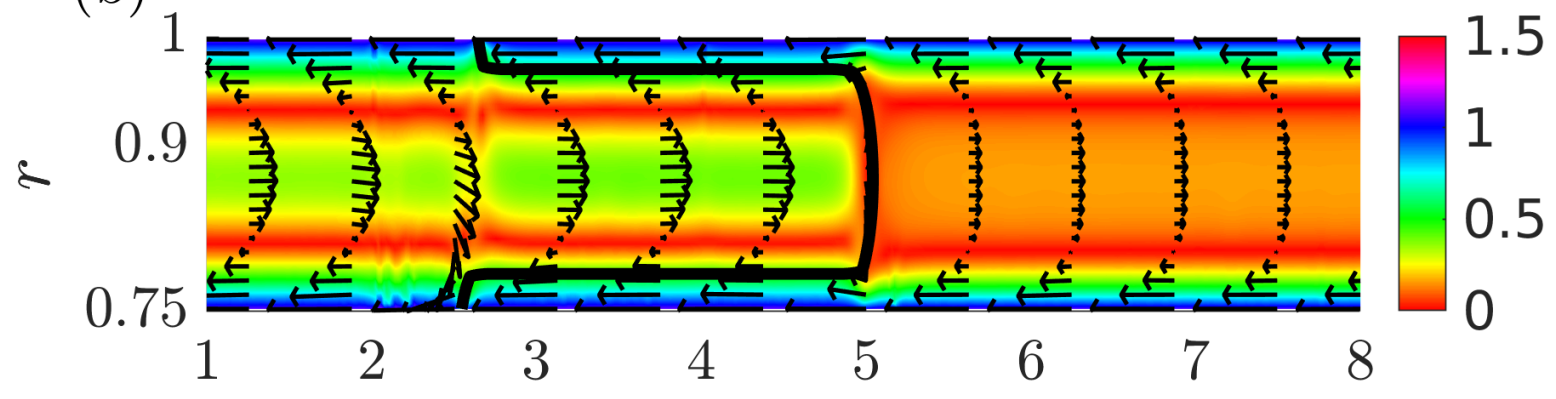

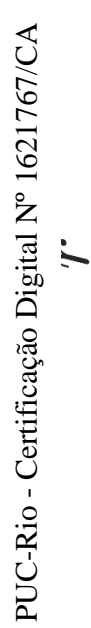

(c)

$z$

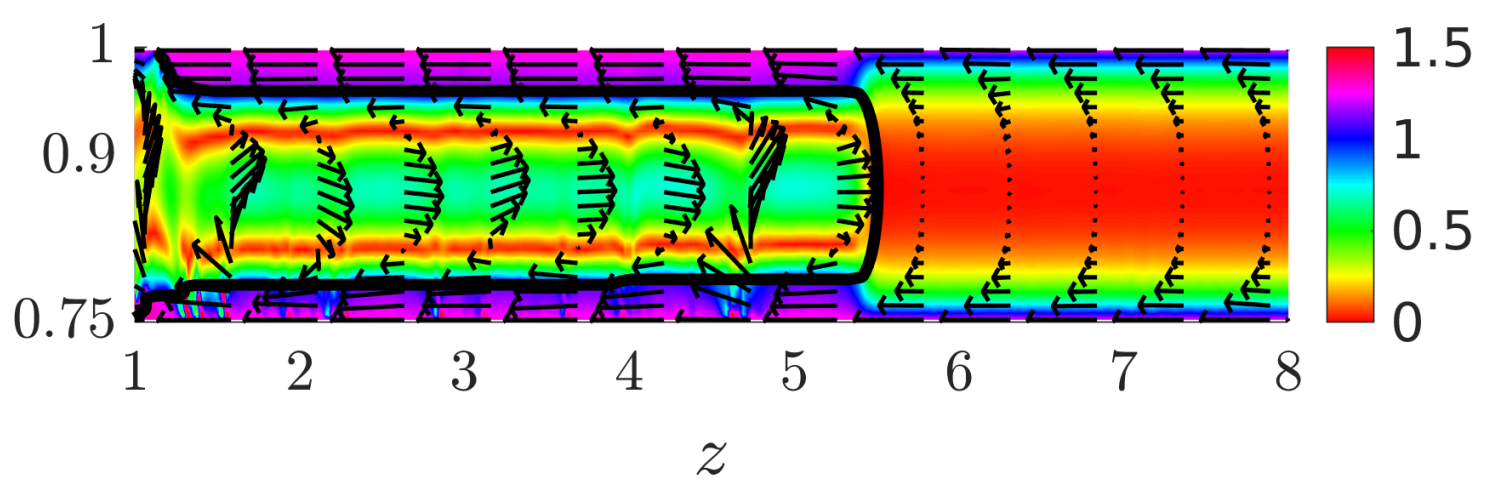

Figura 5.27: Módulo do campo de velocidades $|\vec{u}|$ e campo de velocidades $\vec{u}$ quando um fluido newtoniano desloca um não newtoniano com tempo de relaxação $\lambda=$ a) 0.26 , b) 1.43 , e c) 18 para $\left(w, R_{\eta}, t\right)=(0.75,1,4.3)$.

com sentido contrário do deslocamento em torno de uma região de fluido escoando com sentido de esquerda para direita foi apreciado. Para um tempo de relaxação de $\lambda=1.43$, figura 5.27 (b), a intensidade da velocidade na frente da interface, no sentido do deslocamento, mostra uma diminuição considerável na sua intensidade em comparação com aquele observado em 5.27(a). Este fenômeno é imputado ao aumento do tempo de relaxação. A figura 5.27(c) mostra um deslocamento para $\lambda=18$. A jusante da interface, uma região de 
baixa intensidade contornada por regiões de velocidades maiores foi observado. Entre a interface e as paredes do espaço anular foi percebido um aumento da intensidade da velocidade nos filmes finos. Este comportamento pode ser elucidado usando a conservação de massa e condições inicias da seguinte maneira. Para um deslocamento em regime permanente de um fluido com o maior tempo de relaxação simulado, a interface imiscível induz as partículas na frente dela a posicionar-se nos filmes finos entre a interface e as paredes do anular, o que necessariamente provoca um aumento da velocidade. Também foram observadas oscilações no campo de velocidades dentro da interface. Este comportamento pode estar atribuído à instabilidade de Kelvin-Helmholtz (122). A instabilidade surge durante o escoamento superposto de dois fluidos imiscíveis que possuem sentidos contrários de escoamento. A presença da instabilidade gera perturbações senoidais no campo de velocidades $(123,124)$ que induz à geração de vorticidades. Cabe enfatizar que este fenônemo só apareceu quando o fluido não newtoniano com tempo de relaxação $\lambda=18$ é deslocado.

A figura 5.28 mostra as linhas de corrente para $\left(w, R_{\eta}, t\right)=(0.75,1,4.4)$ quando o fluido não newtoniano é injetado. Figuras 5.28 a) e b) mostraram, atrás da interface, escoamentos de recirculação que transportam o fluido do centro para as paredes do anular. Figura 5.28 c) mostra as linhas de corrente para tempo de relaxação $\lambda=18$. Vórtices que se formaram a uma curta distância a jusante da frente da interface foram observados. Atrás destas estruturas, uma região de mobilidade reduzida foi evidenciada. Para todos os casos, os escoamentos de recirculação na frente da interface que transportam o fluido das paredes para o centro do espaço anular independem das mudanças nos padrões nas linhas de corrente do fluido deslocador.

Escoamentos de recirculação atrás e na frente da interface foram os padrões observados nas figuras 5.29 (a,b) para $\lambda=(0.26,1.43)$. Uma estrutura de vórtice é observada na figura 5.29 c) na região imediatamente atrás da frente da interface de deslocamento. Simultaneamente, o fluido não newtoniano deslocado é transportado lateralmente do centro para a região dos filmes finos, entre a interface imiscível e as paredes, na presença da frente da interface. Foi avistado a ausência de escoamentos de recirculação na frente da interface, qualitativamente semelhante às vistas em deslocamentos instáveis de fluidos newtonianos (vide figura 5.16).

\section{5}



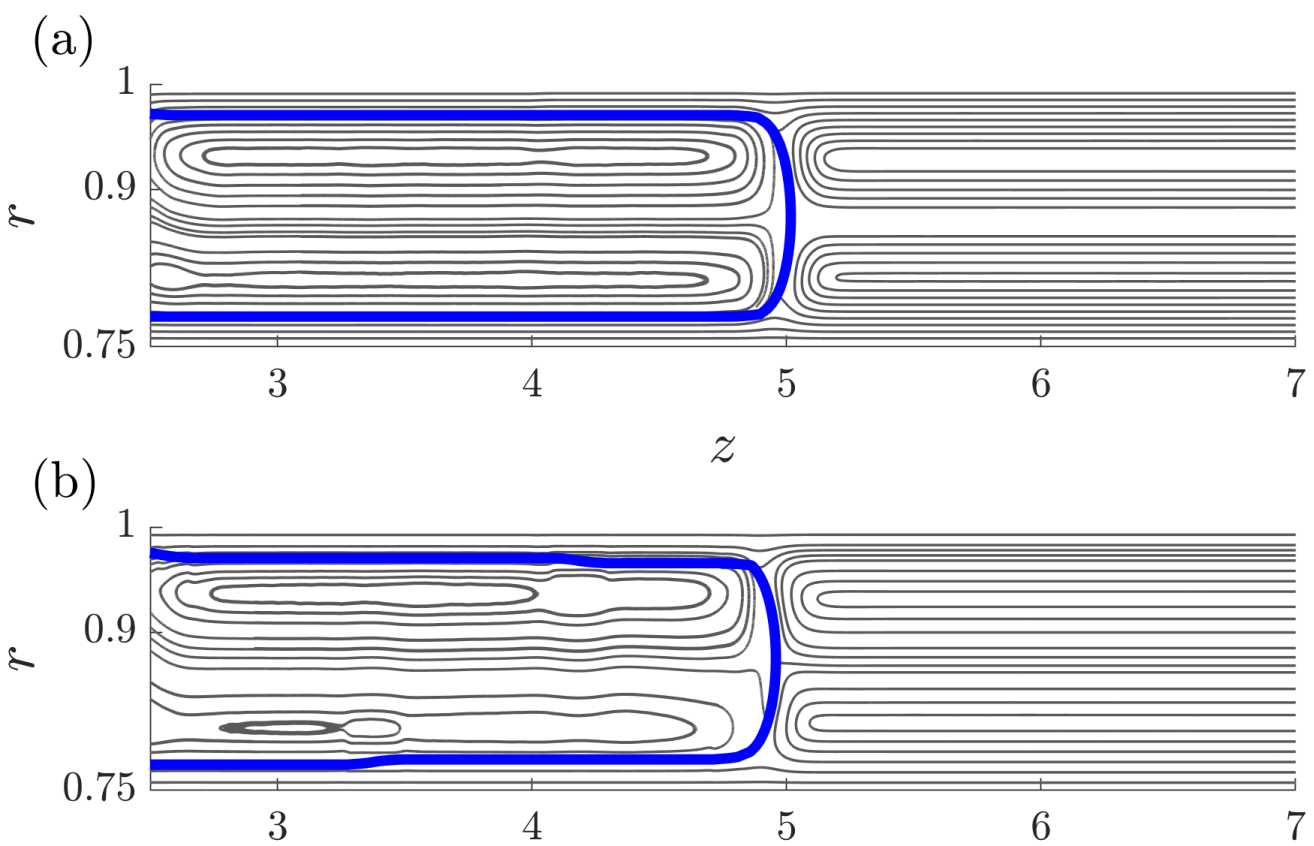

(c) $z$

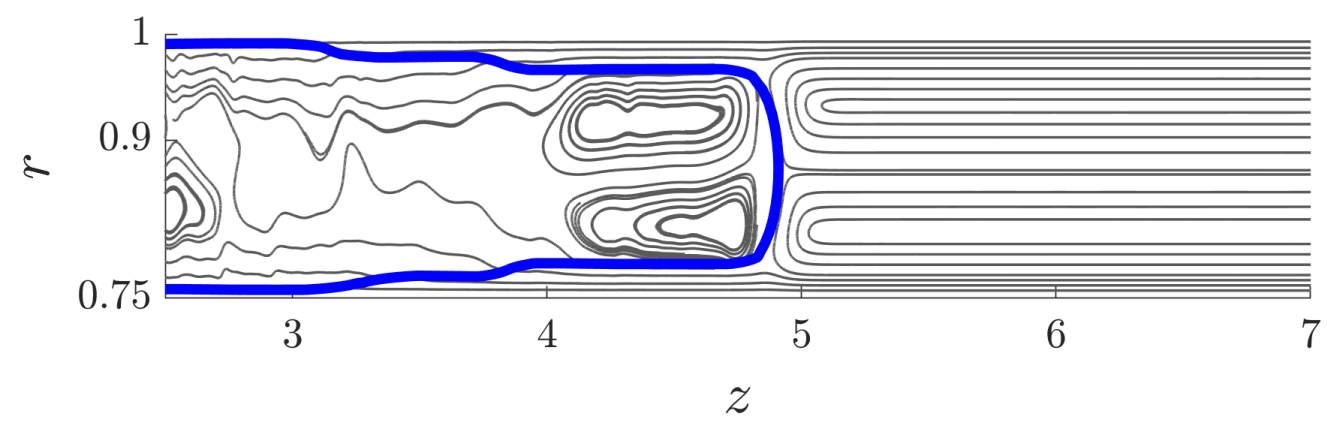

Figura 5.28: Linhas de corrente para $\left(w, R_{\eta}, t\right)=(0.75,1,4.4)$. quando um fluido não newtoniano desloca um newtoniano para $\lambda=$ a) 0.26 b) 1.43 c) 18 .

\section{Efeitos da tensão interfacial na forma da interface}

Na presente seção, nós focaremos na influência da tensão interfacial na topologia e características da interface que se formam durante o deslocamento em um espaço anular. O efeito da tensão interfacial é de equilibrar o salto da tensão normal ao longa da interface que se forma entre os fluidos imiscíveis $(92,125)$. Foram mantidos os parâmetros $(w, R e)=(0.5,1.0)$ constantes para todas as simulações newtonianas com razões de viscosidade $M=0.25$ e 20 . Foram também realizadas simulações envolvendo fluidos não newtonianos, sendo o fluido não newtoniano considerado como deslocador ou deslocado, onde os parâmetros $\left(w, R e, R_{\eta}, \lambda\right)=(0.5,1.0,1,1.43)$ são mantidos fixos.

A figura 5.30 a) mostra a posição axial da ponta da interface $z_{\text {tip }}$ em função do tempo adimensional $t$ para deslocamentos quando os fluidos envolvidos são newtonianos. As simulações com $C a=0.1$ foram obtidas das 


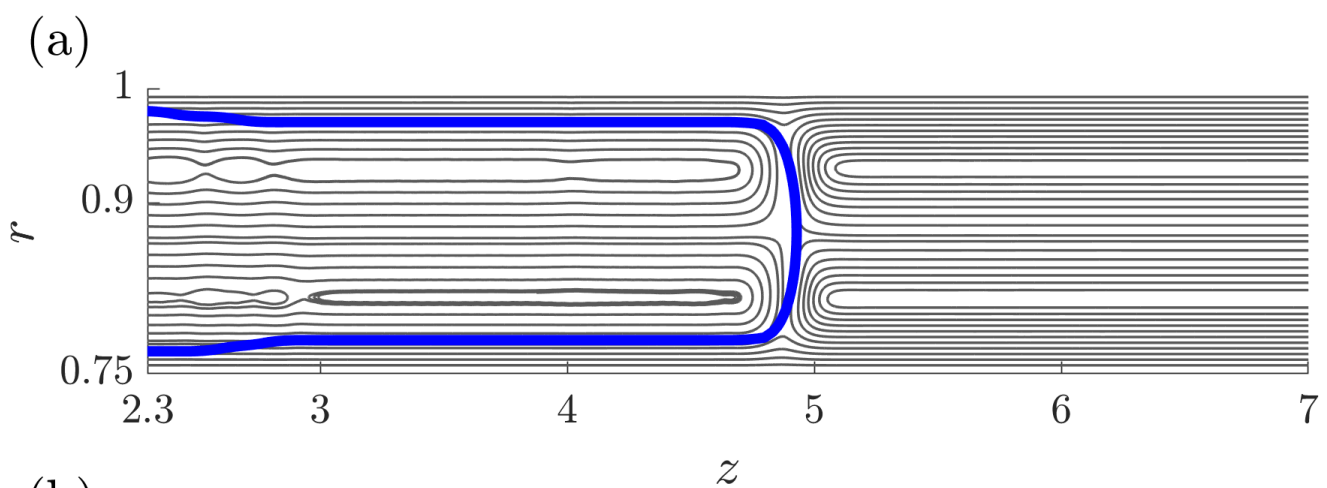

(b)

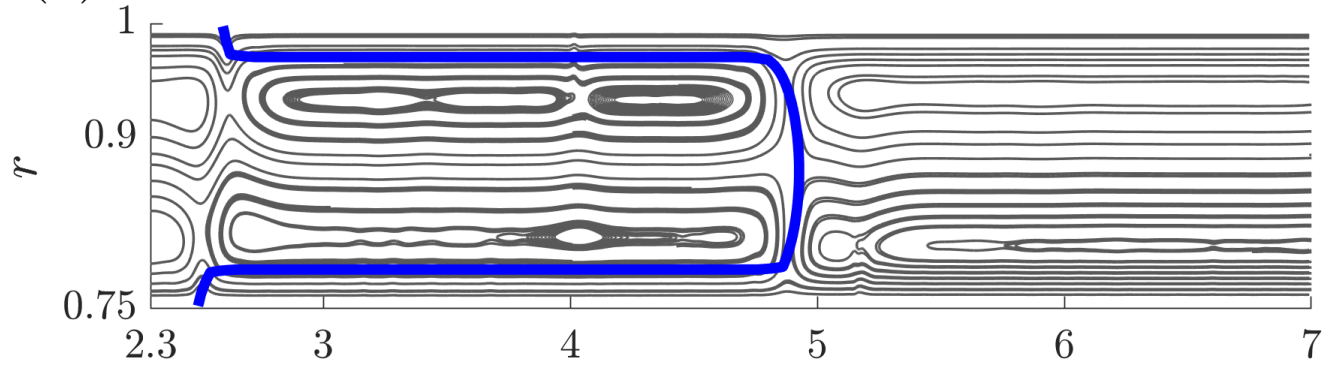

(c)

$z$

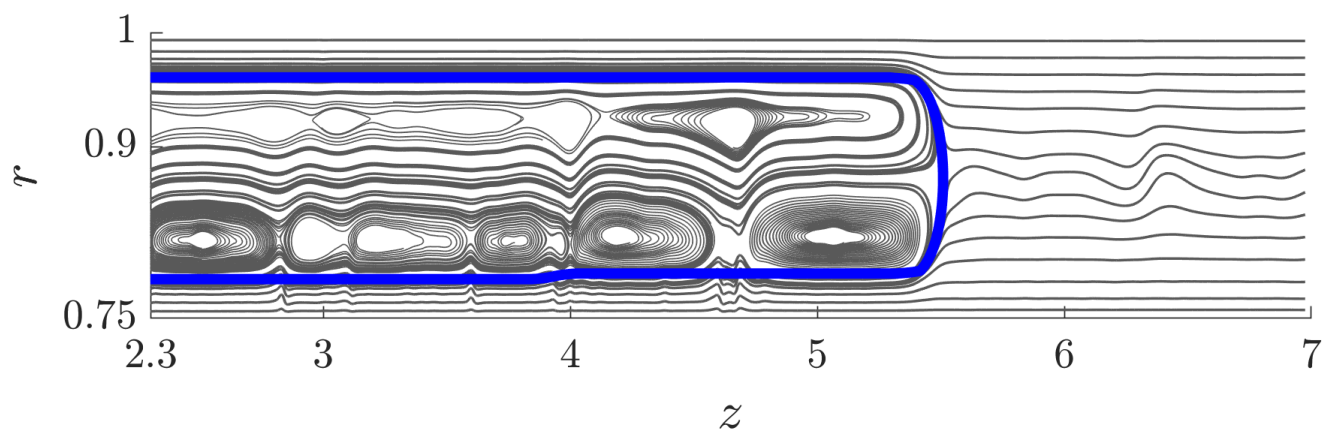

Figura 5.29: Linhas de corrente para $\left(w, R_{\eta}, t\right)=(0.75,1,4.4)$. quando um fluido não newtoniano é deslocado por um newtoniano para $\lambda=$ a) 0.26 b) 1.43 c) 18 .

seções anteriores. Para todos os casos, as interfaces com número de capilaridade $C a=1.0$ mostraram um avanço maior que os casos $C a=0.1$, para o mesmo $M$. Note que $C a$ mostra uma menor incidência no avanço da ponta da interface $z_{\text {tip }}$ para deslocamentos considerados viscosamente instáveis $(M>1)$. Figura 5.30 b) mostra as simulações quando um dos fluidos envolvidos possui função viscosidade não newtoniana. De forma geral, quanto maior é $C a$, maior é o avanço da ponta da interface. Os resultados mostram concordância qualitativa com os observados nas pesquisas desenvolvidas por Kang et al. (117), Dong et al. (116) e Chin et al. (126).

A figura 5.31 mostra a velocidade da ponta $u_{t i p}$ em função do número capilar $C a$, tanto para deslocamentos entre fluidos newtonianos como não newtonianos para o tempo adimensional $t=3.8$. De modo geral, o número 
a)

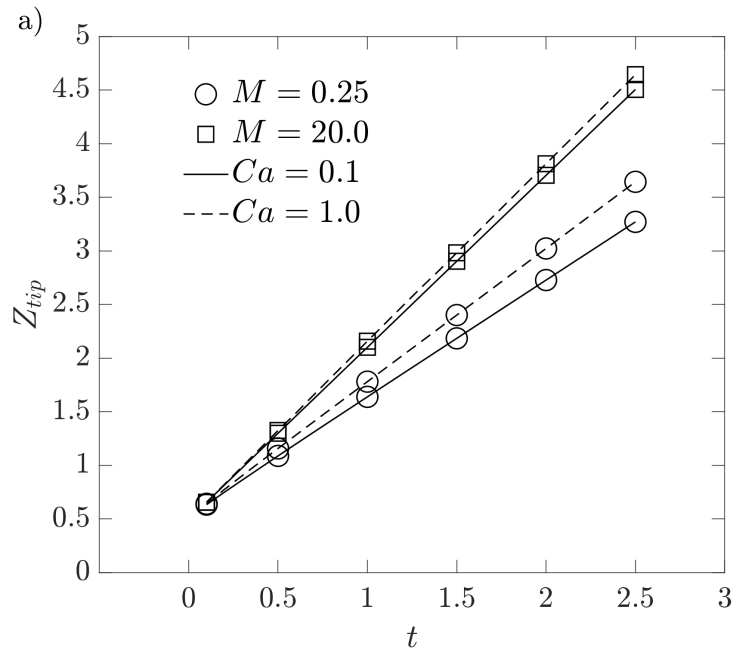

b)

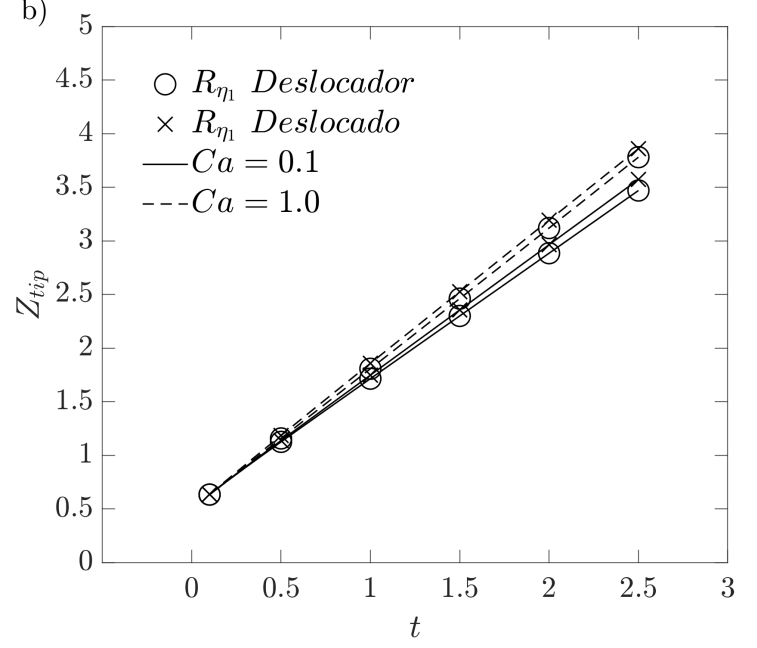

Figura 5.30: Posição da ponta da interface $z_{\text {tip }}$ em função do tempo adimensional $t$. Subfigura 5.30 a) mostra simulações entre fluidos newtonianos. Enquanto, subfigura $5.30 \mathrm{~b}$ ) mostra deslocamentos que envolvem um fluido não newtoniano sendo deslocador ou deslocado.

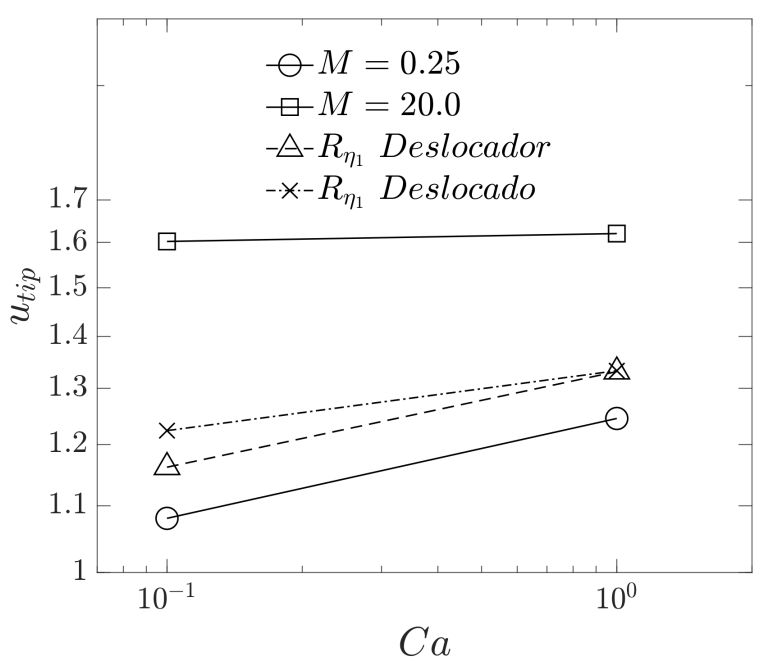

Figura 5.31: Velocidade da ponta da interface de deslocamento $u_{t i p}$ em função do número capilar $C a$. As linhas continuas representam deslocamentos entre fluidos newtonianos, tracejados quando o fluido deslocador é não newtoniano e linhas e pontos quando o fluido deslocado é não newtoniano.

capilar aumenta a velocidade da ponta da interface. Este comportamento é mais acentuado para deslocamento viscosamente estável e quando o fluido não newtoniano é o deslocador.

A figura 5.32 mostra que a ponta da interface possui um maior avanço para $C a=1.0$, em todos os casos. Também foi observado que a interface sofre um afinamento na sua largura. Esta característica é mais pronunciada para o deslocamento entre fluidos newtonianos considerados viscosamente estáveis 


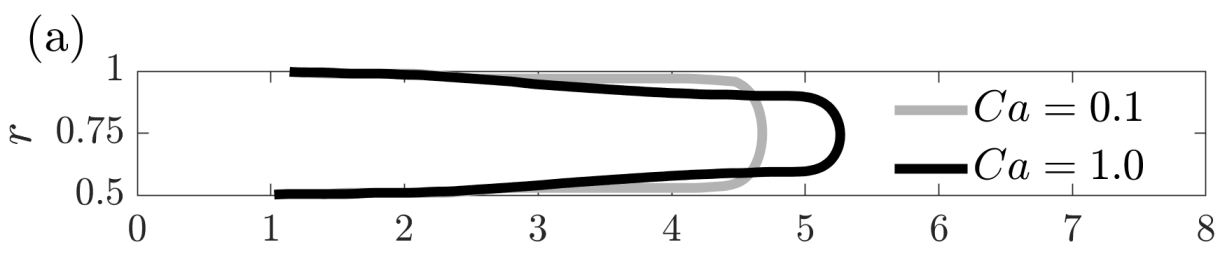

(b)

$z$

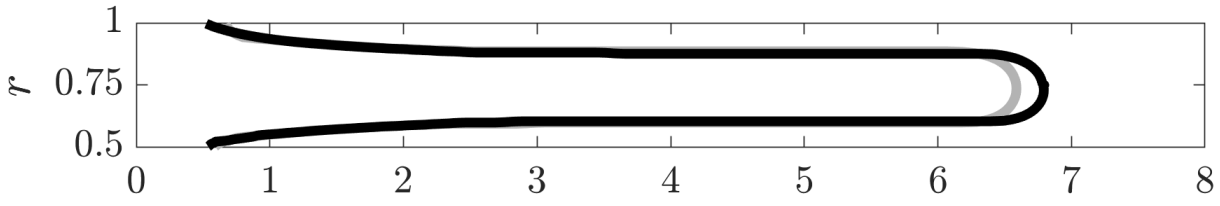

(c)

$z$

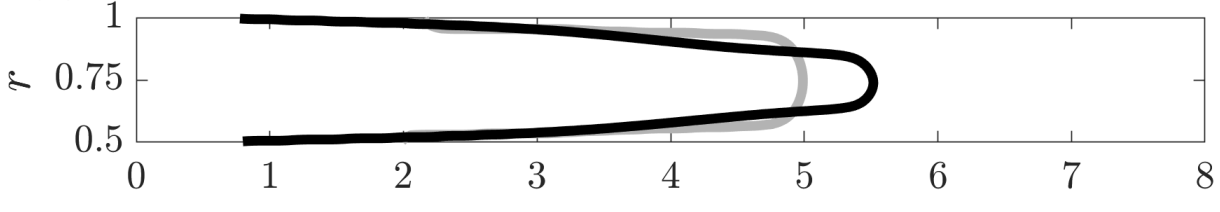

(d)

z

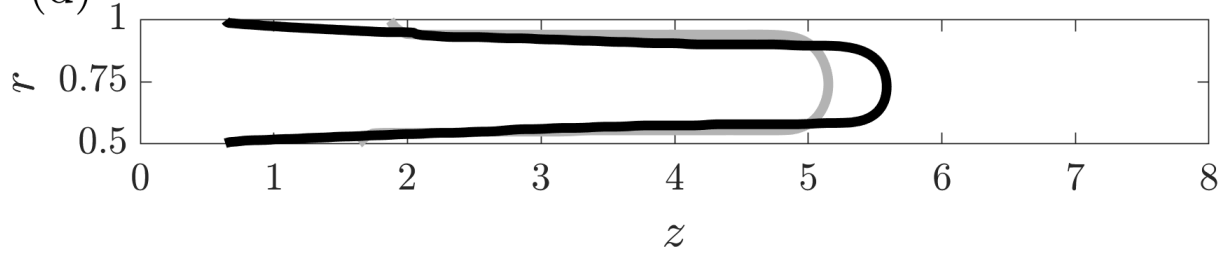

Figura 5.32: Interfaces geradas entre fluidos newtonianos de viscosidade $M=$ a) 0.25, b) 20.0 , e $\left(R_{\eta}, \lambda\right)=(1.0,1.43)$ quando o fluido não newtoniano é c) deslocador d) deslocado, para $C a=0.1$ e 1.0. O tempo adimensional, para todos os casos, é $t=3.8$.

(vide figura 5.32 a) e quando o fluido deslocador é não newtoniano (vide figura $5.32 \mathrm{c})$.

A figura 5.33 mostra a razão de largura $m$ em função da coordenada axial $z$ para o tempo adimensional $t=4$.5. Do modo geral, para maiores $C a$ o parâmetro $m$ não se mostra constante. Foi observado que a interface diminuiu consideravelmente na sua largura para deslocamentos considerados favoráveis.

\section{6}

\section{Fluido newtoniano deslocando outro newtoniano através de um espaço anular com expansão-contração abrupta.}

Nesta seção foi estudada as características da interface durante o deslocamentos de fluidos newtonianos de igual densidade, através um anular que possui expansão-contração abrupta reta localizada na parede externa do espaço anular (vide fig. 5.34).

Foram desenvolvidas simulações axissimétricas para quatro viscosidades 


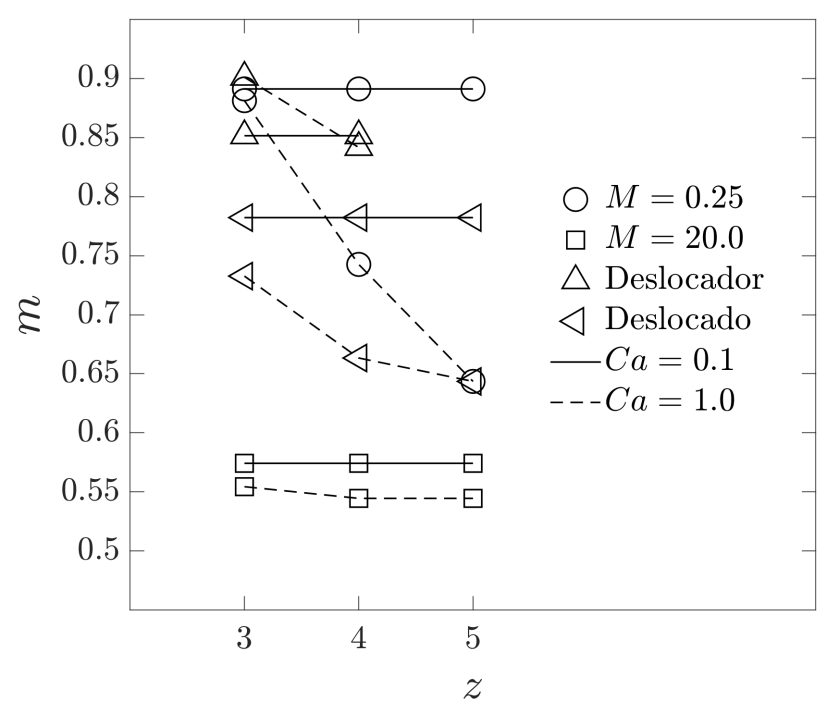

Figura 5.33: Razão de largura $m$ para diferentes posições $z$ e tempo adimensional $t=4.5$.

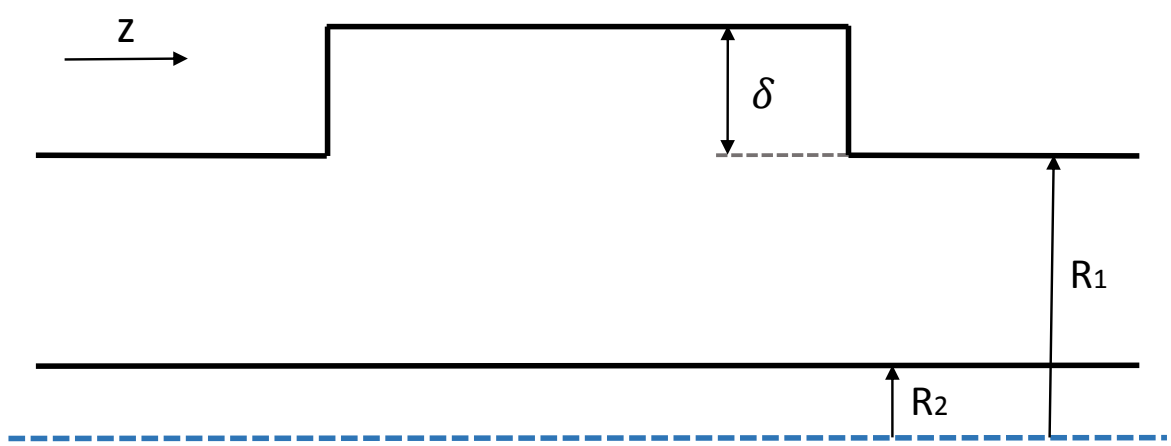

Figura 5.34: Representação esquemática o espaço anular continuo com uma alargamento abrupto na parede externa.

diferentes, $M=0.25,0.5,2$ e 3 . A razão de diâmetros se manteve constante em $w=0.75$ para todos os casos estudados. Número de Reynolds e Capilaridade foram fixados em $R e=1$ e $C a=0.1$. A expansão-contração tem um comprimento de $z=3$ com inicio em $z=3$ para um comprimento do anular de $z=10$. A expansão tem uma largura de $\delta=0.1$.

Figura 5.35 mostra a posição da ponta da interface $z_{\text {tip }}$ em função do tempo adimensional $t$ para diferentes razões de viscosidades $M$. A figura mostra dois comportamentos bem notórios da posição dependente do tempo. Para tempos iniciais, uma taxa quase constante de avanço, para todas as viscosidades foi observado. Uma segunda taxa menor, com início e fim em diferentes tempos dependentes da viscosidade foi apreciada. Finalmente, uma taxa de avanço igual à apresentada nos tempos iniciais foi observada. Além 


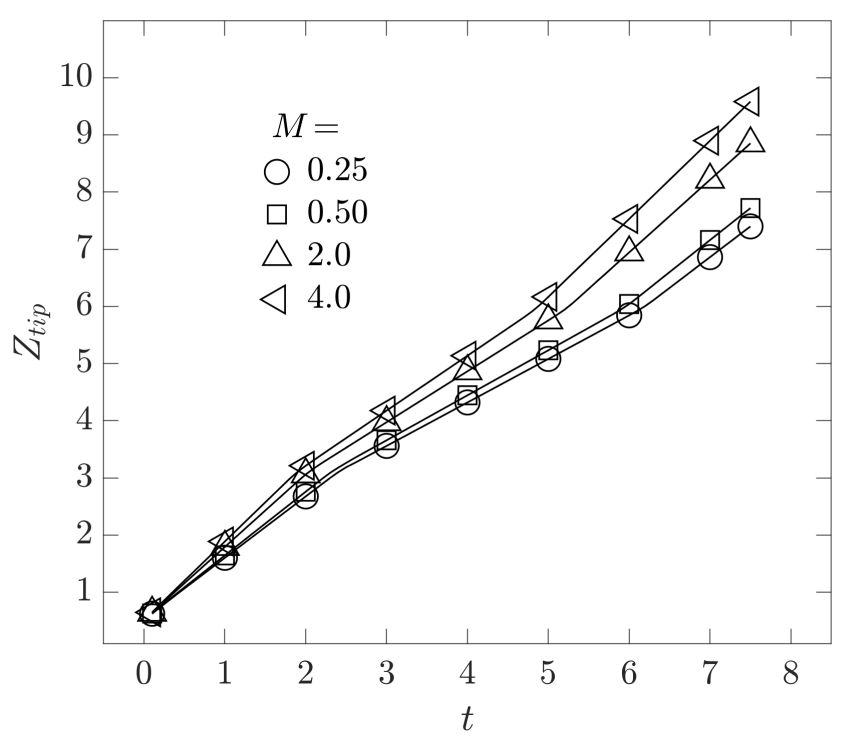

Figura 5.35: Posição da ponta da interface $z_{\text {tip }}$ em função do tempo adimensional $t$ para $(w, l, \delta, R e)=(0.75,3,0.1,1)$ e diferentes $M$.

disso, um maior avanço da posição da ponta da interface para maiores valores de $M$ foi visto.

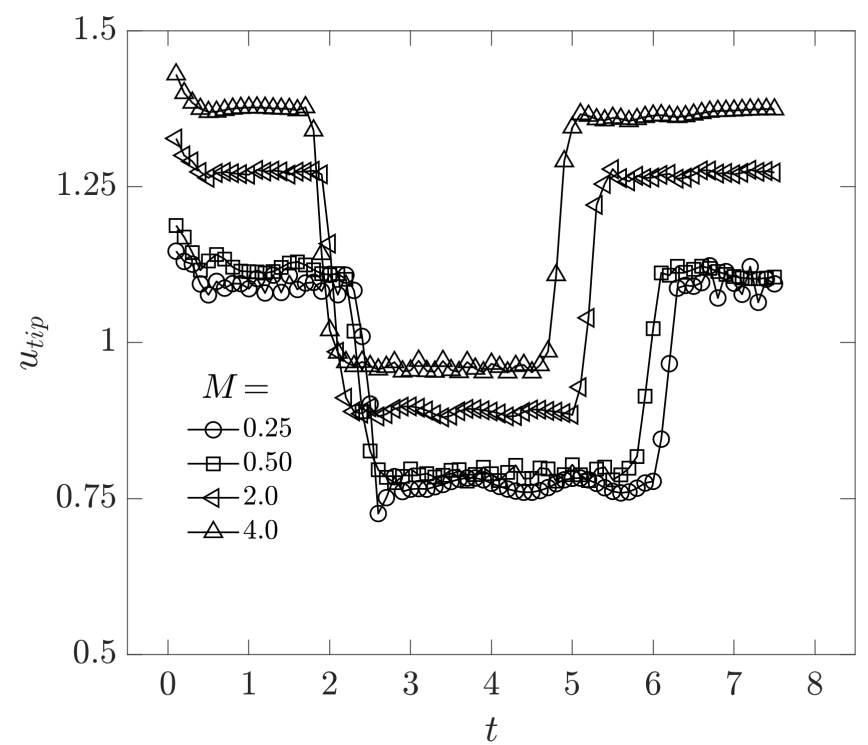

Figura 5.36: Velocidade da ponta da interface $u_{\text {tip }}$ em função do tempo adimensional $t$ para $(w, l, \delta, R e)=(0.75,3,0.1,10)$ e diferentes $M$.

Figura 5.36 mostra a velocidade da ponta $u_{t i p}$ em função do tempo adimensional $t$ para diferentes razões de viscosidades $M$. Os deslocamentos considerados viscosamente instáveis mostram velocidades quase constantes maiores que as velocidades dos deslocamentos estáveis. A seguir, foi observada uma queda abrupta da velocidade, em todos os casos. Este comportamento é 
atribuível à frente da interface que atinge a expansão-abrupta. Depois de um curto tempo de transição, a velocidade apresenta um comportamento quase estável menor que o observado em tempos iniciais. Finalmente, a velocidade da interface mostra uma transição abrupta para seu valor inicial quando a frente da interface atinge o início da contração. Esse comportamento é observado para todas as razões de viscosidade $M$.
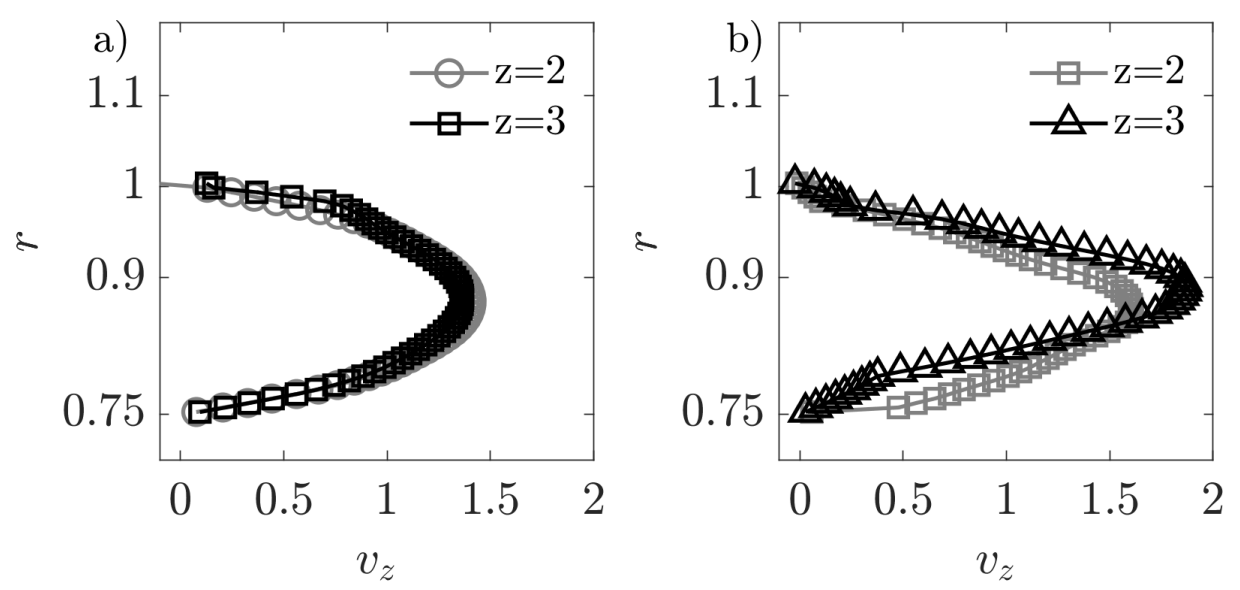

Figura 5.37: Comportamento da componente $v_{z}$ do campo de velocidade $\vec{u}$ para $M=$ a) 0.25 , b) 4 e $z=3$. Para cada subfigura, a componente $v_{z}$ do campo de velocidade desenvolvido dentro do espaço anular e na presença da expansão abrupta foram representadas em cor cinza e preto, respetivamente.
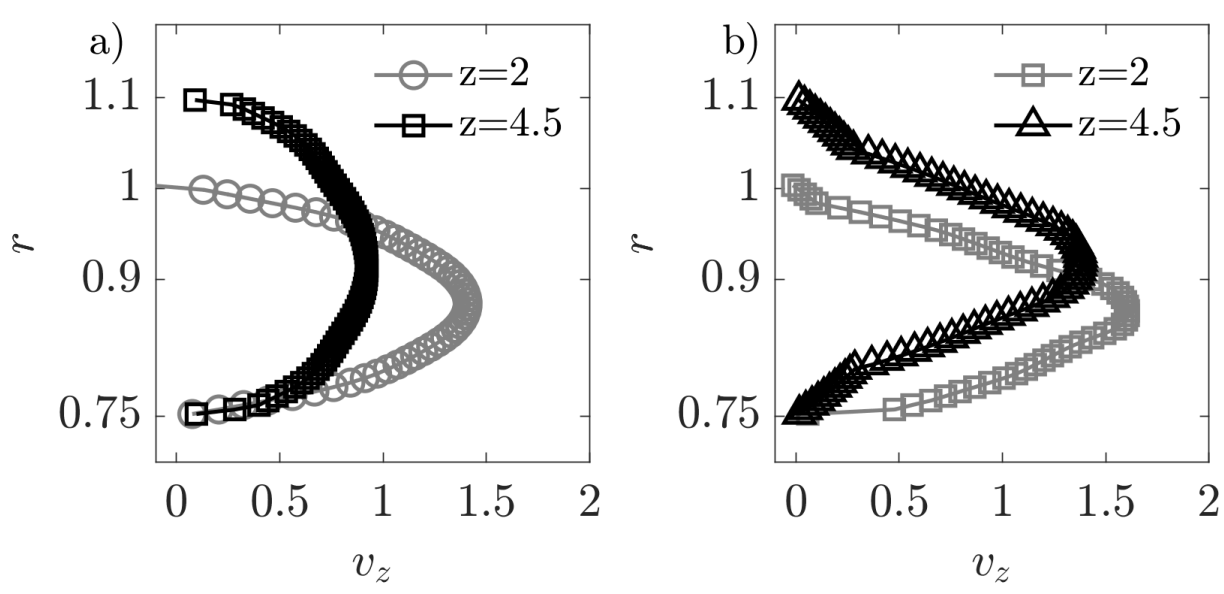

Figura 5.38: Comportamento da componente $v_{z}$ do campo de velocidade $\vec{u}$ para $M=$ a) 0.25 , b) 4 e $z=3$. Para cada subfigura, a componente $v_{z}$ do campo de velocidade desenvolvido dentro do espaço anular e na seção central da expansão-contração abrupta foram representadas em cor cinza e preto, respetivamente. 
A figura 5.37 mostra a componente $u$ do campo de velocidades $\vec{u}$ para diferentes viscosidades $M$ sendo $(a, b)=(0.25,4)$, respetivamente. Como foi observado nas figuras 5.4, 5.5, 5.8 e 5.13, o campo de velocidades que se gera durante o deslocamento entre fluidos newtonianos em espaços anulares contínuos se mostra completamente desenvolvida e permanente, inclusive perto do inicio do domínio. Baseados nos resultados anteriores, para cada viscosidade $M$, a componente $v_{z}$ do campo de velocidade $\vec{u}$ desenvolvido foi representada em cor cinza a fim de observar sua divergência em relação a $u$ da entrada da expansão, em preto. A posição $z=2$ foi escolhida porque se encontra suficientemente afastada, tanto do inicio do domínio, quanto do inicio da expansão. De modo geral, para todos os casos de $M$, a velocidade $u$ diverge na presença da expansão. Note que a velocidade diverge com maior celeridade para deslocamentos viscosamente instáveis (vide figura 5.37(b).

A figura 5.38 mostra o comportamento da componente $u$ do campo de velocidades $\vec{u}$ e diferentes viscosidades $M$ para $(a, b)=,(0.25,4)$, em $z=2.0$ e $z=4.5$. A figura 5.36 tinha mostrado que, posterior a um curto tempo de transição, a velocidade tem um comportamento quase estável. Consequentemente, foi escolhida a posição $z=4.5$ para evitar ingerência das condições das bordas. De modo geral, a componente axial de velocidade apresenta uma intensidade menor longe da expansão que as observadas dentro da reginão expandida. Isto se deve a conservação de massa: menores velocidades aparecerão em espaços confinados maiores.
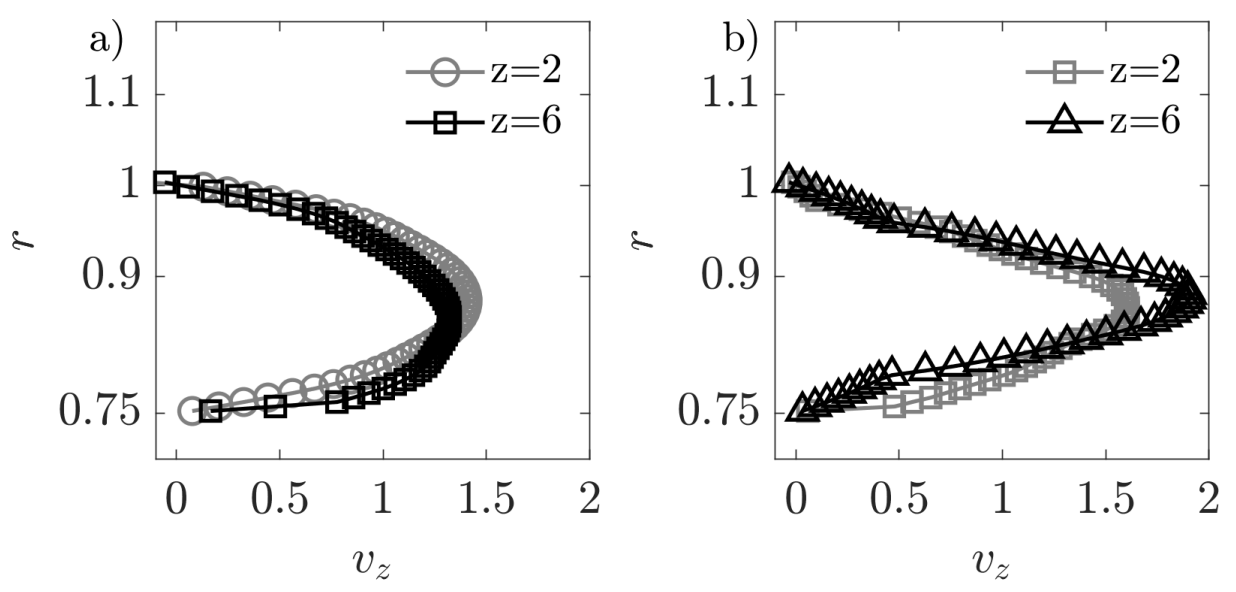

Figura 5.39: Variação da componente $u$ do campo de velocidade $\vec{u}$. Para $M=$ a) 2 , b) 4 , c) 0.25 , d) 0.5 e $L=6$. Para cada sub-figura, a componente $u$ do campo de velocidade desenvolvido dentro do espaço anular

A figura 5.39 compara a variação da componente $u$ do campo de velocidades $\vec{u}$ no fim da expansão-contração, em $z=6$. De modo geral, os 
campos de velocidade tendem a convergir para intensidades características como as observadas para geradas dentro do espaço anular.

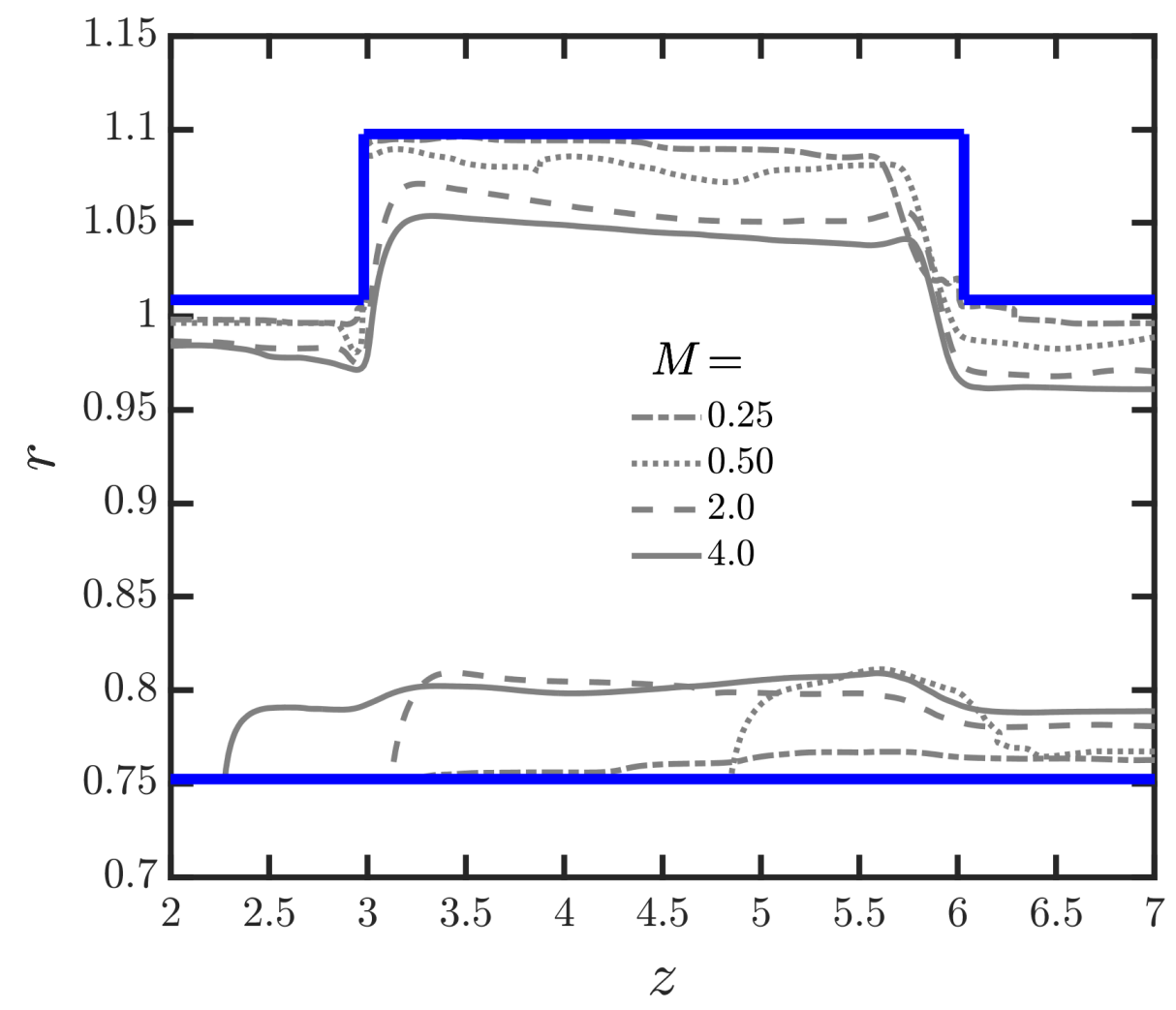

Figura 5.40: Interfaces geradas durante o deslocamento entre fluidos imiscíveis newtonianos, para varias viscosidades $M$.

A figura 5.40 ilustra o efeito da viscosidade $M$ no comportamento da interface de deslocamento dentro da expansão-contração abrupta. À medida que $M$ aumenta, uma região maior de fluido deslocado que não foi removido dentro da expansão-contração é observada. Note que para $M=0.25$ o fluido deslocador consegue remover quase a totalidade do fluido, deixando apenas uma pequena área residual. Cabe ressaltar que, tanto à montante, quanto à jusante da expansão, filmes de fluido não deslocado se formam na parede externa do espaço anular, especialmente para $M=2$ e 4 .

\section{7}

\section{Considerações finais}

Foi investigado numericamente o deslocamento axissimétrico entre fluidos newtonianos imiscíveis através de um anular contínuo, usando simulações da equação de Navier-Stokes acoplada com o método Level-Set rápido. Essas simulações mostraram taxas de avanço da ponta da interface quase constante e velocidades que dependem das propriedades geométricas, reológicas 
e cinemáticas. Para deslocamentos viscosamente estáveis, ao aumentar o número de Reynolds, maior é a velocidade da ponta da interface. Velocidades menores foram observadas com o aumento de Reynolds para deslocamentos viscosamente instáveis.

Em geral, o desvio radial da ponta da interface independe do número de Reynolds e depende da razão de viscosidades. A aproximação de placas planas paralelas para representar um deslocamento em espaços anulares é viável para deslocamentos viscosamente estáveis e a maior razão de diâmetros investigada.

Em relação à largura da interface, esta mostra independência em relação ao número de Reynolds e valores máximos para deslocamentos viscosamente estáveis.

Simulações viscosamente instáveis mostram escoamentos de recirculação a jusante da interface e ausência de escoamentos de recirculação a montante. Para os casos estáveis, escoamentos de recirculação transportam o fluido deslocado próximo das paredes para a região central do espaço anular, enquanto o líquido injetado atrás da interface é transportado lateralmente para longe da região central do espaço anular. Esta topologia gera interfaces mais largas e lentas para casos viscosamente estáveis e gera filmes finos com larguras maiores entre a interface e as paredes do anular para os casos viscosamente instáveis.

Focados nas características da interface, simulações axissimétricas de fluidos não newtonianos que deslocam newtonianos, ou vice-versa, foram executadas em espaços anulares contínuos para várias razões de diâmetros, números capilares, tempos de relaxação e viscosidades. O aumento do parâmetro tempo de relaxação equivale a maiores valores da função viscosidade para uma mesma taxa de cisalhamento, representada pelo parâmetro adimensional $R e$.

As simulações mostram que a velocidade da ponta da interface aumenta quando o tempo de relaxação aumenta, para fluidos não newtoniano sendo deslocados. Para o caso que o fluido dependente da taxa de cisalhamento seja o deslocador, sua velocidade diminui com o aumento do tempo de relaxação.

Ainda com o menor tempo de relaxação investigado (menor nível da função viscosidade dos casos investigados), sendo o fluido não newtoniano deslocador ou deslocado, a velocidade da interface se mostrou maior que um deslocamento newtoniano viscosamente estável com a mesma razão de viscosidades que o patamar newtoniano para altas taxas de cisalhamento e muito menor que um deslocamento viscosamente instável similar ao patamar para baixas taxas de cisalhamento.

A função da tensão interfacial é de estabilizar a interface (92). De modo geral, o aumento do número de capilaridade aumenta a velocidade da interface. 
Para o menor número capilar investigado, a largura da interface se mostrou constante e dependente do tempo de relaxação. Foi observado também que para o maior número de capilaridade, a largura da interface varia ao longo da direção do fluxo e o filme de fluido residente deixado na parede aumenta em espessura em direção à ponta da interface.

Para menores tempos de relaxação em deslocamentos cujo fluido injetado é não newtoniano, a jusante da interface, o fluido deslocador é transportado da região central espaço anular em direção das paredes. Enquanto na frente da interface, o líquido deslocado é transportado lateralmente das paredes para a região central. Para o caso do maior tempo de relaxação, dois vórtices a uma curta distância atrás da interface se formaram. Quando o fluido não newtoniano é deslocado, na medida em que o tempo de relaxação aumenta, escoamentos de recirculação com baixas intensidades de velocidade aparecem na frente da interface. Eventualmente, para altos tempos de relaxação, os escoamentos de recirculação a jusante da interface cessam, provocando um aumento da intensidade da velocidade nos filmes finos entre a interface e as paredes sólidas e surgimento de vórtices atrás da interface. Este fenômeno é atribuído à instabilidade gerada devido às altas taxas de cisalhamento entre o fluido residente perto das paredes e o fluido injetado.

Em relação à largura da interface, maiores larguras se produziram quando o fluido não newtoniano é injetado e menores quando é empurrado, dependentes do tempo de relaxação para as duas configurações.

Para o caso de uma geometria anular com uma expansão-contração abrupta centralizada, a velocidade e a taxa de avanço da ponta da interface para deslocamentos envolvendo fluidos newtonianos mostra dois comportamentos bem marcados. A velocidade e o avanço da ponta da interface, tanto a montante como a jusante da expansão-contração, são iguais e quase constantes e se mostra menor na presença da expansão-contração. Foi observado também que a componente axial da velocidade diverge no inicio da expansão. Esta mostrou-se quase estável com uma intensidade menor no interior da expansão-contração abrupta e converge para a mesma obtida dentro do espaço anular ao atingir a contração.

A pesar de no ser possível realizar um estudo paramétrico usando a abordagem numérica com as mesmas características reológicas, geométricas e cinemática que as investigadas na abordagem experimental, alguns resultados qualitativamente semelhantes foram observados. $\mathrm{Na}$ aborgamen numéricas, para fluidos não newtonianos com tempo de relaxação altos (que representam soluções aquosas de Carbopol com maiores concentrações de polímero) obteve-se filmes finos de fluido não deslocado perto das paredes 
maiores que para casos com tempo de relaxação menores, equivalente a menores volumes adimensionais obtidos experimentalmente. Considerando a configuração geométrica, a dessemelhança entre as duas geometrias estudadas, devido essencialmente à limitação exposta na seção 4.4, não foi possível considerar uma comparação entre os resultados obtidos. A função viscosidade utilizada para modelar o fluido não newtoniano não considera propriedades elásticas, as mesmas que a solução aquosa de Carbopol possui. Portanto, a influência de este parâmetro durante o deslocamento não foi viável de ser estudada, a qual deverá ser considerado para estudos posteriores.

\section{Sugestões para trabalhos futuros}

A análise realizada no presente trabalho deslumbrou a ampla quantidades de parâmetros que influenciam o processo de deslocamento entre fluidos imiscíveis e outros que podem ser estudados futuramente, entre eles se sugerem:

- Deslocamento entre dois fluidos con função viscosidade não newtonianos;

- Influência dos índices de Carreau a e o índice power law $n$;

- Deslocamento entre fluidos com densidade diferentes $\Delta \rho$;

- Implementação de ângulo de contacto dinâmico;

- O método Level-Set rápido tem dificuldades na captura de interfaces com reentrâncias. A implementação de método que não requer reinicialização permitirá um estudo paramétrico mais amplo.

- Diferentes geometrias complexas como expansão-contração suavizada, triangulares, etc;

- Simulações tridimensionais para deslocamentos instáveis, tanto entre fluidos newtonianos como com função viscosidade não newtoniana; 


\section{6 \\ Referências bibliográficas}

1 SZABO, P.; HASSAGER, O. Displacement of one newtonian fluid by another: density effects in axial annular flow. International journal of multiphase flow, Elsevier, v. 23, n. 1, p. 113-129, 1997.

2 BACK, L.; ROSCHKE, E. Shear-layer flow regimes and wave instabilities and reattachment lengths downstream of an abrupt circular channel expansion. Journal of Applied Mechanics, American Society of Mechanical Engineers, v. 39, n. 3, p. 677-681, 1972.

3 CHERDRON, W.; DURST, F.; WHITELAW, J. H. Asymmetric flows and instabilities in symmetric ducts with sudden expansions. Journal of Fluid Mechanics, Cambridge Univ Press, v. 84, n. 01, p. 13-31, 1978.

4 SCOTT, P.; MIRZA, F.; VLACHOPOULOS, J. A finite element analysis of laminar flows through planar and axisymmetric abrupt expansions. Computers and fluids, Elsevier, v. 14, n. 4, p. 423-432, 1986.

5 DURST, F.; MELLING, A.; WHITELAW, J. Low reynolds number flow over a plane symmetric sudden expansion. Journal of Fluid Mechanics, Cambridge University Press, v. 64, n. 1, p. 111-128, 1974.

6 CHRISTIANSEN, E.; KELSEY, S.; CARTER, T. Laminar tube flow through an abrupt contraction. AIChE Journal, Wiley Online Library, v. 18, n. 2 , p. $372-380,1972$.

7 NACCACHE, M. F.; BARBOSA, R. S. Creeping flow of viscoplastic materials through a planar expansion followed by a contraction. Mechanics Research Communications, Elsevier, v. 34, n. 5, p. 423-431, 2007.

8 FEARN, R.; MULLIN, T.; CLIFFE, K. Nonlinear flow phenomena in a symmetric sudden expansion. Journal of Fluid Mechanics, Cambridge University Press, v. 211, p. 595-608, 1990.

9 SOBEY, I. J. Observation of waves during oscillatory channel flow. Journal of Fluid Mechanics, Cambridge University Press, v. 151, p. 395-426, 1985.

10 SOBEY, I. J.; DRAZIN, P. G. Bifurcations of two-dimensional channel flows. Journal of Fluid Mechanics, Cambridge University Press, v. 171, p. 263-287, 1986.

11 FOUMENY, E.; INGHAM, D.; WALKER, A. Bifurcations of incompressible flow through plane symmetric channel expansions. Computers \& fluids, Elsevier, v. 25, n. 3, p. 335-351, 1996. 
12 BOGER, D. Viscoelastic flows through contractions. Annual review of fluid mechanics, v. 19, n. 1, p. 157-182, 1987.

13 COChRAnE, T.; WALTERS, K.; WEBSTER, M. On newtonian and non-newtonian flow in complex geometries. Philosophical Transactions of the Royal Society of London A: Mathematical, Physical and Engineering Sciences, The Royal Society, v. 301, n. 1460, p. 163-181, 1981.

14 HALMOS, A.; BOGER, D.; CABELLI, A. The behavior of a power-law fluid flowing through a sudden expansion: Part i. a numerical solution. AIChE Journal, Wiley Online Library, v. 21, n. 3, p. 540-549, 1975.

15 YTREHUS, J. D. et al. Experimental investigation of wellbore fluid displacement in concentric and eccentric annulus. In: AMERICAN SOCIETY OF MECHANICAL ENGINEERS. ASME 2017 36th International Conference on Ocean, Offshore and Arctic Engineering. [S.l.], 2017. p. V008T11A030-V008T11A030.

16 MENDES, P. R. S.; NACCACHE, M. F.; VINAGRE, H. T. On numerical simulations of complex flows of viscoplastic materials. ASME-PUBLICATIONS-FED, New York; American Society of Mechanical Engineers; 1995, v. 252, p. 17-24, 2000.

17 MITSOULIS, E.; HUILGOL, R. Entry flows of bingham plastics in expansions. Journal of non-newtonian fluid mechanics, Elsevier, v. 122, n. 1, p. 45-54, 2004.

18 MENDES, P. S.; DUTRA, E. S. Viscosity function for yield-stress liquids. Appl. Rheol, v. 14, n. 6, p. 296-302, 2004.

19 ROUSTAEI, A.; GOSSELIN, A.; FRIGAARD, I. Residual drilling mud during conditioning of uneven boreholes in primary cementing. part 1: Rheology and geometry effects in non-inertial flows. Journal of Non-Newtonian Fluid Mechanics, Elsevier, v. 220, p. 87-98, 2015.

20 VRADIS, G.; OTUGEN, M. The axisymmetric sudden expansion flow of a non-newtonian viscoplastic fluid. Journal of Fluids Engineering, American Society of Mechanical Engineers, v. 119, n. 1, p. 193-200, 1997.

21 AleXAndrou, A. N.; MCGILVREAY, T. M.; BURGOS, G. Steady herschel-bulkley fluid flow in three-dimensional expansions. Journal of Non-Newtonian Fluid Mechanics, Elsevier, v. 100, n. 1, p. 77-96, 2001.

22 BURGOS, G. R.; ALEXANDROU, A. N. Flow development of herschel-bulkley fluids in a sudden three-dimensional square expansion. Journal of Rheology (1978-present), The Society of Rheology, v. 43, n. 3, p. 485-498, 1999.

23 ROUSTAEI, A.; FRIGAARD, I. Residual drilling mud during conditioning of uneven boreholes in primary cementing. part 2: Steady laminar inertial flows. Journal of Non-Newtonian Fluid Mechanics, Elsevier, v. 226, p. 1-15, 2015. 
24 HAMMAD, K. J.; VRADIS, G. C. Creeping flow of a bingham plastic through axisymmetric sudden contractions with viscous dissipation. International journal of heat and mass transfer, Elsevier, v. 39, n. 8, p. 1555-1567, 1996.

25 HAMMAD, K. J. The effect of hydrodynamic conditions on heat transfer in a complex viscoplastic flow field. International journal of heat and mass transfer, Elsevier, v. 43, n. 6, p. 945-962, 2000.

26 ROUSTAEI, A.; FRIGAARD, I. The occurrence of fouling layers in the flow of a yield stress fluid along a wavy-walled channel. Journal of Non-Newtonian Fluid Mechanics, Elsevier, v. 198, p. 109-124, 2013.

27 FRIGAARD, I.; RYAN, D. Flow of a visco-plastic fluid in a channel of slowly varying width. Journal of non-newtonian fluid mechanics, Elsevier, v. 123, n. 1, p. 67-83, 2004.

28 PUTZ, A.; FRIGAARD, I.; MARTINEZ, D. On the lubrication paradox and the use of regularisation methods for lubrication flows. Journal of Non-Newtonian Fluid Mechanics, Elsevier, v. 163, n. 1, p. 62-77, 2009.

29 BEIRUTE, R. M.; FLUMERFELT, R. W. et al. Mechanics of the displacement process of drilling muds by cement slurries using an accurate rheological model. In: SOCIETY OF PETROLEUM ENGINEERS. SPE Annual Fall Technical Conference and Exhibition. [S.1.], 1977.

30 MCLEAN, R. et al. Displacement mechanics in primary cementing. Journal of Petroleum Technology, Society of Petroleum Engineers, v. 19, n. 02, p. 251-260, 1967.

31 JAKOBSEN, J. et al. Displacements in eccentric annuli during primary cementing in deviated wells. In: SOCIETY OF PETROLEUM ENGINEERS. SPE Production Operations Symposium. [S.l.], 1991.

32 CLARK, C. R.; CARTER, G. L. et al. Mud displacement with cement slurries. Journal of Petroleum Technology, Society of Petroleum Engineers, v. 25, n. 07, p. 775-783, 1973.

33 TEHRANI, M.; BITTLESTON, S.; LONG, P. Flow instabilities during annular displacement of one non-newtonian fluid by another. Experiments in Fluids, Springer, v. 14, n. 4, p. 246-256, 1993.

34 ALBA, K.; FRIGAARD, I. Dynamics of the removal of viscoplastic fluids from inclined pipes. Journal of Non-Newtonian Fluid Mechanics, Elsevier, v. 229, p. 43-58, 2016.

35 COUTURLER, M. et al. Design rules and associated spacer properties for optimal mud removal in eccentric annuli. In: SOCIETY OF PETROLEUM ENGINEERS. CIM/SPE International Technical Meeting. [S.l.], 1990.

36 GABARD, C.; HULIN, J.-P. Miscible displacement of non-newtonian fluids in a vertical tube. The European Physical Journal E, Springer, v. 11, n. 3, p. 231-241, 2003. 
37 TARDY, P.; BITTLESTON, S. A model for annular displacements of wellbore completion fluids involving casing movement. Journal of Petroleum Science and Engineering, Elsevier, v. 126, p. 105-123, 2015.

38 ERGE, O. et al. Laminar to turbulent transition of yield power law fluids in annuli. Journal of Petroleum Science and Engineering, Elsevier, v. 128, p. $128-139,2015$.

39 BEVERLY, C.; TANNER, R. Numerical analysis of three-dimensional bingham plastic flow. Journal of non-newtonian fluid mechanics, Elsevier, v. 42, n. 1-2, p. 85-115, 1992.

40 ETRATI, A.; ROUSTAEI, A.; FRIGAARD, I. Strategies for mud-removal from washouts during cementing of vertical surface casing. Journal of Petroleum Science and Engineering, Elsevier, v. 195, p. 107454, 2020.

41 NACCACHE, M. F.; PINTO, H. A. M.; ABDU, A. Flow displacement in eroded regions inside annular ducts. Journal of the Brazilian Society of Mechanical Sciences and Engineering, Springer, v. 40, n. 9, p. 420, 2018.

42 ASSOCIATION, G. P. et al. Physical properties of glycerine and its solutions. [S.l.]: Glycerine Producers' Association, 1963.

43 VOLK, A.; KÄHLER, C. J. Density model for aqueous glycerol solutions. Experiments in Fluids, Springer, v. 59, n. 5, p. 75, 2018.

44 TABUteAU, H.; COUSSOT, P.; BRUYN, J. R. de. Drag force on a sphere in steady motion through a yield-stress fluid. Journal of rheology, SOR, v. 51, n. 1, p. 125-137, 2007.

45 EVANS, I. D. Letter to the editor: On the nature of the yield stress. Journal of Rheology, SOR, v. 36, n. 7, p. 1313-1318, 1992.

46 SIKORSKI, D.; TABUTEAU, H.; BRUYN, J. R. de. Motion and shape of bubbles rising through a yield-stress fluid. Journal of Non-Newtonian Fluid Mechanics, Elsevier, v. 159, n. 1-3, p. 10-16, 2009.

47 BARNES, H. A. A review of the slip (wall depletion) of polymer solutions, emulsions and particle suspensions in viscometers: its cause, character, and cure. Journal of Non-Newtonian Fluid Mechanics, Elsevier, v. 56, n. 3, p. 221-251, 1995.

48 ROBERTS, G. P.; BARNES, H. A. New measurements of the flow-curves for carbopol dispersions without slip artefacts. Rheologica Acta, Springer, v. 40, n. 5, p. 499-503, 2001.

49 COUSSOT, P. et al. Macroscopic vs. local rheology of yield stress fluids. Journal of Non-Newtonian Fluid Mechanics, Elsevier, v. 158, n. 1-3, p. 85-90, 2009.

50 HUANG, N. et al. Flow of wet granular materials. Physical review letters, APS, v. 94, n. 2, p. 028301, 2005. 
51 OVARLEZ, G.; BERTRAND, F.; RODTS, S. Local determination of the constitutive law of a dense suspension of noncolloidal particles through magnetic resonance imaging. Journal of rheology, SOR, v. 50, n. 3, p. 259-292, 2006.

52 BARNES, H. A.; NGUYEN, Q. D. Rotating vane rheometry - a review. Journal of Non-Newtonian Fluid Mechanics, Elsevier, v. 98, n. 1, p. $1-14,2001$.

53 POUMAERE, A. et al. Unsteady laminar flows of a carbopol® gel in the presence of wall slip. Journal of Non-Newtonian Fluid Mechanics, Elsevier, v. 205, p. 28-40, 2014.

54 COUSSOT, P. et al. Avalanche behavior in yield stress fluids. Physical review letters, APS, v. 88, n. 17, p. 175501, 2002.

55 COUSSOT, P.; ANCEY, C. Rheophysical classification of concentrated suspensions and granular pastes. Physical Review E, APS, v. 59, n. 4, p. $4445,1999$.

56 TANNER, R. I. Engineering rheology. [S.l.]: OUP Oxford, 2000. v. 52.

57 BALMFORTH, N. J.; FRIGAARD, I. A.; OVARLEZ, G. Yielding to stress: recent developments in viscoplastic fluid mechanics. Annual Review of Fluid Mechanics, Annual Reviews, v. 46, p. 121-146, 2014.

58 KIM, J.-S. et al. Rheological control of cement paste for applying prepackaged eccs (engineered cementitious composites) to self-consolidating and shotcreting processes. KSCE Journal of Civil Engineering, Springer, v. 14, n. 5 , p. 743-751, 2010.

59 MAHAUT, F. et al. Yield stress and elastic modulus of suspensions of noncolloidal particles in yield stress fluids. Journal of Rheology, SOR, v. 52, n. 1, p. 287-313, 2008.

60 NGUYEN, Q.; BOGER, D. Measuring the flow properties of yield stress fluids. Annual Review of Fluid Mechanics, Annual Reviews 4139 El Camino Way, PO Box 10139, Palo Alto, CA 94303-0139, USA, v. 24, n. 1, p. 47-88, 1992.

61 HEMPHILL, T.; CAMPOS, W.; PILEHVARI, A. Yield-power law model more accurately predicts mud rheology. Oil and Gas Journal;(United States), v. 91, n. 34, 1993.

62 MERLO, A. et al. An innovative model for drilling fluid hydraulics. In: SOCIETY OF PETROLEUM ENGINEERS. SPE Asia Pacific Oil and Gas Conference. [S.l.], 1995.

63 MAGLiONE, R. et al. A drilling well as viscometer: Studying the effects of well pressure and temperature on the rheology of the drilling fluids. In: SOCIETY OF PETROLEUM ENGINEERS. European Petroleum Conference. [S.l.], 1996. 
64 ESCUDIER, M. et al. Fully developed laminar flow of non-newtonian liquids through annuli: comparison of numerical calculations with experiments. Experiments in fluids, Springer, v. 33, n. 1, p. 101-111, 2002.

65 KELESSIDIS, V. et al. Optimal determination of rheological parameters for herschel-bulkley drilling fluids and impact on pressure drop, velocity profiles and penetration rates during drilling. Journal of Petroleum Science and Engineering, Elsevier, v. 53, n. 3, p. 203-224, 2006.

66 OZBAYOGLU, M.; OMURLU, C. Comparative study of yield-power law drilling fluids flowing through annulus. Petroleum Science and Technology, Taylor \& Francis, v. 25, n. 8, p. 1041-1052, 2007.

67 FOUNARGIOTAKIS, K.; KELESSIDIS, V.; MAGLIONE, R. Laminar, transitional and turbulent flow of herschel-bulkley fluids in concentric annulus. The Canadian Journal of Chemical Engineering, Wiley Online Library, v. 86, n. 4 , p. $676-683,2008$.

68 HAMED, S. B.; BELHADRI, M. Rheological properties of biopolymers drilling fluids. Journal of Petroleum Science and Engineering, Elsevier, v. 67, n. 3 , p. 84-90, 2009.

69 MAJIDI, R. et al. Quantitative analysis of mud losses in naturally fractured reservoirs: the effect of rheology. SPE Drilling \& Completion, Society of Petroleum Engineers, v. 25, n. 04, p. 509-517, 2010.

70 SORGUN, M.; OZBAYOGLU, M. Predicting frictional pressure loss during horizontal drilling for non-newtonian fluids. Energy Sources, Part A: Recovery, Utilization, and Environmental Effects, Taylor \& Francis, v. 33, n. 7, p. 631-640, 2011.

71 REED, T.; PILEHVARI, A. et al. A new model for laminar, transitional, and turbulent flow of drilling muds. In: SOCIETY OF PETROLEUM ENGINEERS. SPE Production Operations Symposium. [S.l.], 1993.

72 FERRY, J. D. Viscoelastic properties of polymers. [S.l.]: John Wiley \& Sons, 1980.

73 EWOLDT, R. H.; MCKINLEY, G. H. Creep ringing in rheometry or how to deal with oft-discarded data in step stress tests! Rheol. Bull, v. 76, n. 4, 2007.

74 DINKGREVE, M. et al. Carbopol: From a simple to a thixotropic yield stress fluid. Journal of Rheology, SOR, v. 62, n. 3, p. 773-780, 2018.

75 KIM, J.-Y. et al. Rheological properties and microstructures of carbopol gel network system. Colloid and Polymer Science, Springer, v. 281, n. 7, p. 614-623, 2003.

76 ISLAM, M. T. et al. Rheological characterization of topical carbomer gels neutralized to different ph. Pharmaceutical research, Springer, v. 21, n. 7, p. 1192-1199, 2004. 
77 CHEVALIER, T. et al. Boundary layer (shear-band) in frustrated viscoplastic flows. EPL (Europhysics Letters), IOP Publishing, v. 102, n. 4, p. $48002,2013$.

78 MENDES, P. R. de S. et al. Flow of viscoplastic liquids through axisymmetric expansions-contractions. Journal of Non-Newtonian Fluid Mechanics, Elsevier, v. 142, n. 1, p. 207-217, 2007.

79 BELL, J. B.; MARCUS, D. L. A second-order projection method for variable-density flows. Journal of Computational Physics, Elsevier, v. 101, n. 2, p. 334-348, 1992.

80 RAI, M.; MOIN, P. Direct simulations of turbulent flow using finite-difference schemes. In: 27th Aerospace Sciences Meeting. [S.l.: s.n.], 1991. p. 369.

81 BEAM, R. M.; WARMING, R. F. An implicit finite-difference algorithm for hyperbolic systems in conservation-law form. Journal of computational physics, Elsevier, v. 22, n. 1, p. 87-110, 1976.

82 BRILEY, W.; MCDONALD, H. Solution of the multidimensional compressible navier-stokes equations by a generalized implicit method. Journal of Computational Physics, Elsevier, v. 24, n. 4, p. 372-397, 1977.

83 PATANKAR, S. Numerical heat transfer and fluid flow. [S.l.]: CRC press, 1980.

84 KIM, J.; MOIN, P. Application of a fractional-step method to incompressible navier-stokes equation. 1984.

85 JIANG, G.-S.; WU, C.-c. A high-order weno finite difference scheme for the equations of ideal magnetohydrodynamics. Journal of Computational Physics, Elsevier, v. 150, n. 2, p. 561-594, 1999.

86 DORR, F. W. The direct solution of the discrete poisson equation on a rectangle. SIAM review, SIAM, v. 12, n. 2, p. 248-263, 1970.

87 THOMPSON, P. A.; TROIAN, S. M. A general boundary condition for liquid flow at solid surfaces. Nature, Nature Publishing Group, v. 389, n. 6649, p. 360-362, 1997.

88 SETHIAN, J. A.; SMEREKA, P. Level set methods for fluid interfaces. Annual review of fluid mechanics, Annual Reviews 4139 El Camino Way, PO Box 10139, Palo Alto, CA 94303-0139, USA, v. 35, n. 1, p. 341-372, 2003.

89 SUSSMAN, M.; SMEREKA, P.; OSHER, S. A level set approach for computing solutions to incompressible two-phase flow. Journal of Computational physics, Elsevier, v. 114, n. 1, p. 146-159, 1994.

90 OSHER, S.; FEDKIW, R. P. Level set methods: an overview and some recent results. Journal of Computational physics, Elsevier, v. 169, n. 2, p. 463-502, 2001. 
91 PENG, D. et al. A pde-based fast local level set method. Journal of computational physics, Elsevier, v. 155, n. 2, p. 410-438, 1999.

92 CHANG, Y.-C. et al. A level set formulation of eulerian interface capturing methods for incompressible fluid flows. Journal of computational Physics, Academic Press, v. 124, n. 2, p. 449-464, 1996.

93 CHEN, S. et al. A simple level set method for solving stefan problems. Journal of Computational Physics, Academic Press, v. 135, n. 1, p. 8-29, 1997.

94 ENRIGHT, D. et al. A hybrid particle level set method for improved interface capturing. Journal of Computational physics, Elsevier, v. 183, n. 1, p. 83-116, 2002.

95 OLSSON, E.; KREISS, G.; ZAHEDI, S. A conservative level set method for two phase flow ii. Journal of Computational Physics, Elsevier, v. 225, n. 1 , p. $785-807,2007$.

96 ZHANG, Y. et al. 3d jet impact and toroidal bubbles. Journal of Computational Physics, Elsevier, v. 166, n. 2, p. 336-360, 2001.

97 OSHER, S.; FEDKIW, R. Level set methods and dynamic implicit surfaces. [S.l.]: Springer Science \& Business Media, 2006. v. 153.

98 SETHIAN, J.; YU, J. A second-order projection method for two dimensional/axisymmetric two-fluid flows. center pure appl. math., rep. Univ. Calif., Berkeley. Submitted, 2002.

99 HOU, T. Y. et al. A hybrid method for moving interface problems with application to the hele-shaw flow. Journal of Computational Physics, Elsevier, v. 134, n. 2, p. 236-252, 1997.

100 CHOPP, D. L. Computing minimal surfaces via level set curvature flow. 1991.

101 OSHER, S.; SETHIAN, J. A. Fronts propagating with curvature-dependent speed: algorithms based on hamilton-jacobi formulations. Journal of computational physics, Elsevier, v. 79, n. 1, p. 12-49, 1988.

102 ADALSTEINSSON, D.; SETHIAN, J. A. A fast level set method for propagating interfaces. J. Comput. Phys, v. 118, n. 2, 1994.

103 KANG, M. Peng, barry merriman, stanley osher, hongkai zhao, 2 and. Journal of Computational Physics, v. 155, p. 410-438, 1999.

104 OSHER, S.; SHU, C.-W. High-order essentially nonoscillatory schemes for hamilton-jacobi equations. SIAM Journal on numerical analysis, SIAM, v. 28, n. 4, p. 907-922, 1991.

105 PAK, B.; CHO, Y. I.; CHOI, S. U. Separation and reattachment of non-newtonian fluid flows in a sudden expansion pipe. Journal of Non-Newtonian Fluid Mechanics, Elsevier, v. 37, n. 2-3, p. 175-199, 1990. 
106 SHU, C.-W.; OSHER, S. Efficient implementation of essentially non-oscillatory shock-capturing schemes. Journal of computational physics, Elsevier, v. 77, n. 2, p. 439-471, 1988.

107 MENDES, P. R. de S. Dimensionless non-newtonian fluid mechanics. Journal of non-Newtonian fluid mechanics, Elsevier, v. 147, n. 1-2, p. 109-116, 2007.

108 SIQUEIRA, I.; MENDES, P. de S. On the pressure-driven flow of suspensions: Particle migration in apparent yield-stress fluids. Journal of Non-Newtonian Fluid Mechanics, Elsevier, v. 265, p. 92-98, 2019.

109 CHANDRASEKHAR, S. Hydrodynamic and hydromagnetic stability. [S.l.]: Courier Corporation, 2013.

110 BRACKBILL, J. U.; KOTHE, D. B.; ZEMACH, C. A continuum method for modeling surface tension. Journal of computational physics, Elsevier, v. 100, n. 2, p. 335-354, 1992.

111 TURNER, J. Buoyancy effects in fluids, cambridge univ. Press Cambridge, 1973.

112 SAFFMAN, P. G.; TAYLOR, G. I. The penetration of a fluid into a porous medium or hele-shaw cell containing a more viscous liquid. Proceedings of the Royal Society of London. Series A. Mathematical and Physical Sciences, The Royal Society London, v. 245, n. 1242, p. 312-329, 1958.

113 HOMSY, G. M. Viscous fingering in porous media. Annual review of fluid mechanics, Annual Reviews 4139 El Camino Way, PO Box 10139, Palo Alto, CA 94303-0139, USA, v. 19, n. 1, p. 271-311, 1987.

114 WOODING, R.; MOREL-SEYTOUX, H. J. Multiphase fluid flow through porous media. Annual review of fluid mechanics, Annual Reviews $4139 \mathrm{El}$ Camino Way, PO Box 10139, Palo Alto, CA 94303-0139, USA, v. 8, n. 1, p. 233-274, 1976.

115 CHUOKE, R. et al. The instability of slow, immiscible, viscous liquid-liquid displacements in permeable media. Society of Petroleum Engineers, 1959.

116 DONG, B. et al. Lattice boltzmann simulation of viscous fingering phenomenon of immiscible fluids displacement in a channel. Computers \& Fluids, Elsevier, v. 39, n. 5, p. 768-779, 2010.

117 KANG, Q.; ZHANG, D.; CHEN, S. Immiscible displacement in a channel: simulations of fingering in two dimensions. Advances in water resources, Elsevier, v. 27, n. 1, p. 13-22, 2004.

118 BENSIMON, D. et al. Viscous flows in two dimensions. Reviews of Modern Physics, APS, v. 58, n. 4, p. 977, 1986. 
119 FRIGAARD, I.; SCHERZER, O.; SONA, G. Uniqueness and non-uniqueness in the steady displacement of two visco-plastic fluids. ZAMM-Journal of Applied Mathematics and Mechanics/Zeitschrift für Angewandte Mathematik und Mechanik, Wiley Online Library, v. 81, n. 2, p. 99-118, 2001.

120 LONG, P. Experimental studies of fluid-fluid displacement in annuli. Tese (Doutorado) — University of Cambridge, 1991.

121 RASMUSSEN, H. K.; HASSAGER, O.; SAASEN, A. Viscous flow with large fluid-fluid interface displacement. International journal for numerical methods in fluids, Wiley Online Library, v. 28, n. 5, p. 859-881, 1998.

122 BAU, H. H. Kelvin-helmholtz instability for parallel flow in porous media: a linear theory. The Physics of Fluids, American Institute of Physics, v. 25, n. 10, p. 1719-1722, 1982.

123 DRAZIN, P. Kelvin-helmholtz instability of finite amplitude. Journal of Fluid Mechanics, Cambridge University Press, v. 42, n. 2, p. 321-335, 1970.

124 BLAAUWGEERS, R. et al. Shear flow and kelvin-helmholtz instability in superfluids. Physical review letters, APS, v. 89, n. 15, p. 155301, 2002.

125 GUNZBURGER, M. D. Finite element methods for viscous incompressible flows: a guide to theory, practice, and algorithms. [S.l.]: Elsevier, 2012.

126 CHIN, J. Lattice boltzmann simulation of the flow of binary immiscible fluids with different viscosities using the shan-chen microscopic interaction model. Philosophical Transactions of the Royal Society of London. Series A: Mathematical, Physical and Engineering Sciences, The Royal Society, v. 360, n. 1792, p. 547-558, 2002.

127 NEVES, S. C. M.; PELAES, E. G.; SINAIS, L. d. P. de. Estudo e implementação de técnicas de segmentação de imagens. Revista Virtual de Iniciação Acadêmica da UFPA-Universidade Federal do Pará-Departamento de Engenharia Elétrica e de Computação, v. 1, n. 2, 2008. 
A

\section{Difusão solução aquosa na mistura água/glicerina}

Para avaliar a difusão entre os fluidos miscíveis envolvidos no deslocamento, em primeira instância posiciona-se a mistura glicerina-água (fluido mais denso) em um becker, a seguir acrescenta-se cuidadosamente a solução aquosa de carbopol (fluido menos denso), com objetivo de formar una interface entre os fluidos (vide figura A.1).

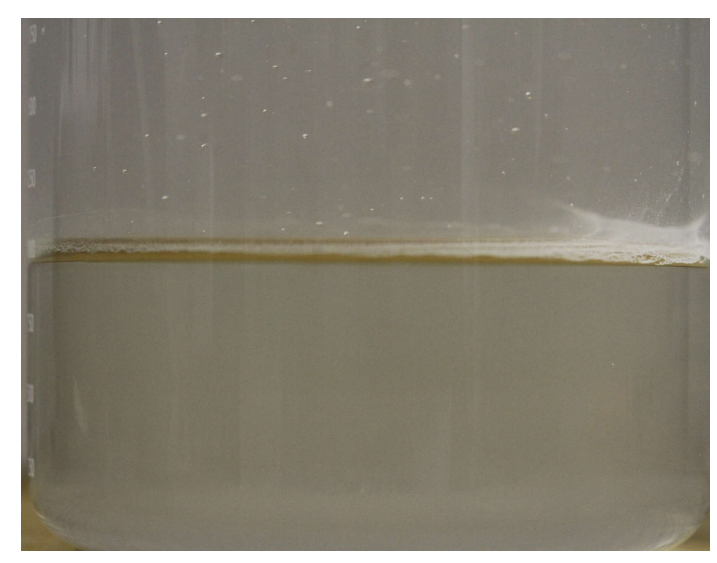

Figura A.1: Interface gerada entre os fluidos envolvidos no deslocamento

Uma máquina fotográfica Canon EOS 7D foi utilizada para registrar a evolução da interface ao longo do tempo. Foram obtidas imagens em diferentes intervalos de tempo, sendo que as primeiras cinco foram capturadas com uma periodicidade de um segundo. As restantes foram captadas em intervalos de 10 segundos. Foi desenvolvida uma rotina de processamento digital de imagens para obter, em função do tempo de contato entre os fluidos, uma região intermediária de faces paralelas pela ação da difusão.

Para obter a largura da interface difusa utilizou-se processamento digital de imagens. Para transformar a informação contida em sinais de formato analógico para digital, o método descrito em (127) foi usado. A sequência é apresentada na figura A.3.

A imagem obtida pela câmara encontra-se em formato RGB. Foi desenvolvida uma rotina em MatLab para transformar a imagem analógica colorida em uma matriz digital em tons de cinza. A expressão matemática utilizada para a imagem em escala de cinzas é: 


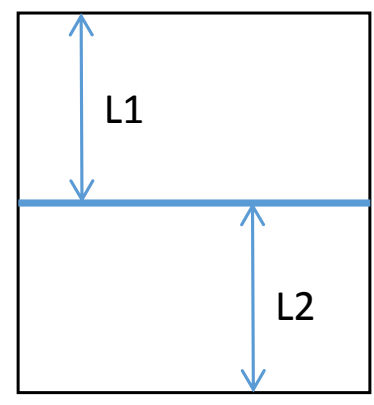

$t=0$

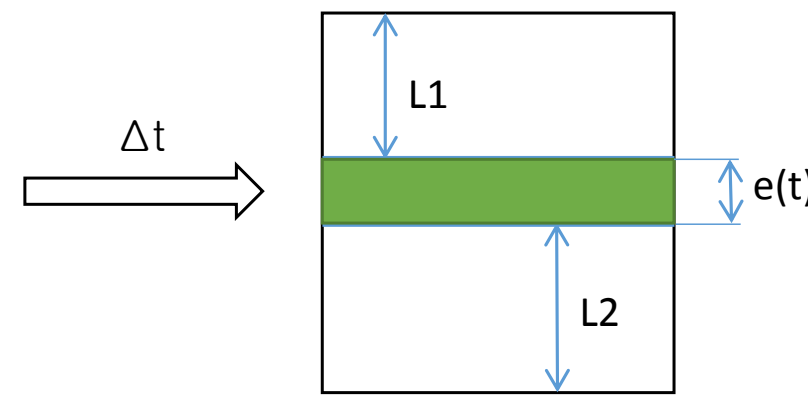

$t+\Delta t$

Figura A.2: Representação esquemática da obtenção da largura da zona de difusão

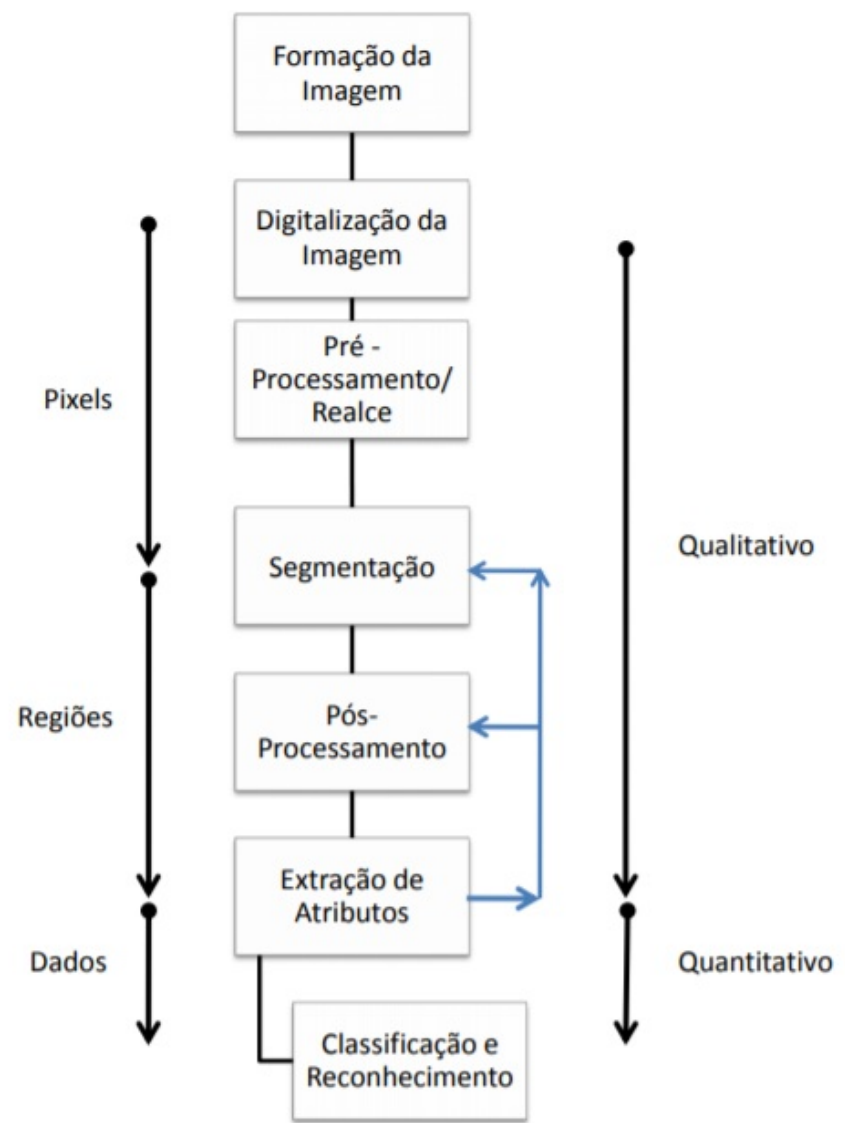

Figura A.3: Sequência do processamento digital de imagen.

Tons de cinza $=0.2989 *$ Vermelho $+0.5870 *$ Verde $+0.1140 *$ Azul $(\mathrm{A}-1)$

Uma vez feita a transformação para tons de cinza, é necessário segmentar. Nesta etapa se procura distinguir as formas de interesse do fundo da imagem. 

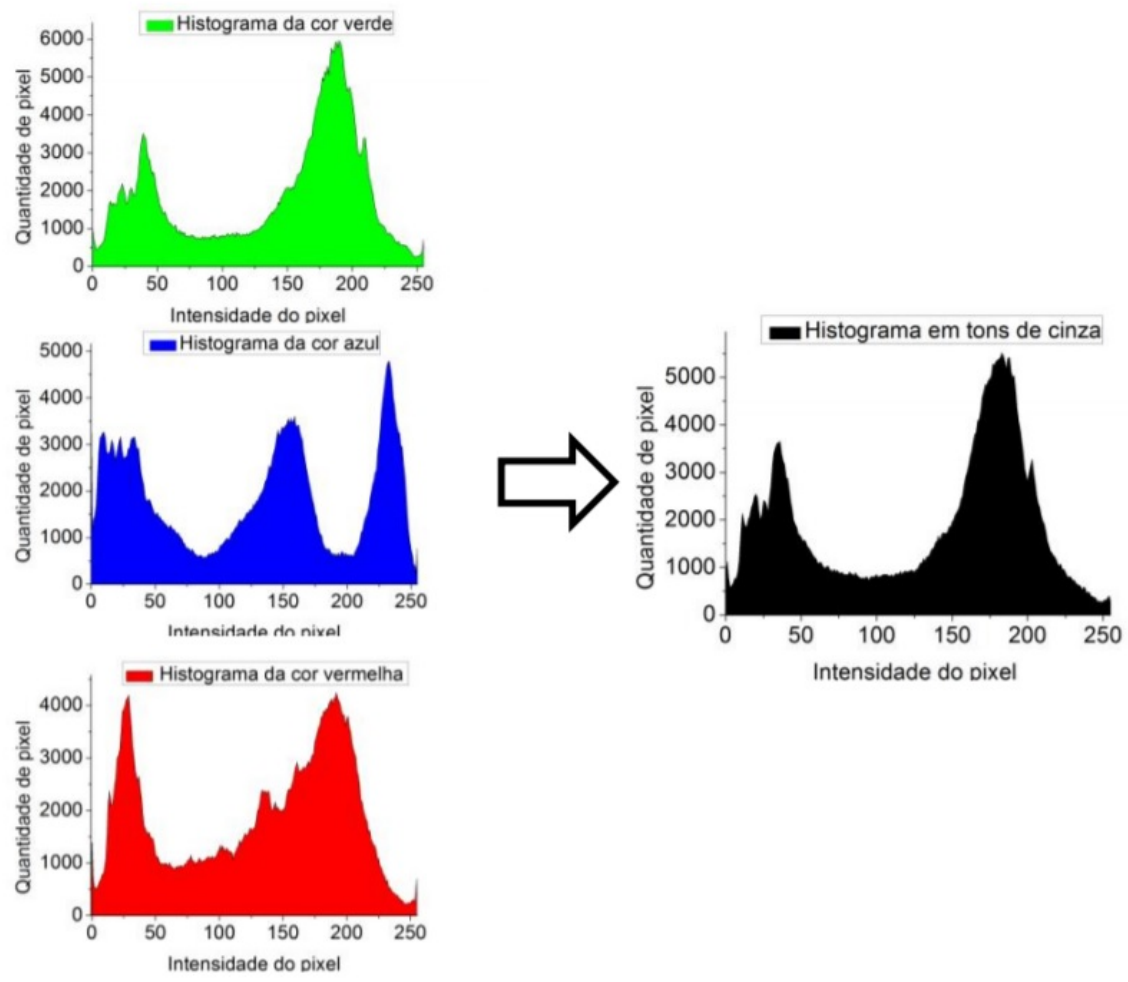

Figura A.4: Transformação de RGB para tons de cinza

Um método comumente utilizado é segmentação por limiarização. O critério se define como:

$$
\begin{cases}\text { O pixel pertence ao objeto de interesse se } & I>\alpha \\ \text { O pixel não pertence ao objeto de interesse se } & I<\alpha\end{cases}
$$

Um histograma típico é apresentado na Fig. A.5. O limiar de segmentação foi estabelecido usando o comando Auto Threshold de Matlab: 


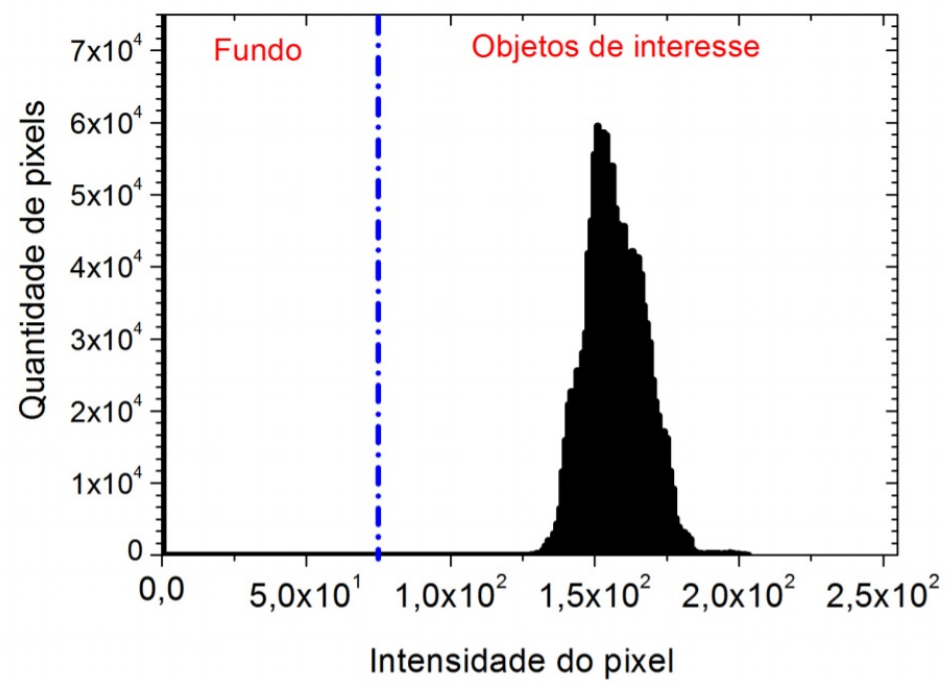

Figura A.5: Limiarização do histograma

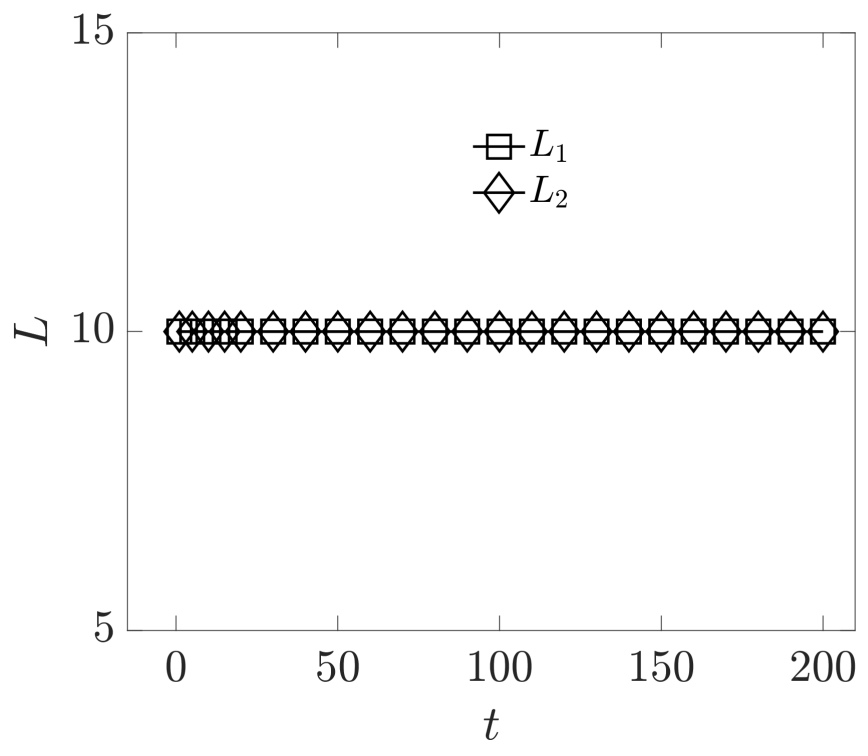

Figura A.6: Largura da interface $L$ em função do tempo da mistura água/glicerina e fluido não newtoniano com tensão limite de escoamento aparente $\tau_{y}=7.10 \mathrm{~Pa}$.

Figura A.6 mostra a largura $L$ em função do tempo, tanto para o fluido deslocador como deslocado. Uma aparente invariância dos comprimentos ao longo do tempo, foi observado. Baseados neste resultado, foi assumido que um deslocamento fluido-fluido imiscível. 